\title{
FUNCTIONAL ANALYSIS OF CHROMATIN ASSEMBLY GENES IN TETRAHYMENA THERMOPHILA
}

\author{
by \\ Renu Jeyapala \\ Bachelor of Science \\ Integrative Biology and Psychology, University of Toronto, 2011
}

\author{
A thesis presented to Ryerson University \\ In partial fulfilment of the requirements for the degree of \\ Master of Science \\ In the program of Molecular Science
}

Toronto, Ontario, Canada

(C) Renu Jeyapala, 2015 


\section{Author's Declaration}

I hereby declare that I am the sole author of this thesis. This is a true copy of the thesis, including any required final revisions, as accepted by my examiners.

Renu Jeyapala

I authorize Ryerson University to lend this thesis to other institutions or individuals for the purpose of scholarly research.

Renu Jeyapala

I further authorize Ryerson University to reproduce this thesis by photocopying or by other means, in total or in part, at the request of other institutions or individuals for the purpose of scholarly research.

Renu Jeyapala

I understand that my thesis may be made electronically available to the public.

Renu Jeyapala 


\title{
FUNCTIONAL ANALYSIS OF CHROMATIN ASSEMBLY GENES IN TETRAHYMENA \\ THERMOPHILA
}

\section{Abstract}

\author{
Renu Jeyapala
}

Master of Science, Molecular Science, Ryerson University, 2015

The basic structural unit of chromatin is the nucleosome composed of $\sim 147$ base pairs of DNA wrapped around an octamer of histone proteins. Post-translational modifications such as histone acetylation or the substitution of histone variants in place of core histones have been implicated in various chromatin related processes. There are two distinct chromatin assembly pathways. Replication-dependent mediated by CAF-1 (H3-H4) and replication-independent mediated by HIRA (H3.3-H4). Miss-regulation of chromatin assembly patterns result in the onset of many disease states such as cancer. Tetrahymena thermophila is a useful model for understanding basic questions in chromatin biology due to the segregation of transcriptionally active and silent chromatin into two distinct nuclei. To better characterize replication-dependent and independent chromatin assembly pathways in $T$. thermophila, I have engineered somatic knockouts (HIRA, CAC2,UBN1 and UBN2) and initiated the functional analysis of these chromatin assembly genes mediated in growth and development. The absence of CAC2 results in larger macronuclei and speculated to be a result of reduced histone $\mathrm{H} 3-\mathrm{H} 4$ deposition onto chromatin during growth. 


\section{Acknowledgements}

First and foremost, I express my extreme gratitude and appreciation toward Dr. Jeffrey Fillingham for providing me with an exceptional opportunity to grow and gain knowledge in the field of molecular biology under his supportive guidance. I am also extremely thankful to Dr.Jyoti Garg who provided me with exceptional insights and assistance throughout the depth of my thesis. I would like to recognize and appreciate Dr. Ron Pearlman at York University for his mentoring and allowing me the privilege of utilizing the equipment and facilities in his lab. I would also like to acknowledge the contributions of the Natural Sciences and Engineering Research Council of Canada (NSERC) for funding this opportunity.

This journey turned out to a memorable experience due to the laughter, stories, support and assistance that I was able to have with my fellow colleagues; Syed Nabeel Hyder Shah, Nora Saud Dannah, Matthew D.R. Cadorin, and Alejandro Saettone. I must extend my greatest gratitude to the staff of the Department of Chemistry and Biology of Ryerson University for their willingness to help and provide assistance during classes, labs, and T.A.ships. Finally I am forever in debt to my parents, my sister Sagana, family, and my closest friends for their unconditional support, motivation, and guidance. The last couple months of this journey met with an obstacle from which completion of this endeavour seemed like it was only a dream. My families drive, soothing words, and inevitable sacrifices, are what provided me with the encouragement and motivation to move forward. I would like to dedicate my thesis to my mentor, guide and most importantly, my friend-Baby Aunty. Even in the most tiring of times, our education was your priority. You will always be in my memory. 


\section{Table of Contents}

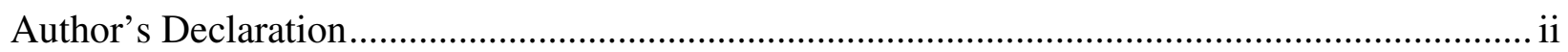

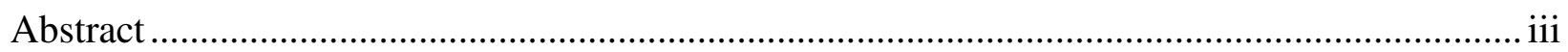

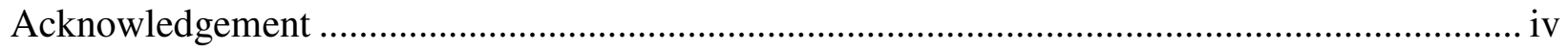

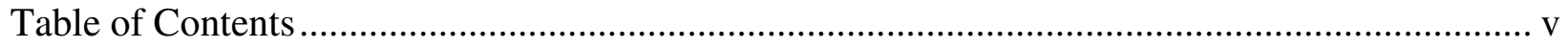

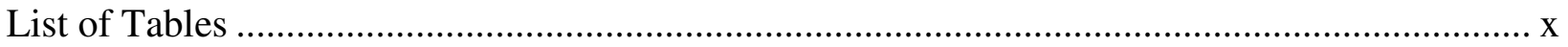

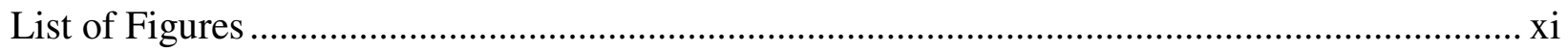

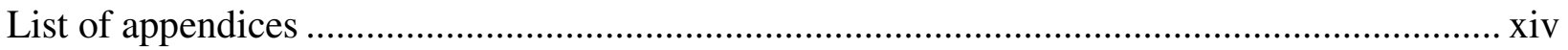

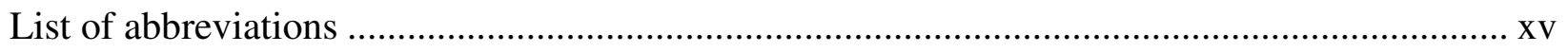

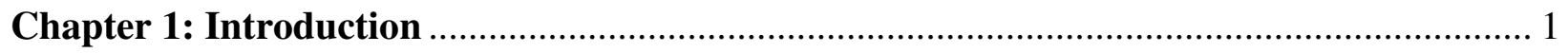

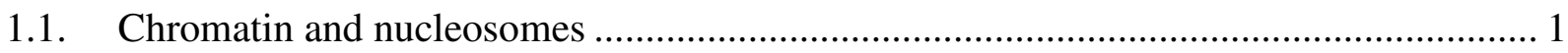

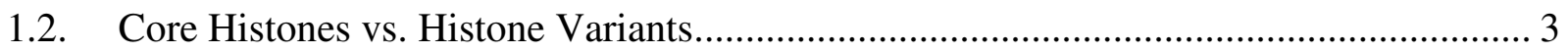

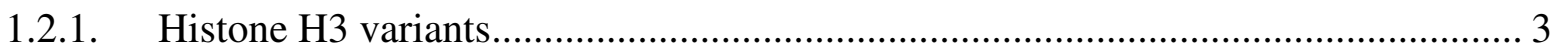

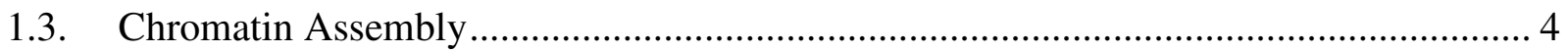

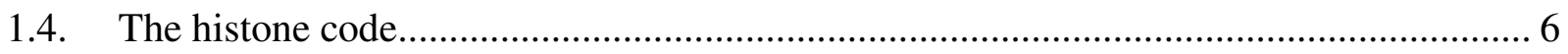

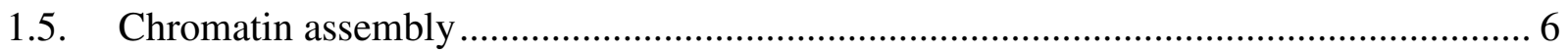

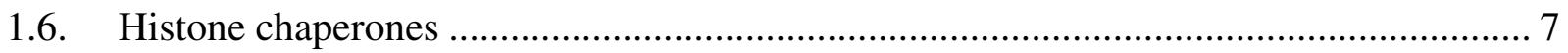

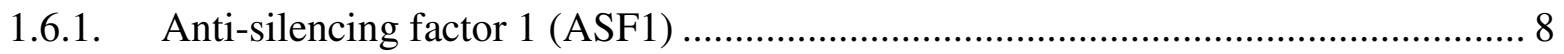

1.6.2. Chromatin assembly factor 1 (CAF-1) …………............................................... 9

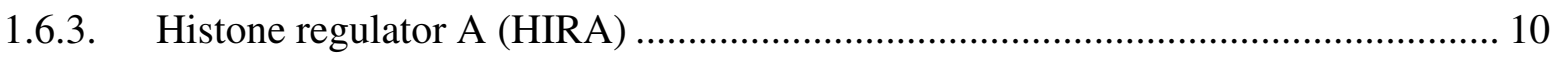

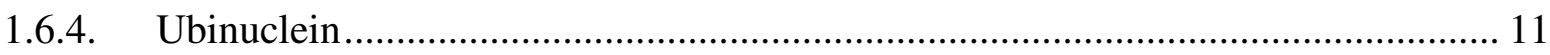

1.6.5. HIRA-UBN-CABIN1-ASF1 functions collectively as the HUCA complex in

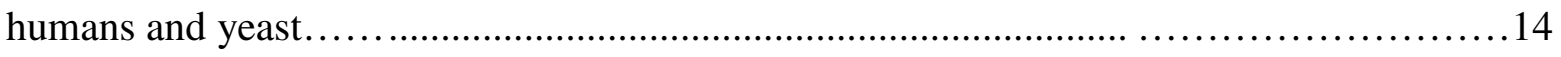

1.6.6. Medical relevance of the HUCA complex.......................................................... 15

1.6.7. Phyletic and divergence patterns of major histone chaperone components ........... 16 
1.7. Replication-Dependent and Replication-Independent Nucleosome Assembly ............ 16

1.7.1. Replication-dependent chromatin assembly ............................................ 17

1.7.2. Replication-independent chromatin assembly ........................................... 18

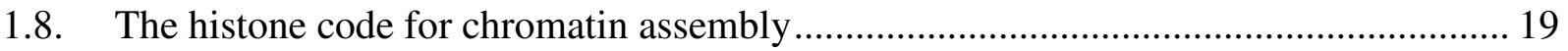

1.9. Senescence associated heterochromatin formation .............................................. 20

1.10. Tetrahymena thermophila an ideal model organism - T. Thermophila has two distinct

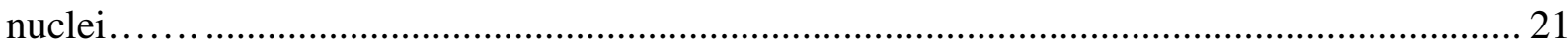

1.10.1. Sexual phase of $T$. Thermophila life cycle................................................ 22

1.10.2. T. thermophila-a good model organism to study chromatin biology.................... 24

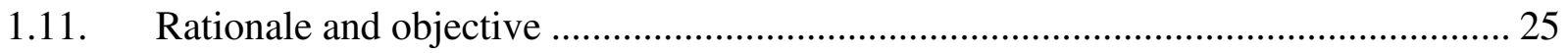

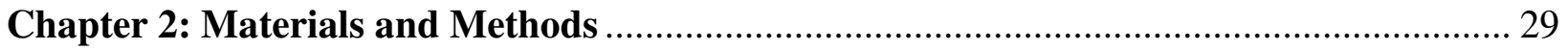

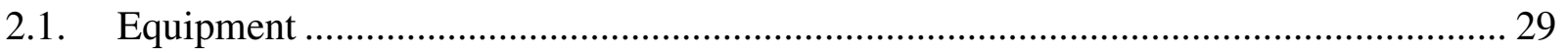

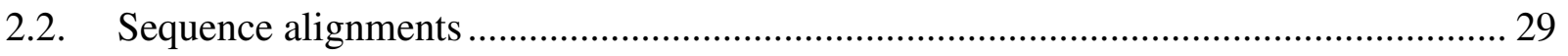

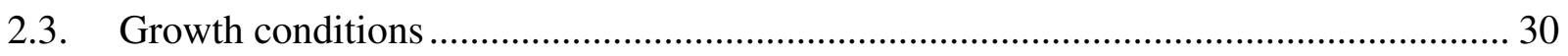

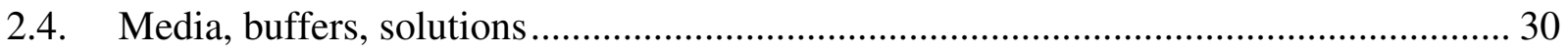

2.5. E. coli plasmid DNA mini-preparation .............................................................. 31

2.6. Manual T. thermophila genomic DNA extraction ................................................ 31

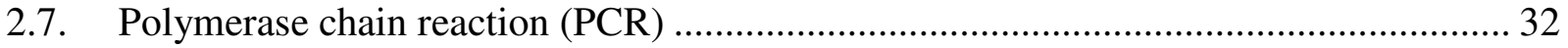

2.8. DNA restriction digest/linearization .......................................................... 33

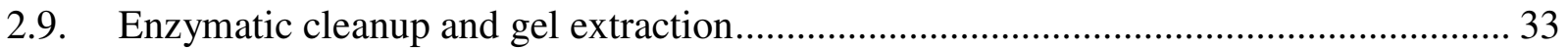

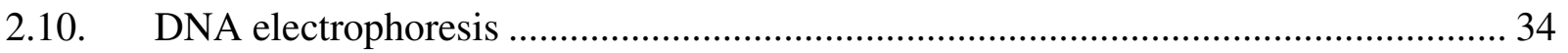

2.11. DNA ligation and transformation into competent E. coli................................... 34

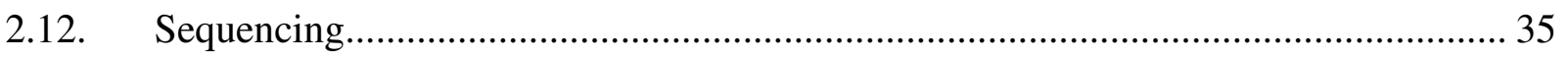

2.12.1. E. coli plasmid DNA isolation for sequencing ............................................. 35

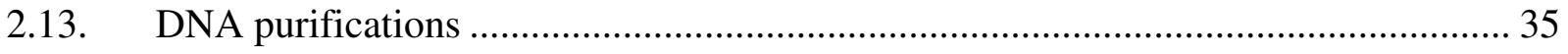


2.14. Plasmid DNA digestion for Biolistic Bombardment............................................. 35

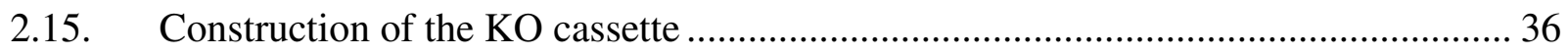

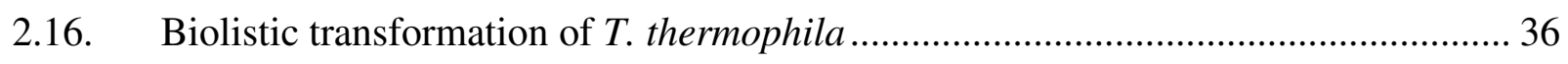

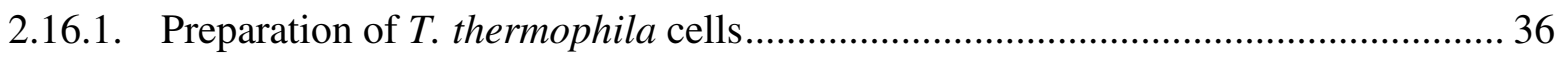

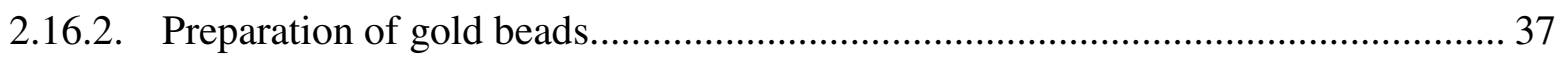

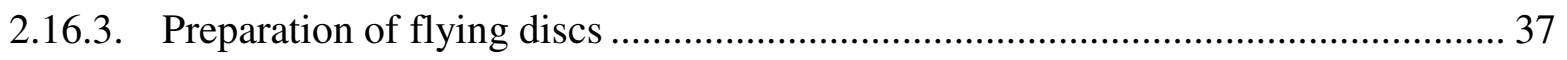

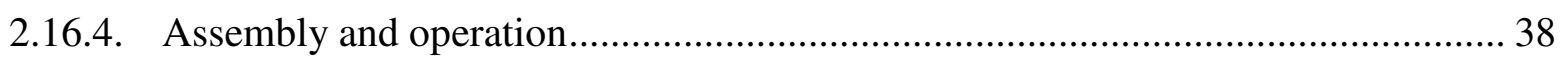

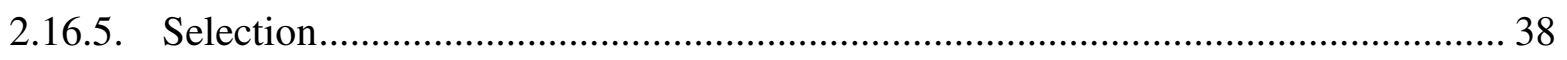

2.17. Phenotypic assortment of transformants................................................................. 39

2.18. Single-cell cloning to produce pure cell line ............................................................. 39

2.19. Verification of correct antibiotic cassette insertion in T. thermophila genome ......... 39

2.20. Reverse Transcription-PCR (RT-PCR) to determine complete gene replacement .... 40

2.21. Viability assay to determine if mating pairs complete or abort conjugation............... 43

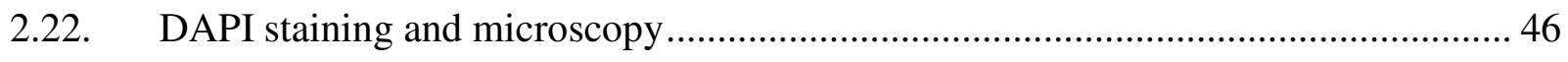

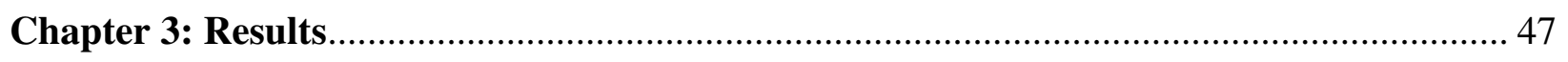

3.1. Conservation of HUCA complex from yeast to human ................................................ 47

3.2. Preparation of template DNA for amplification of T. thermophila HIRA, CAC2, UBN1

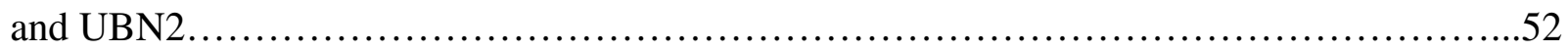

3.3. Amplification and molecular cloning of $\sim 1 \mathrm{~Kb}$ homologous sequences flanking up and down regions of T. thermophila HIRA, CAC2, UBN1, and UBN2 ..................................... 53

3.4. Engineering of HIRA, CAC2, UBN1 and UBN2 KO cassettes..................................... 55

3.5. Linearization of $\mathrm{KO}$ construct for transformation into T. thermophila ............................ 60

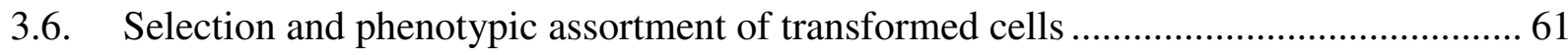

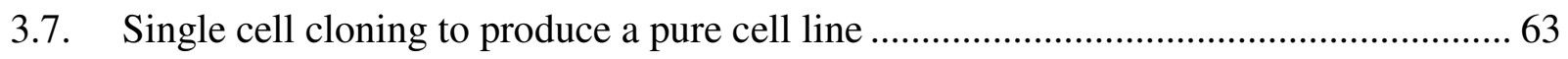

3.8. Correct integration of knockout cassette in MAC chromosome …….............................. 64 
3.9. RT-PCR to determine whether all MAC copies of HIRA, CAC2, UBN1 and UBN2 were replaced as expected if the respective gene is non-essential ...................................... 70

3.10. Cell pairing level during conjugation ......................................................... 78

3.11. Drug screening assay for $6 \mathrm{mp}$ resistance and paromomycin sensitivity .................. 78

3.12. DAPI staining for preliminary phenotypic analysis during vegetative growth and starvation

3.12.1. DAPI staining for preliminary phenotypic analysis during conjugation

Chapter 4: Discussion 84

4.1. Expression of CAC2 is non-essential for growth 84

4.2. Expression of HIRA and UBN1 are essential for growth 85

4.3. UBN1 of T. thermophila follows the periodic signature of the HUN domain similar to

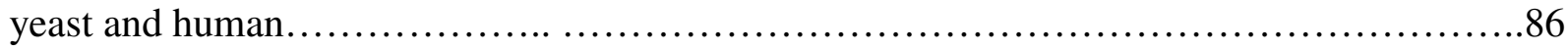

4.4. Maternal expression of CAC2 and UBN2 are not required for Tetrahymena to complete conjugation 86

4.5. Deletion of CAC2 appears to affect the nuclear integrity of the MAC. 87

4.6. Conclusion and future directions 87

Appendices 90

Appendix 1 - Accession numbers. 90

T. thermophila accession numbers 90

Appendix 2 - Composition of all media, buffers, and solutions used 91

Appendix 3 - Primers 92 
3.1. Sequencing primers

3.2. PCR primers to amplify gene sequences for molecular cloning …........................... 92

3.3. Primers for PCR verification of correct integration ................................................ 93

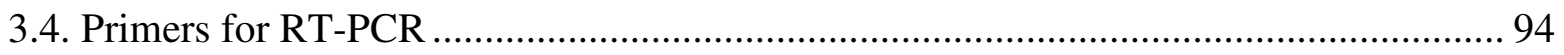

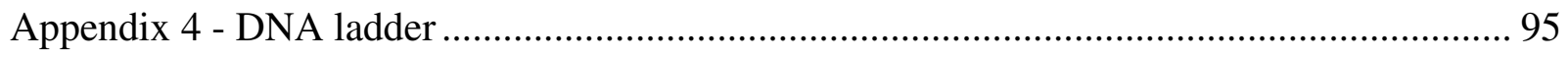

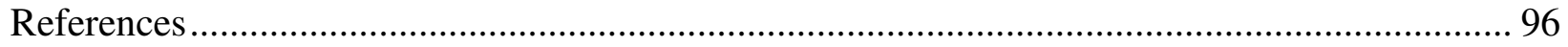




\section{List of Tables}

Table 1: PCR conditions for 2x PrimeSTAR Max DNA Polymerase (TaKaRa) ....................... 33

Table 2: The PCR programs used for confirmation of correct integration for HIRA, CAC2,

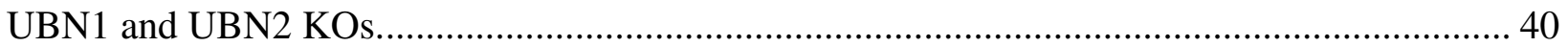

Table 3: PCR program used for RT-PCR of HIRA and CAC2 ........................................... 42

Table 4: PCR program used for RT-PCR of UBN1 and UBN2 ........................................ 43

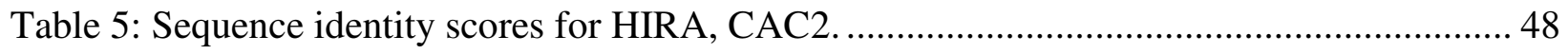

Table 6: Sequence identity score of the HUN domain using HUN domain sequence ................ 48

Table 7: Number of mating pairs in a 100 cell sample to determine conjugation pair efficiency 78

Table 8: Average of individual mating pairs conferring resistance to 6-mp and parmomycin

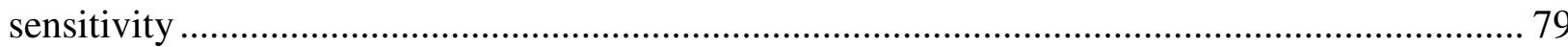

Table 9: ImageJ results for the mean diameter of MACs in CAC2, HIRA, UBN1 and UBN2 ... 81 


\section{List of Figures}

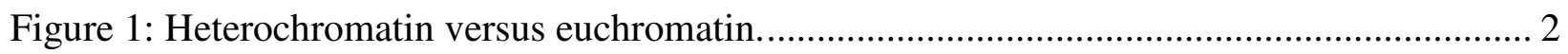

Figure 2: An outline of the three major processes of chromatin assembly .................................. 5

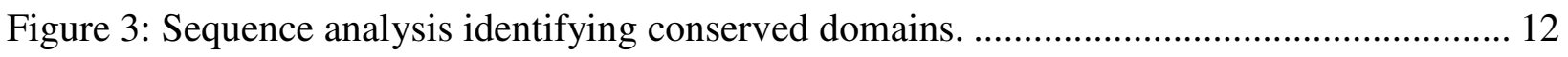

Figure 4: Sequence analysis identifying conserved domains across HPC2 orthologs ................. 13

Figure 5:Replication-dependent and independent chromatin assembly..................................... 18

Figure 6: Vegetative T. thermophila outlining the silent germline MIC and active somatic MAC

Figure 7: All gene copies can be replaced if the gene is non-essential........................................ 22

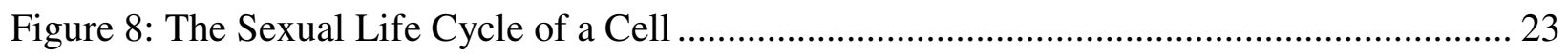

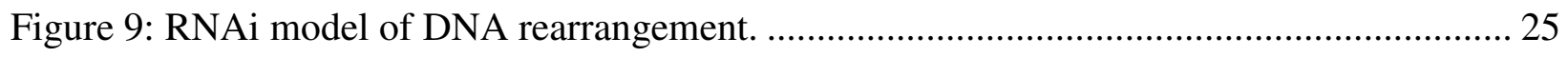

Figure 10: Expression profile for developmentally expressed TTHERM_00113110(UBN1).... 27

Figure 11: Expression profile for TTHERM_00335810 (UBN2 ……....................................... 28

Figure 12: Genetics of WT 427 and WT428 MIC and MAC................................................... 45

Figure 13: Genetics of KO transformant 427 and 428 strains MIC and MAC............................. 46

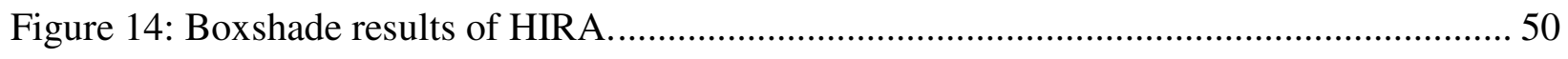

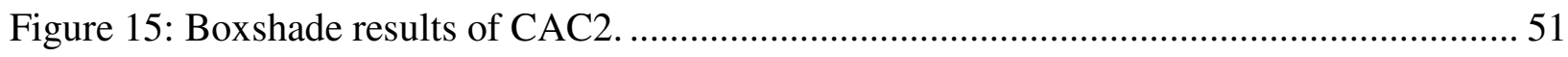

Figure 16: Boxshade results of the HUN domain of UBN orthologs ...........................................52

Figure 17: Purified T. thermophila genomic DNA.................................................................... 53

Figure 18: KO strategy outlining amplification of 5' and 3'homologous genomic DNA ( 1kb).

Figure 19: Agarose gel analysis of PCR-amplified T. thermophilaUP and DOWN sequences for

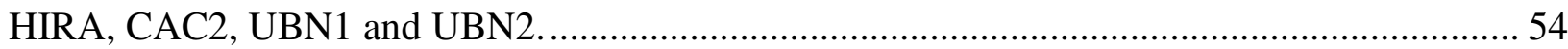


Figure 20: pNEO4 plasmid. 56

Figure 21: Ligation of 5' and 3' homologous sequences of HIRA, CAC2, UBN1 and UBN2 with pNEO4 plasmid.

Figure 22: Agarose gel electrophoresis of post-transformation diagnostic restriction enzyme digests 58

Figure 23: Agarose gel electrophoresis of post-transformation restriction enzyme digests of plasmids extracted from bacterial DH5alpha clones with SacII and SacI 59

Figure 24: Schematic of MAC KO approach used for all four genes. 60

Figure 25:. Agarose gel electrophoresis of linearized KO cassette released from pNEO4 plasmid for HIRA, CAC2, UBN1, UBN2 61

Figure 26: A schematic outlining accelerated phenotypic assortment .63

Figure 27: Schematic outlining the primer pairs used to determine whether or not correct integration of the $\mathrm{KO}$ cassette. 65

Figure 28: Agarose gel electrophoresis of PCR using HIRA-UPConf-F and NeoR primers. .... 66 Figure 29: Agarose gel electrophoresis of PCR using CAC2-UPConf-F and NeoR primers. ... 67 Figure 30: Agarose gel electrophoresis of PCR using UBN1-UPConf-F and NeoR primers. ... 68 Figure 31: Agarose gel electrophoresis of PCR using UBN2-UPConf-F and NeoR primers. ..... 69 Figure 32: Intron-flanking primers for RT-PCR. Introns are in red and exons are in green....... 71 Figure 33: Agarose analysis of PCR for total RNA (tRNA, rRNA,mRNA) and DNA extracted from WT cells utilizing UpRT-F/UpRT-R primers for HIRA 72

Figure 34: Agarose analysis of PCR for total RNA (tRNA, rRNA,mRNA) and DNA extracted from WT cells utilizing UpRT-F/UpRT-R primers for UBN1 73 
Figure 35: RT-PCR on total RNA (tRNA, rRNA, and mRNA) extracted from CAC2 KOs analyzed with respective RT-PCR primers

Figure 36: RT-PCR on total RNA (tRNA, rRNA, and mRNA) extracted from UBN2 KOs ....... 75

Figure 37: RT-PCR on total RNA (tRNA, rRNA, and mRNA) extracted from HIRA KOs

analyzed with respective RT-PCR primers................................................................. 76

Figure 38: RT-PCR on total RNA (tRNA, rRNA, and mRNA) extracted from UBN1 KOs ....... 77

Figure 39: Immunofluorescence of vegetative and starved CAC2, HIRA, UBN1 and UBN2 KOs

Figure 40: Immunofluorescence of conjugating CAC2, HIRA, UBN1 and UBN2 KOs 83 


\section{List of appendices}

Appendix 1 - Accession number........................................................... 98

Appendix 2 - Composition of all media, buffers, and solutions used ............................99

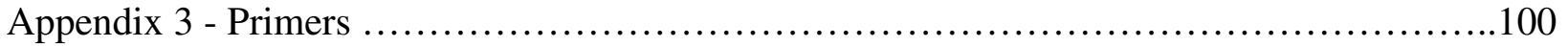

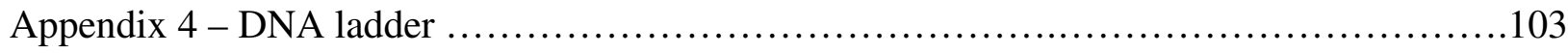




\section{List of abbreviations}

AP/MS: Affinity purification-Mass-Spectrometry

ASF1: Anti-Silencing Factor-1

BLAST: Basic Local Alignment Search Tool

Bp: base pair

CAC2: Chromatin assembly factor-1 subunit 2 (p60)

CAF-1: Chromatin assembly factor-1

C-: carboxy

CTD: carboxy-terminus domain

DAPI: 4', 6-diamidino-2-phenylindole

$\mathrm{ddH}_{2} \mathrm{O}$ : double distilled water

DMSO: dimethyl sulfoxide

DNA: deoxyribonucleic acid

EDTA: ethylenediaminetetraacetic acid

HAT: Histone Acetyl Transferase

H2A: Histone H2A

H2B: Histone H2B

H3: Histone $\mathrm{H} 3$

H4: Histone H4

HIRA: Histone Regulator A

IES: internal eliminated sequence

$\mathrm{K}$ : Lysine

$\mathrm{Kb}$ : kilo base pair

KO: knockout

M: molar

MAC: macronucleus

MIC: micronucleus

mRNA: messenger RNA

$\mu:$ micro 
$\mathrm{N}$ : amino

PCR: polymerase chain reaction

PTM: Post-translational modifications

PSF: penicillin streptomycin fungizone

Psi: pounds per square inch

RNA: ribonucleic acid

RNAi: RNA interference

rpm: rotations per minute

RT: reverse transcriptase

scnRNA: scan RNA

SDS: Sodium Dodecyl Sulfate

SPP: sequestrinproteose peptone

TBE: tris/borate/EDTA

UTR: untranslated region

UV: ultraviolet

v/v: volume/volume

WT: wildtype

w/v: weight/volume 


\section{Chapter 1: Introduction}

\subsection{Chromatin and nucleosomes}

Chromatin is a thread-like structure composed of DNA and proteins that form chromosomes which are found within the nuclei of eukaryotic cells. Humans have enough DNA in a single cell that when stretched reaches $2 \mathrm{~m}$ in length (Annunziato, 2008). This results in the biological problem of how eukaryotes fit DNA within the tiny 10-20 micron diameter nuclei of cells. Chromatin has four pivotal functions; 1. Package DNA 2.Reinforce DNA structures to enable mitosis and meiosis 3. Prevent DNA damage 4. Regulate gene expression and DNA replication (Annunziato, 2008). There are three levels of DNA packaging .The most basic structural unit of DNA is the nucleosome. Nucleosomes are composed of $\sim 147$ base pairs of DNA wrapped twice around a hetero-octamer of histone proteins. Repetitive units of nucleosomes create a "beads-on-a-string" appearance and the most basic chromatin fibre. Multiple nucleosomes then wrap into a 30nm chromatin fibre prior to higher-order packaging into metaphase state chromosomes for mitosis and meiosis (Fischle, Wang, \& Allis, 2003) (Figure 1). 


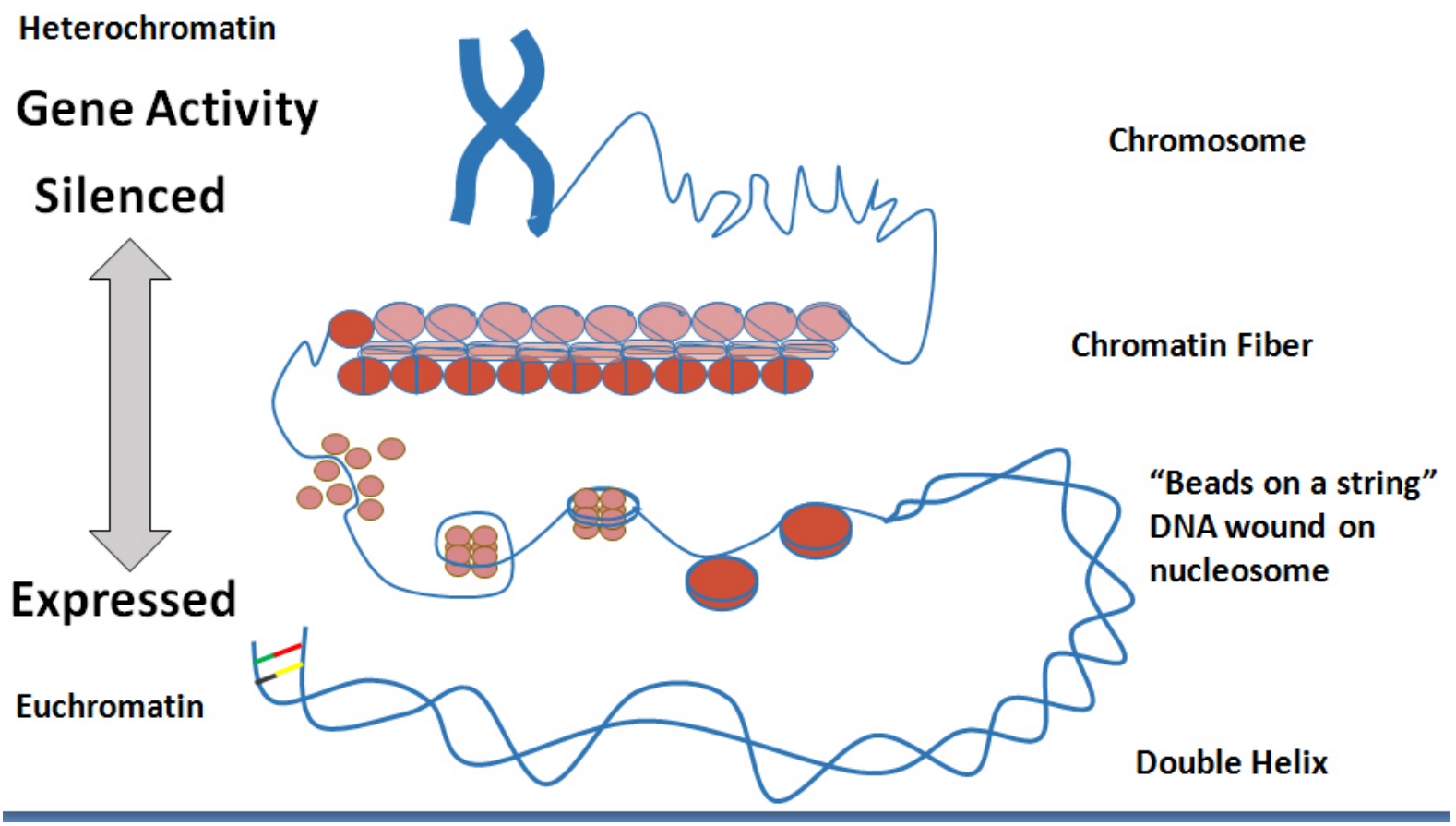

Figure 1: Heterochromatin versus euchromatin. DNA as a double stranded helix is accessible to DNA replication and transcription machineries and is expressed. DNA is packaged into higher order structures forming a tightly coiled chromosome where DNA is silenced in a heterochromatic state.

DNA in the nucleus exists in two forms and reflects the level of cell activity.

Euchromatin is the more "relaxed" state of chromatin containing DNA encoding active genes. The loose state of chromatin allows greater access to DNA and RNA polymerases needed for DNA replication and transcription respectively. The second form is a more tightly condensed form characteristic of transcriptionally inactive DNA known as heterochromatin.

Heterochromatin is responsible for regulating gene expression as well as protection of chromosome structure during cell division (Figure 1). Both chromatin states are distinguished cytologically by how intensely the DNA stains with giemsa stain. Euchromatic forms of DNA stain less intensely than heterochromatic DNA due to the dispersed nature of euchromatin within the cell (Annunziato, 2008). 


\subsection{Core Histones vs. Histone Variants}

Histones are generally divided into three main groups, core histones, histone variants, and linker histones that are defined by their expression profiles during the cell cycle, and have different distribution and deposition characteristics. Core histones are small highly basic proteins that package and order DNA through the formation of nucleosomes (Marino-Ramirez, Kann, Shoemaker, \& Landsman, 2005). There are four core histones; H2A, H2B, H3 and H4. The nucleosome core is made of two $\mathrm{H} 2 \mathrm{~A}-\mathrm{H} 2 \mathrm{~B}$ dimers that associate with an $\mathrm{H} 3-\mathrm{H} 4$ tetramer, forming an octomer of proteins around which DNA is wrapped. Histone variants differ from their core histone counterparts by structure (a few amino acids), have specific expression, localization, and species-distribution patterns .Core histones are deposited in a replicationdependent manner to package newly replicated DNA and their expression peaks during the $\mathrm{S}$ phase of the cell cycle. However, histone variants are expressed throughout the cell cycle and peaks outside the S phase (Marino-Ramirez, Kann, Shoemaker, \& Landsman, 2005). Linker histones ( $\mathrm{H} 1$ and $\mathrm{H} 5)$ are found on the surface of nucleosomes and bind nucleosomes at the entry and exit sites of DNA providing structural integrity (Annunziato, 2008).

\subsubsection{Histone $\mathrm{H3}$ variants}

H3.3 and centromeric H3 (CenH3) are two major histone H3 variants (Ahmad \& Henikoff, 2002). H3.1 is equivalent to core histone $\mathrm{H} 3$ in eukaryotes and is deposited in replication-dependent chromatin assembly. $\mathrm{CenH} 3$ is an essential histone $\mathrm{H} 3$ variant that binds to centromeres at the DNA locus and directs the formation of kinetochores required to mediate adequate chromosome segregation. H3.3 differs from core histone $\mathrm{H} 3$ by only 5 amino acids. Histone variant $\mathrm{H} 3.3$ is expressed throughout the cell cycle and found to localize at 
transcriptionally active and inactive regions of chromosomes (Ahmad \& Henikoff, 2002;

Goldberg et al., 2010). Yeast has only one H3 histone and is most similar to the eukaryotic H3.3

variant. However, yeast H3.3- like histones are deposited in both replication-dependent and independent chromatin assembly pathways (Baxevanis \& Landsman, 1998).

\subsection{Chromatin Assembly}

Nuclear events such as mitotic chromosome condensation, DNA recombination, replication, and transcription are all influenced by chromatin structure. Chromatin assembly is a term used to describe changes to chromatin structure that occur by several mechanisms including histone post-translational modifications (PTMs), ATP-dependent chromatin assembly (nucleosome sliding), or by selective deposition of histone variants (B. Li, Carey, \& Workman, 2007a) (Figure 2). PTMs of specific amino acids on the N-terminus tail of histone proteins such as acetylation, phosphorylation, and methylation modify chromatin structure and influence chromatin accessibility to DNA and RNA polymerase for transcription and replication respectively (Kornberg, 1977). An important histone PTM is acetylation that is catalyzed by a class of enzymes named histone acetyl transferases (HATs). HATs transfer an acetyl group from acetyl coenzyme A to specific lysine residues of histone proteins which destabilize the interaction between the DNA and nucleosomes (Roth, Denu, \& Allis, 2001). PTMs generally alter the structure of chromatin and create recognizable binding cites for regulatory proteins that contain domains i.e. bromodomains that recognize acetylated lysine residues (Figure 2) (Zeng \& Zhou, 2002).

ATP-dependent chromatin assembly proceeds through 3 pathways: nucleosome sliding along the DNA, nucleosome conformational change, and nucleosome eviction from the DNA 
(Narlikar, Fan, \& Kingston, 2002). ATP-dependent chromatin-assembly complexes hold ATPase domains where the hydrolysis of ATP enables the repositioning of nucleosomes by sliding along the DNA, expulsion of histones, or facilitate the deposition of histone variants in place of core histones resulting in nucleosomal confirmation changes. This results in the formation of nucleosome-free regions that convert DNA to more active states and reveal other regulatory elements such as transcription factor binding sites (Figure 2).Selective deposition of histone variants in place of canonical histones consists of histone variant incorporation that occurs typically in a replication-independent manner compared to core histones that are deposited behind the replication fork during the S-phase (Figure 2) (Jin et al., 2005).

1. ATP-dependent
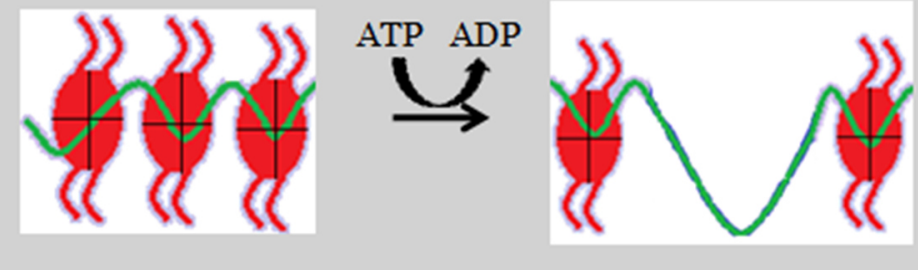

2. Histone variant exchange!!!
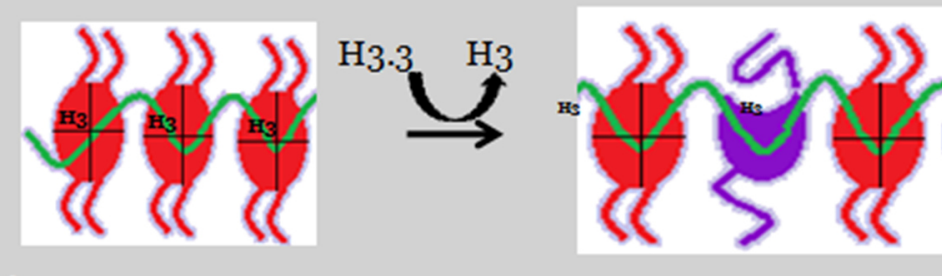

3. Post-translational modifications

Gen5 = HAT (Histone Acetyltransferase)

$\rightarrow$ Methylation $\rightarrow$ Phosphorylation
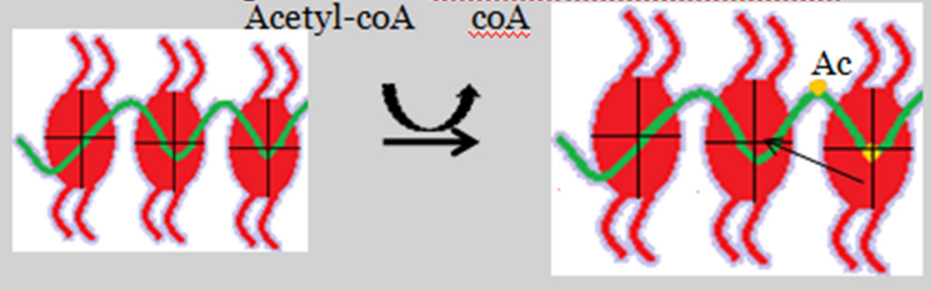

Figure 2: An outline of the three major processes of chromatin assembly. 1. ATP-dependent nucleosome sliding 2. Selective histone variant deposition (purple) 3. Post-translational modifications of $\mathrm{N}$-terminus tails of histones (acetylation in yellow). Through these processes DNA is made more or less accessible to DNA and RNA polymerases. 


\subsection{The histone code}

The histone code hypothesis predicts that the post-translational modifications, alone or in combination, act as extremely selective binding platforms for specific regulatory proteins that drive distinct nuclear processes. Binding of specific regulatory proteins is believed to result in the stabilization or destabilization of transcriptional machinery at target regions and promote or inhibit transcription. Methylation of lysine residues on the $\mathrm{N}$-terminus tails of histone $\mathrm{H} 3$ have been studied in depth. Methylation of lysine 4 and 36 is associated with transcriptional activation and methylation of lysine 9 and 27 results in transcriptional inactivation. The unique combination of modifications on the N-terminus amino acids influences the recruitment of "readers" that contain specific domains to recognize a pattern of modifications (Zeng \& Zhou, 2002). Recruitment of bromodomain containing factors such as transcription factor TAF250 to the promoter regions of genes is crucial for the activation of some genes. The recruitment and anchoring of chromodomain containing programmed DNA degradation 1 protein (PDD1) recognizes heterochromatin regions involved in the removal of internally eliminated sequences (IES) during conjugation in T. thermophila. The lack of histone acetylation prevents effective binding of bromodomain containing transcription factors resulting in transcriptional inactivation of target regions (Strahl \& Allis, 2000).

\subsection{Chromatin assembly}

DNA is tightly packaged into heterochromatin through the interactions between the highly lysine and arginine rich basic histone proteins and the negatively charged backbone of DNA. This tight interaction between nucleosomal units and DNA makes chromatin a highly stable structure. For cellular machineries like DNA and RNA polymerase to access DNA, 
chromatin must be unwound and cleared of histone proteins to convert the chromatin to its active euchromatin states. Conversely, the DNA has to be repackaged into chromatin when the chromatin is silenced. This is largely achieved by histone chaperones that regulate the assembly and dissassembly of nucleosomes (Ransom, Dennehey, \& Tyler, 2010). Chromatin assembly begins with the deposition of core histones (H3- H4) as a tetramer onto DNA followed by two $\mathrm{H} 2 \mathrm{~A} / \mathrm{H} 2 \mathrm{~B}$ dimers. Once the nucleosome core particle is assembled, 146 base pairs of DNA is wrapped around the nucleosome and followed by the incorporation of linker histones. The linker histones enable further compaction of DNA to tightly coiled chromatin fibres. Differentially modified histones can produce differences in chromatin structure and activity. Histone tail modifications regulate the interaction between nucleosomes and DNA and the subsequent recruitment of regulatory factors required for gene activation or repression (Marino-Ramirez et al., 2005).

\subsection{Histone chaperones}

Molecular chaperone is a term used to describe proteins that prevent or reverse incorrect interactions that occur when interactive surfaces are exposed to the environment. More specifically, histone chaperones shield non-specific interactions between negatively charged DNA surfaces and positively charged histone surfaces. Histone chaperones assist and guide histones in the formation of nucleosomes without actually being a part of the nucleosomes themselves (De Koning, Corpet, Haber, \& Almouzni, 2007). H2A-H2B dimers are found on the periphery of the central $\mathrm{H} 3-\mathrm{H} 4$ tetramers within the nucleosome. $\mathrm{H} 2 \mathrm{~A}-\mathrm{H} 2 \mathrm{~B}$ dimers are not assembled onto the DNA until H3-H4 tetramers have been deposited. Similarly, during chromatin disassembly, H2A-H2B dimers are removed prior to removal of $\mathrm{H} 3-\mathrm{H} 4$ tetramers 
from the DNA (Ransom et al., 2010). It is hypothesized that the stepwise nature of the chromatin assembly and disassembly contributes to the presence of histone chaperones specific to $\mathrm{H} 2 \mathrm{~A}$ H2B dimers and H3-H4 tetramers (Avvakumov, Nourani, \& Cote, 2011).

\subsubsection{Anti-silencing factor 1 (ASF1)}

ASF1 is a histone chaperone implicated in transcription silencing, nucleosome assembly, and DNA damage (Burgess \& Zhang, 2013). Histones H3.1-H4 and H3.3-H4 exist as dimers when bound to some histone chaperones however $\mathrm{H} 3.1-\mathrm{H} 4$ and $\mathrm{H} 3.3-\mathrm{H} 4$ exist as tetramers in the nucleosome (Tagami, Ray-Gallet, Almouzni, \& Nakatani, 2004). The explanation for this discrepancy was shown by the binding of histone chaperone ASF1 to H3.1-H4 and H3.3-H4. ASF1 binds to H3.1-H4 and $\mathrm{H} 3.3-\mathrm{H} 4$ dimers resulting in a physical occlusion of the $\mathrm{H} 3.1-\mathrm{H} 4$ and H3.3-H4 tetramerization interface (Winkler et al., 2012). Since ASF1 binds to newly synthesized H3.1-H4 and H3.3-H4 dimers, this suggests that the process of chromatin assembly involves the formation of H3-H4 tetramers from two dimers of H3-H4 (Ransom et al., 2010). The carboxyl-terminus of histone H3.1 (residues 122-135) consists of a highly conserved aminoacid sequence found in histone variant H3.3 a well. The carboxyl-terminus of H3.1 and H3.3 has been identified as the primary site of interaction between $\mathrm{H} 3.1 / \mathrm{H} 3.3-\mathrm{H} 4$ and ASF1 (Tagami et al., 2004; Galvani et al., 2008). Disruption of ASF1 N-terminus sequence by single-site mutations that replaced Valine 94 with an Arginine residue (V94R) abolished the interaction between ASF1 and H3.1/H3.3-H4 completely. Also, this highly conserved amino-acid sequence at the C-terminus of H3.1 and H3.3 has been identified as the site of tetramerization between two H3.1-H4 or H3.3-H4 dimers. This supports that ASF1 must bind and recruit H3.1-H4 and H3.3$\mathrm{H} 4$ dimers to the nucleus followed by the release of this interface in order for tetramerization to 
occur prior to deposition onto DNA (Mousson et al., 2005).ASF1 has been recognized as a key player that presents $\mathrm{H} 3.1$ and $\mathrm{H} 3.3$ to chromatin assembly factor 1 (CAF-1) and histone regulator A (HIRA) respectively. ASF1 acts as a bridge to stabilize contacts between H3.1-H4 and H3.3H4 with the respective assisting chaperones such as HIRA required for gene silencing (Daganzo et al., 2003), and CAF-1 mediated in replication-coupled chromatin assembly (Antczak, Tsubota, Kaufman, \& Berger, 2006).

\subsubsection{Chromatin assembly factor 1 (CAF-1)}

CAF-1 is a trimeric protein complex consisting of three subunits- p150, p60, and p48 (CAC1, CAC2, CAC3 respectively). ASF1 delivers newly synthesized histones to CAF-1 for deposition onto newly replicated DNA in the nucleus. Co-immunoprecipitation assays have shown that it is the N-terminus domains of ASF1 that binds to the B-domain of the CAC2 subunit of CAF-1 in human and Schizosaccharomyces pombe (Malay, Umehara, MatsubaraMalay, Padmanabhan, \& Yokoyama, 2008). The C-terminus tail of ASF1 was also shown to interact with the B-domain of CAC1 and CAC3 and increase the stability of the ASF1-CAF-1 complex by 10 folds (Liu, Roemer, Port, \& Churchill, 2012). ASF1 binding to H3.1-H4 dimers occludes the tetramerization interface. Therefore it is known that ASF1 has to be removed for H3-H4 tetramers to form. How ASF1 is removed from $\mathrm{H} 3.1-\mathrm{H} 4$ dimers and how the histones are transferred to CAF-1 remains unclear. It is predicted that ASF1 binds to CAC2 of CAF-1, and the binding of the CAC3 subunit weakens the affinity with which ASF1 is bound to H3.1-H4 dimers. This stimulates the transfer of $\mathrm{H} 3.1-\mathrm{H} 4$ dimers to CAF-1 for deposition onto DNA (Mello et al., 2002). CAF-1 can bind to two H3.1-H4 dimers or a single cross-linked (H3$\mathrm{H} 4)_{2}$ tetramer with similar affinities. Also, CAF-1 of yeast has shown to bind to two copies of 
$\mathrm{H} 3-\mathrm{H} 4$ in vivo suggesting CAF-1 acts to first assemble and then deposit an $(\mathrm{H} 3.1-\mathrm{H} 4)_{2}$ tetramer onto DNA (Winkler et al., 2012). CAF-1 is responsible for loading new histone H3.1- H4 tetramers onto DNA in a replication-coupled manner through an interaction with proliferating cell nuclear antigen (PCNA). PCNA encircles DNA and travels along the replication fork preventing DNA polymerase from disconnecting from the replicating DNA (Tagami et al., 2004).

\subsubsection{Histone regulator A (HIRA)}

Hir1, Hir2, Hir3 (or Cabin1 in humans) and Hpc2 (or Ubinuclein (UBN) in humans) comprise the HIR/HIRA complex in yeast and humans. (Galvani et al., 2008; Green et al., 2005). HIR of yeast and HIRA of humans co-purifies with ASF1 (Galvani et al., 2008; Green et al., 2005). Similar to the interaction between ASF1 with CAF-1, H3-H4 and H3.3-H4 dimers, the N-

terminus of ASF1 is required to bind with the N-terminus WD repeats (B-domain) of HIR/HIRA (Galvani et al., 2008). The ASF1-HIR/HIRA complex functions collectively to deposit histones onto DNA in a replication-independent manner. Specifically histone variant H3.3 in humans and histone H3 in yeast (Tagami et al., 2004). Histone deposition has been shown to be impaired and greatly reduced by HIRA/HIR when mutations are introduced to the N-terminus of ASF1 that inhibits HIR/HIRA binding (Green et al., 2005; Sanematsu et al., 2006). This suggests that HIR/HIRA and ASF1 function together for histone replacement throughout the cell cycle in contrast to CAF-1 that can function independently of ASF1 to deposit H3-H4. In yeast, when members of the HIR complex were deleted, the remaining HIR proteins still associate with each other except when HPC2 is deleted. When HPC2 is deleted, HIR3 was not detected at all suggesting that it is through HPC2 that HIR3 associates with the HIR complex. Also, in the 
absence of any one of the HIR complex members, the remaining HIR proteins reduced association with ASF1. When HIR3 is deleted, small amounts of HIR2 is recovered suggesting HIR3 must be the more peripheral region of the HIRA complex. This suggested that HIR3 associates with HIR1 and HIR2 via HPC2 to form the HIRA complex, and that all subunits of HIRA are required for normal interactions with ASF1 (Green et al., 2005; Sanematsu et al., 2006).

\subsubsection{Ubinuclein}

To identify the candidate human orthologs of yeast HPC2, a bioinformatic approach was used. Two orthologs (UBN1 and UBN2) of yeast HPC2 in humans were identified (Figure 4). Both UBN1 and UBN2 contain the conserved HPC2 related domain (HRD) also known as the HPC2-Ubinuclein-1 Domain (HUN) or Conserved Domain III. The HUN domain is an evolutionarily conserved HIRA/HIR-binding domain, which directly interacts with the Nterminus WD repeats of HIRA/HIR in humans and yeast respectively (Banumathy et al., 2009). The HUN domain has a characteristic pattern of conserved acidic residues (Balaji, Iyer, \& Aravind, 2009) (Figure 3). The HUN domain is also predicted to be the histone tail binding subunit of the HIR/HIRA complex (Balaji et al., 2009). UBN1 and HPC2 were shown to copurify with histone variant H3.3 (humans)/ H3 (yeast) and the HIRA/HIR-ASF1 chaperone complex in humans and yeast respectively (Tagami et al., 2004; Green et al., 2005; Banumathy et al., 2009). The removal of HIR/HIRA or UBN1 was shown to destabilize the other in vitro and no physical interaction between ASF1 and UBN/HPC2 has been determined. Therefore, ASF1 and UBN/HPC2interact independently with HIRA/HIR. This supports the idea that HIRA/HIR forms a scaffold for the HIR-ASF1-HPC2/ HIRA-ASF1-UBN complex in yeast and humans 
respectively (Banumathy et al., 2009). Outside the HUN domain, UBN1 and UBN2 of humans do not show much similarity to yeast HPC2, however UBN1 and UBN2 do share other regions of similarity to each other.UBN1 in humans has been implicated in chromatin-assembly pathways important in cell senescence. Cell senescence is an important physiological determinants of cell proliferation, stem cell renewal, tumor progression and suppression, and aging (Logan \& Nusse, 2004; Herbig, Ferreira, Condel, Carey, \& Sedivy, 2006; Jeyapalan, Ferreira, Sedivy, \& Herbig, 2007). Similar to humans, two hypothetical orthologs of yeast HPC2 (UBN1 and UBN2) were identified in T, thermophila (Figure 4) (Banumathy et al., 2009; Balaji et al., 2009).

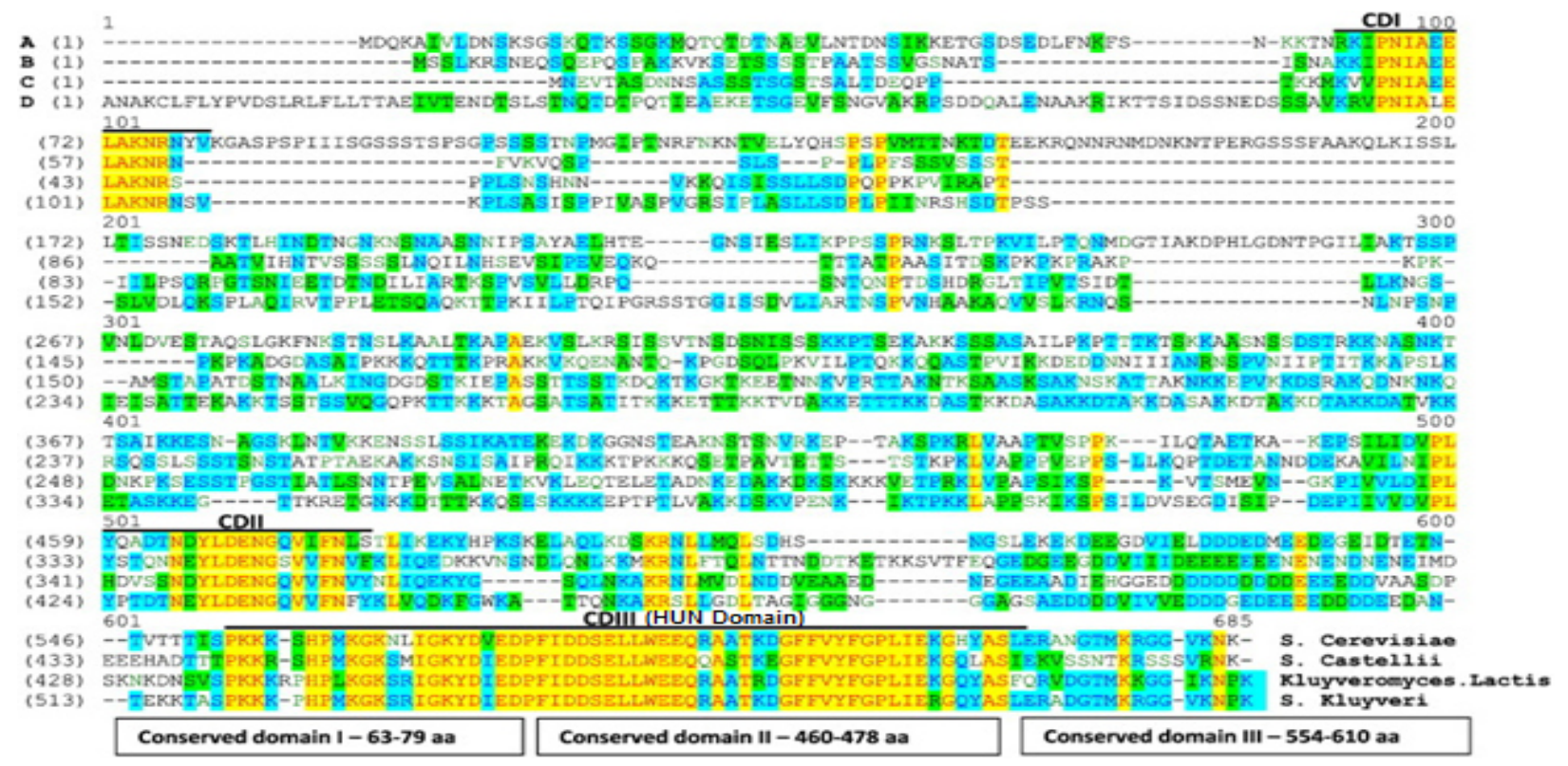

Figure 3: Sequence analysis identifying conserved domains. CDI, CDII, and CDIII across HPC2 homologs in various species of Ascomycete yeast. CDIII is equivalent to the previously identified HRD/HUN domain (Vishnoi et al., 2011). 


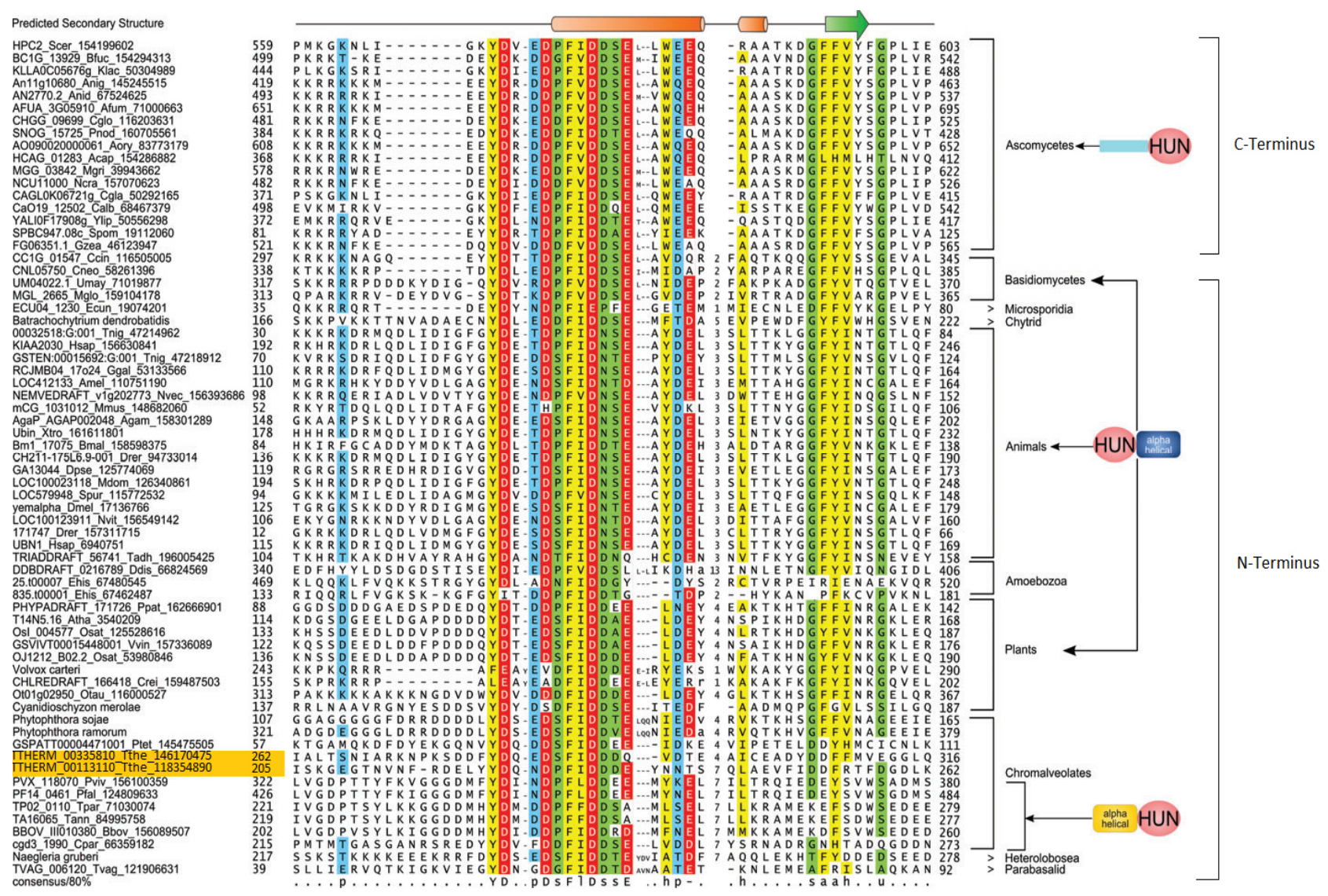

Figure 4: Sequence analysis identifying conserved domains across HPC2 orthologs in various species using S.cerevisiae HPC2 as query sequence. Two hypothetical HPC2 orthologs (UBN1/UBN2) of T. thermophila were identified (Modified from (Balaji et al., 2009)). 


\subsubsection{HIRA-UBN-CABIN1-ASF1 functions collectively as the HUCA complex in humans and yeast}

The three conserved domains in HPC2 of yeast are known as Conserved Domain 1, 2 , and 3 (CDI, CDII and CDIII) (Figure 3) (Vishnoi et al., 2011). CDI is unnecessary for HIR complex assembly, but plays a role in the repression of histone genes by recruiting the HIR complex to the HIR-dependent histone gene loci. CDII is required for the stability of HPC2 in the HIR complex. CDIII is equivalent to the HUN domain and is predicted to interact with HIR directly to form the HIR-ASF1-HPC2 complex (Vishnoi et al., 2011). Both yeast HIR1 and HIR2 and the human homologue HIRA encode for WD ( $\beta$-propellor) repeats present at the $\mathrm{N}$ terminus. In yeast both HIR1 and HIR2 act as transcriptional co-repressors that regulate gene expression through targeting gene promoters without binding to DNA directly. HIR1 and HIR2 are recruited to histone genes by their recognition of a site-specific DNA binding protein that is present at the promoter of each negatively regulated gene (Spector, Raff, DeSilva, Lee, \& Osley, 1997). HPC2 interacts with the HIR-ASF1 complex of yeast and UBN1 with the HIRA-ASF1 complex of humans through the HUN domain which binds to the N-terminus WD repeats of HIR/HIRA (Banumathy et al., 2009).

The C-terminus sequence of the HUN domain in UBN1 of humans (FYINSGT) contains the $\mathrm{F}$ and I residues required for binding to HIRA (Figure 16). UBN1 and ASF1 interact independently with HIRA suggesting that HIRA is a scaffold for UBN1 and ASF1 proteins with H3.3-H4 in humans. Similar to HIRA, CAC2 binds to ASF1 through a B domain-like motif and holds WD repeats making the interaction of CAF-1/ASF1/histone H3/H4 complex analogous to 
the HIRA/ASF1 interaction. These similarities reinforce the parallel between HIRA and CAC2 of CAF-1. Although these similarities exist, there has been no evidence suggesting a physical interaction between UBN1 and CAF-1 (Banumathy et al., 2009). This may be the role of UBN2 in humans and one of the recently identified hypothetical UBN in T. thermophila.

\subsubsection{Medical relevance of the HUCA complex}

Miss-expression of chromatin assembly genes results in genome instability in yeast and the onset of many disease states in humans (Burgess \& Zhang, 2013). Defective human HIRA is implicated in haploinsufficiency syndromes such as DiGeorge syndrome which has a T-cell mediated response that in some patients is due to an absent or hypoplasticthymus (Lamour, 1995). HIRA is located on chromosome 22 and is deleted in patients that have Digeorge Syndrome. Digeorge syndrome is a congenital developmental disorder characterized by heart defects and poor immunity where a reduction in HIRA results in increased incidence of truncusarterious (Farrell et al., 1999). Also, HIRA deposits H3.3 onto nucleosomes of paternal chromatin during male pronucleus formation in sexually reproducing animals. This indicates HIRA has an important role in fertility (Bonnefoy et al, 2007). Miss-expression of ASF1 and CAC2 results in renal, endometrial and cervical cancer. This is believed to be because ASF1 and CAC2 are involved in cell proliferation, where an increased abundance of these factors in cancer cells result in the enhanced proliferation status of cancer cells (Zhang et al., 2005). UBN1 of humans has shown expression in cancer cell lines and tumors like Wilms tumor (Banumathy et al., 2009). HIRA, CABIN1, UBN1 and ASF1 play very important roles in human health and it would be beneficial to acquire a better understanding of this collective complex by using $T$. Thermophila as a model. 


\subsubsection{Phyletic and divergence patterns of major histone chaperone components}

Some species exhibit the apparent loss of either the CAC2 ortholog (Guillardia) or the

HIRA ortholog (kinetoplastids) yet continue to survive suggesting a continued functional overlap between the two orthologs (Balaji et al., 2009). CAF-1 and HIR/HIRA pathways share overlapping functions in several chromatin-related processes in both yeast and humans. Deletion of HIR 1 and subunits of CAF-1 produced viable progeny but resulted in decreased rates of histone $\mathrm{H} 3$ exchange in yeast. Also, in HeLa cells when CAF-1 is knocked-down, HIRA assembles nucleosomes during replication suggesting a functional overlap in human cells as well (Ray-Gallet et al., 2011).

\subsection{Replication-Dependent and Replication-Independent Nucleosome Assembly}

Core histone H3.1 was shown to co-purify with CAF-1 and H3.3 with HIRA suggesting that canonical H3.1 and variant $\mathrm{H} 3.3$ are deposited onto chromatin using two distinct pathways (Tagami et al., 2004). In humans, H3.1 is deposited in a DNA replication-dependent pathway with CAF-1 while histone variant $\mathrm{H} 3.3$ is substituted in place of canonical H3.1 in a DNA replication-independent pathway with HIRA in humans. The single $\mathrm{H} 3$ variant in yeast is deposited in replication-dependent and independent pathways (Tagami et al., 2004). 


\subsubsection{Replication-dependent chromatin assembly}

The N-terminus of ASF1 binds to newly-synthesized dimers of H3.1/H4 upstream from the histone chaperone CAF-1 in the cytoplasm and recruits $\mathrm{H} 3-\mathrm{H} 4$ to the nucleus. Through an interaction between the N-terminus of ASF1 and the CAC2 subunit of CAF-1 of both yeast and humans, the newly synthesized $\mathrm{H} 3-\mathrm{H} 4$ dimers are passed off to CAF-1 prior to deposition onto the newly replicated DNA strand (Figure 5). It is understood that ASF1 has to be removed from the tetramerization interface of $\mathrm{H} 3$ to enable formation of $\mathrm{H} 3-\mathrm{H} 4$ tetramers (Tagami et al., 2004). In yeast, ASF1 is required for the acetylation of $\mathrm{H} 3$ lysine 56 (H3K56ac) which acts as a crucial marker of newly synthesized histone $\mathrm{H} 3$ and efficient association of $\mathrm{H} 3-\mathrm{H} 4$ with histone chaperones CAF-1 in vitro and in vivo (Lee, Ou, Lee, \& Juan, 2009). ASF1 binds H3-H4 with equivalent affinity as CAC2 of CAF-1 raising the question on how $\mathrm{H} 3-\mathrm{H} 4$ can be transferred from ASF1 to other histone chaperones. It is seen that the binding of CAC3 and CAC1 subunits to ASF1 enhances the stability of the CAF-1-ASF1 complex and reduces the affinity with which H3-H4 binds to ASF1. This stimulates the transfer of H3-H4 to CAF-1 (Su et al., 2012). CAF-1 can bind to two H3.1-H4 dimers or a single cross-linked (H3-H4) 2 tetramer with similar affinities. Also, CAF-1 has shown to bind to two copies of H3.1-H4 in vivo suggesting CAF-1 acts to first assemble and then deposit an (H3.1-H4)2 tetramer onto DNA (Winkler et al., 2012). In DNA-replication coupled nucleosome assembly, the H3.1 complex appears to be recruited near target sites through the interaction of CAF-1 with replication machineries such as PCNA at the replication fork (Figure 5). Immediately following DNA replication, newly synthesized H3.1$\mathrm{H} 4$ molecules are deposited onto the newly replicated DNA while parental $\mathrm{H} 3-\mathrm{H} 4$ complexes are transferred as a complete $(\mathrm{H} 3-\mathrm{H} 4)_{2}$ tetramer unit to the parental strand behind the replication fork (Winkler et al., 2012). 


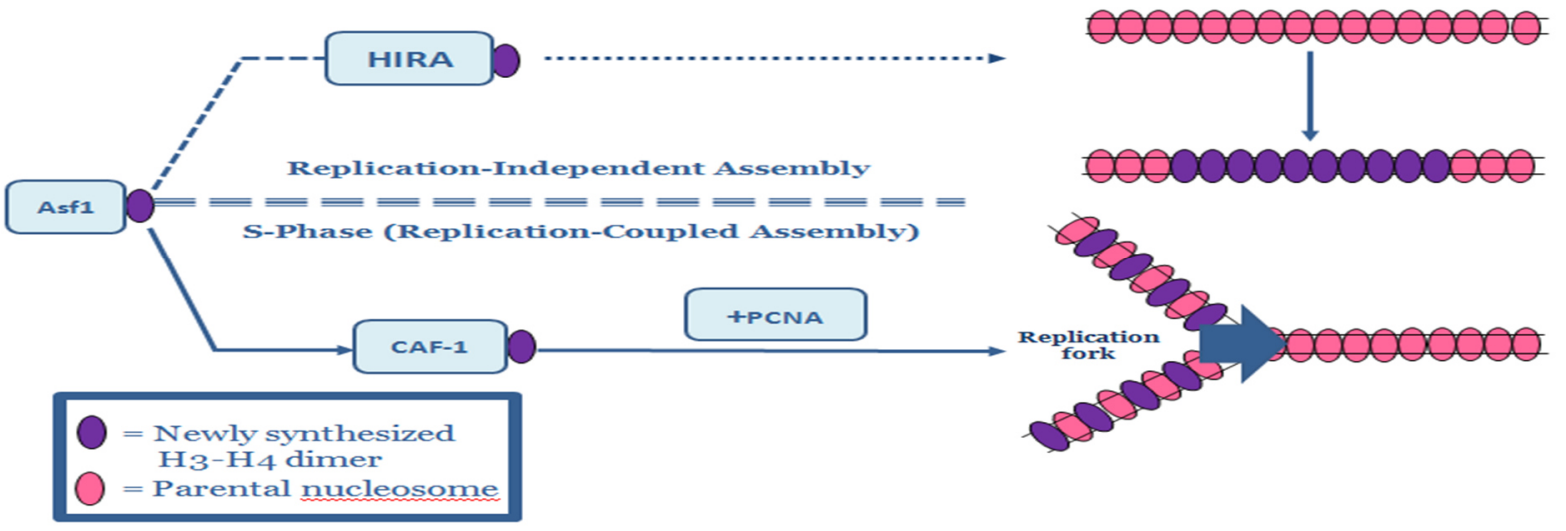

Figure 5: Replication-dependent and independent chromatin assembly. In this model ASF1binds to $\mathrm{H} 3 / \mathrm{H} 3.3-\mathrm{H} 4$ dimers and present them to CAC2 subunit of CAF-1 or HIRA. CAF1 and HIRA in turn assemble the histones onto DNA in a replication-coupled or independent manner respectively.

\subsubsection{Replication-independent chromatin assembly}

Replication -independent chromatin assembly involves nucleosome disassembly and assembly during transcription and repair. Replication-independent nucleosome assembly plays a vital role in maintenance of epigenetic memory and genome stability (Avvakumov et al., 2011; Burgess \& Zhang, 2013). During transcription, histone chaperones work with ATP-dependent chromatin remodelers to remove nucleosomes and expose the promoter sequences required for transcription. Histones are modified ahead of RNA Polymerase II (RNAPII) destabilizing the interaction between the histones and DNA allowing for elongation of the RNA transcript to occur smoothly (B. Li, Carey, \& Workman, 2007b).

Similar to the interaction between ASF1 and CAF-1, the N-terminus of ASF1 binds to the HIRA complex and facilitates the transfer of $\mathrm{H} 3.3-\mathrm{H} 4$ dimers for the deposition onto DNA in a replication-independent manner (Figure 5) (Green et al., 2005). It is possible that the H3.3-H4 tetramers are first assembled on HIRA followed by its deposition onto DNA or HIRA may 
deposit two H3.3-H4 dimers onto DNA (Figure 5) (Ransom et al., 2010; Tagami et al., 2004).Small fractions of parental $(\mathrm{H} 3.3-\mathrm{H} 4)_{2}$ tetramers split into two dimers of H3.3-H4 enabling the formation of "mixed nucleosomes" that contain both new and old H3.3-H4 dimers. This is in opposition to parental $\mathrm{H} 3.1-\mathrm{H} 4$ molecules that usually do not split and are deposited as tetramers behind the replication fork of the parental strand (Xu et al., 2010). Therefore, unlike new H3.1-H4 dimer molecules that are most likely deposited in a tetrameric form, new $\mathrm{H} 3.3-\mathrm{H} 4$ dimers may be deposited in both dimeric and tetrameric forms (Burgess \& Zhang, 2013). Both replication- independent and replication-dependent chromatin assembly is present in $T$.

thermophila, however the roles of CAF-1 and HIRA have not been functionally characterized till date (Green et al., 2005; Cui, Liu, \& Gorovsky, 2006).

\subsection{The histone code for chromatin assembly}

Newly-synthesized histone $\mathrm{H} 3-\mathrm{H} 4$ dimers are acetylated before being assembled into nucleosomes (Roth et al., 2001). In yeast, ASF1 is essential for H3K56ac. Histones carrying H3K56ac co-purify with CAF-1 in budding yeast. In S.cerevisiae deletion of ASF1 as well as mutating H3K56 highly diminishes CAF-1 binding with $\mathrm{H} 3$, suggesting $\mathrm{H} 3 \mathrm{~K} 56 \mathrm{ac}$ is required for CAF-1 binding to newly synthesized H3-H4 dimers (Q. Li et al., 2008). Evidence shows that several N-terminus lysine residues of $\mathrm{H} 3$ (K9, K14, K18, K23, and K27) play important roles in nucleosome assembly ( $\mathrm{Li}$ et al., 2008). Methylation of lysine 4 and 36 results in the recruitment of bromodomain containing transcription factors that result in gene activation and transcription. Tri-methylation of lysine 9 and 27 results the inactivation of gene regions (Fischle et al., 2003). Phosphorylation of histone H4 Serine 47 (H4S47ph) promotes nucleosome assembly of H3.3-H4 
and inhibits nucleosome assembly of $\mathrm{H} 3.1-\mathrm{H} 4$ by increasing the binding affinity of HIRA to H3.3-H4 and reducing the association of CAF-1 with H3.1-H4 (Kang et al., 2011).

\subsection{Senescence associated heterochromatin formation}

Cell senescence is an irreversible cell proliferation arrest triggered by activated oncogenes and is an important tumor suppression mechanism (Campisi, 2005). Senescence is also caused by telomere attrition caused by repetitive cell division (Ramirez et al., 2001). Cell senescence contributes to tissue aging through depletion of renewable stem cell population resources. Cell senescence results in the formation of specialized domains of facultative heterochromatin called senescence-associated heterochromatin foci (SAHF) that result from the condensation of individual chromosomes on heterochromatic regions and repress proliferating genes. Repression of proliferating genes result in senescence associated cell cycle arrest. Two key regulators of SAHF are HIRA and ASF1. The physical interaction between HIRA and ASF1 is required for telomeric silencing (Zhang et al., 2005). SAHF is dependent upon a trimeric complex of HIRA, ASF1, and histone H3.3. SAHF mediated by HIRA and ASF1 requires localization of HIRA to acute promyelocytic leukemia (PML) nuclear bodies or organelles enriched in PMLs. This is because PML bodies involved in the onset of cell senescence. Therefore it is on PML bodies that HIRA containing complexes are assembled or modified prior to the formation of SAHF (Banumathy et al., 2009). 


\subsection{Tetrahymena thermophila an ideal model organism - T. Thermophila has two distinct nuclei}

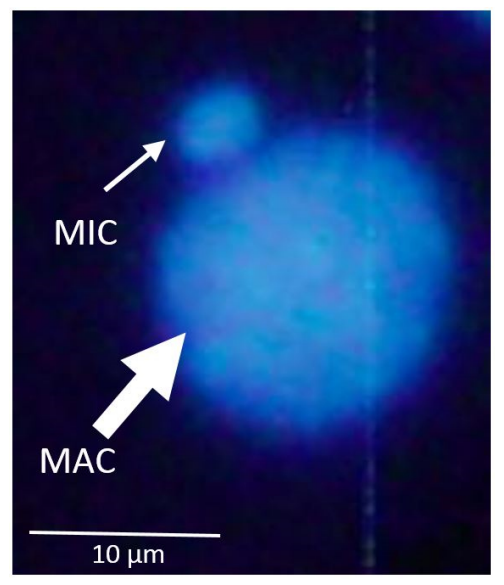

Figure 6: Vegetative $T$. thermophila outlining the silent germline MIC and active somatic MAC
T.thermophila is a unicellular eukaryote that provides a great number of experimental benefits for the study of chromatin biology. A characteristic feature of $T$. Thermophila is the distinct separation of the germ-line and somatic chromatin into two different nuclei; the Micronucleus (MIC) and the Macronucleus (MAC) (Turkewitz, Orias, \& Kapler, 2002). The MIC is transcriptionally silent during vegetative growth and diploid. The MIC holds 5 chromosomes responsible for stable genetic inheritance in progeny (genotype). The somatic MAC is transcriptionally active during vegetative growth polyploid nucleus containing $\sim 45$ copies of each chromosome

(45C). The MAC is responsible for phenotype (Figure 6). The T. Thermophila genome has more than 27,000 predicted protein-coding genes, 15,000 of which are similar to genes in other organisms (Eisen et al., 2006).The MIC divides mitotically and the MAC divides amitotically during vegetative growth. Continual amitotic divisions results in unequal segregation of alleles for a given gene. Over time, the complete loss of one allele can result in progeny that are homozygous for one allele for a given gene. This phenomenon is known as phenotypic assortment (Orias \& Flacks, 1975). In experimental conditions, phenotypic assortment can be accelerated through increasing the concentration of drug resistant by the plasmid used for cloning (Figure 7) (Orias, 2012). 


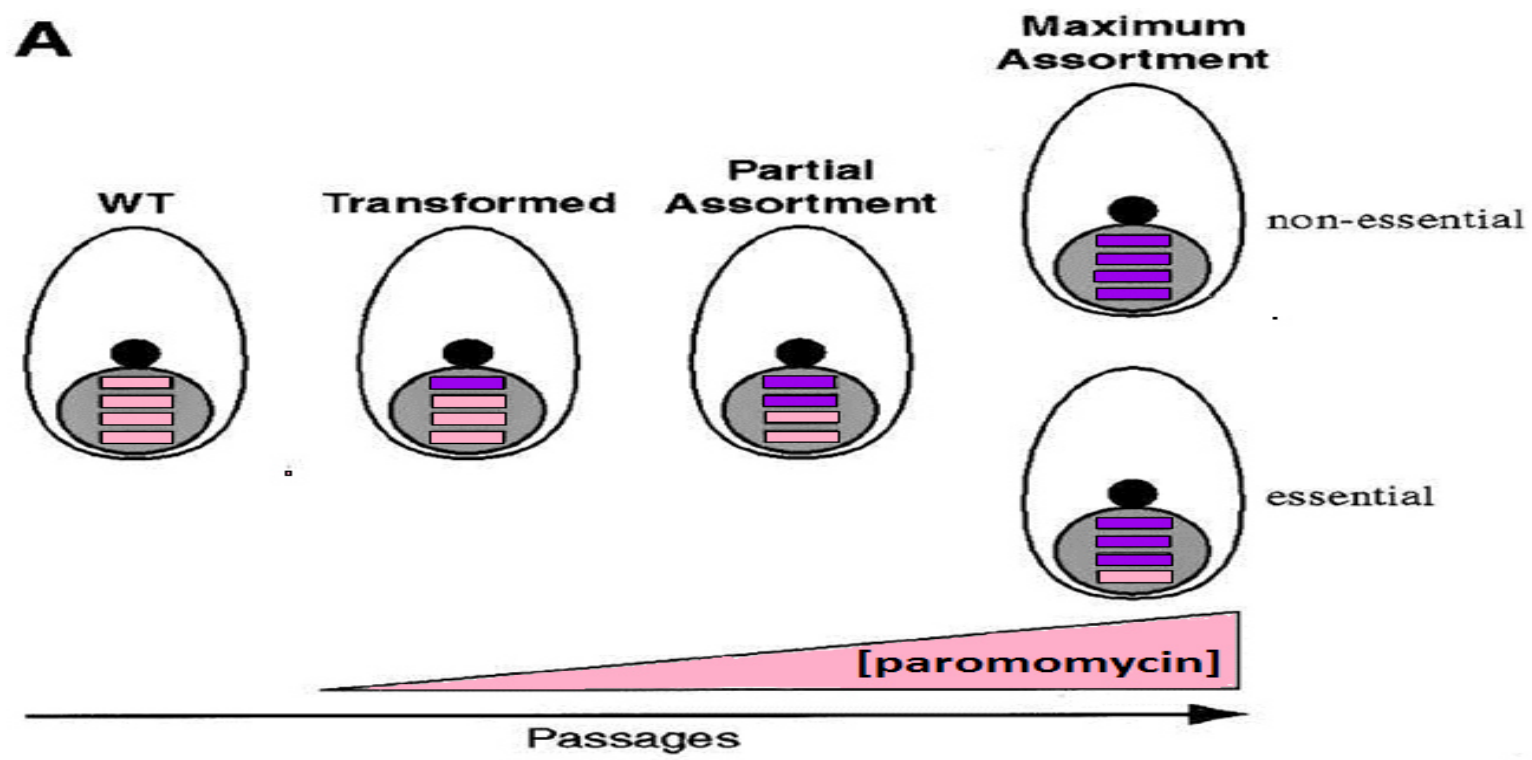

Figure 7: All gene copies can be replaced if the gene is non-essential while all copies of essential genes cannot through phenotypic assortment driven homozygosity.

\subsubsection{Sexual phase of $T$. Thermophila life cycle}

T.thermophila has 7 different mating types. Each of the seven is capable of mating with another but not with the same type (Phillips, 1968). Pairing of starved T. thermophila cells of different mating types initiates conjugation. The MIC undergoes meiosis and produces four haploid nuclei. Three are degraded and one is selected. The selected haploid nuclei divides mitotically and produces two haploid pronuclei. This is followed by a reciprocal nuclear exchange where one of the haploid pronuclei migrates to the adjacent pair and fuses with the stationary haploid pronuclei found in the partner. Fusion of the two haploid pronuclei results in the formation of a new diploid zygote nucleus. The diploid zygotic nucleus divides mitotically twice and forms four identical nuclei. Two of these will develop into the new MACs and two develop into the new MICs and the old parental MACs are then reabsorbed. After re-feeding, the 
pairs separate and one of the MICs are degraded while the other divides mitotically. The final step is cell division enabling four new daughter cells to be produced, each with one new MIC and MAC (Figure 8) (Martindale, Allis, \& Bruns, 1982).

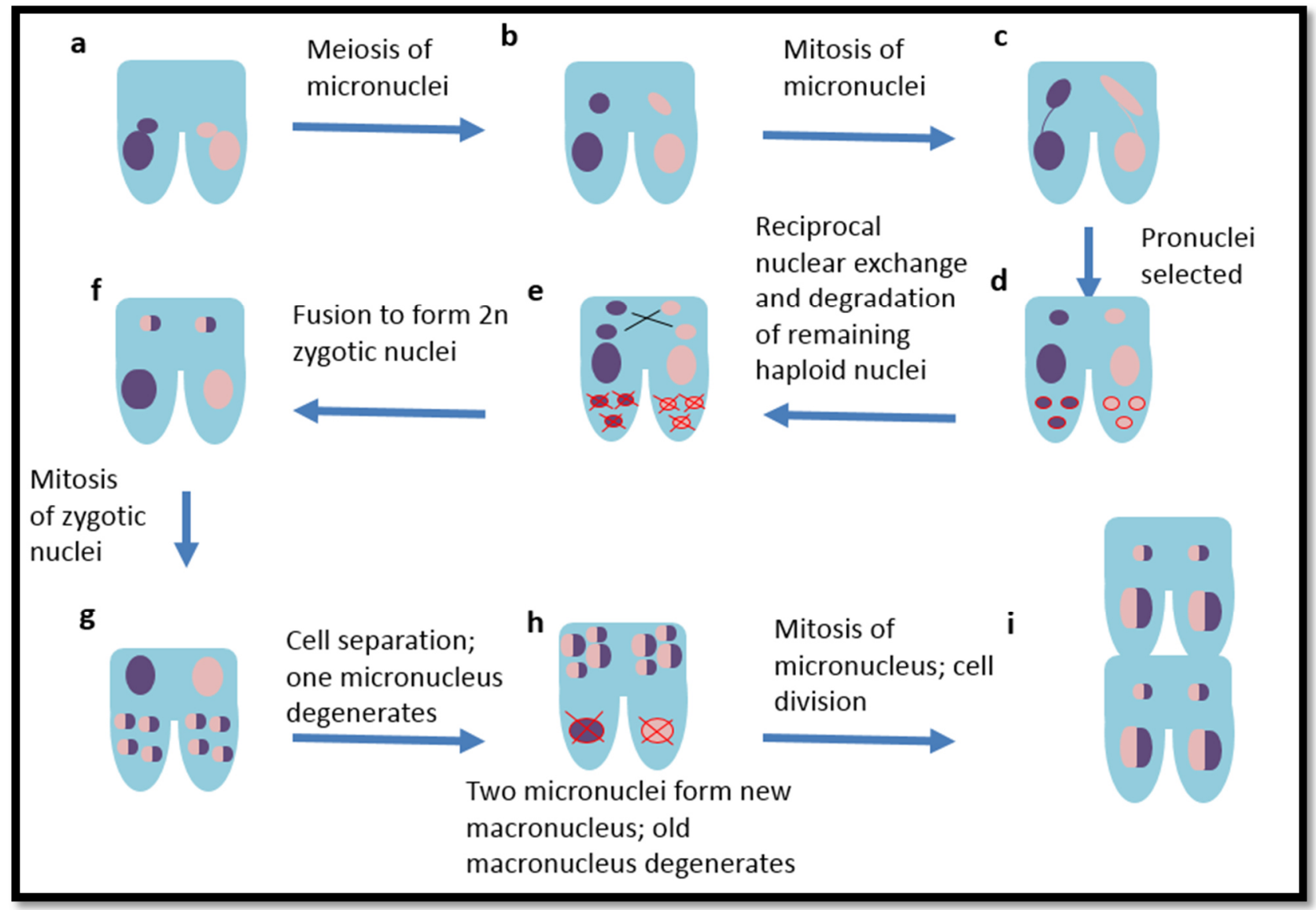

Figure 8: The Sexual Life Cycle of a Cell. Starvation stimulates conjugation and then mixing equivalent concentrations of different mating types enables the MIC to undergo meiosis to generate haploid products. Three of the meiotic products are degraded, while selected nuclei divides mitotically to generate two gametic haploid nuclei of identical genetic composition. Nuclear exchange and formation of zygote nucleus occurs. The zygote nucleus undergoes two mitotic divisions and products differentiate into MICs and MACs, while the old MAC is resorbed. The conjugants then separate, and divide during vegetative growth. 


\subsubsection{T. thermophila-a good model organism to study chromatin biology}

During development of the new MAC, massive genome chromosomal rearrangement and endoreplication occurs where $\sim 15 \%$ of the MIC genome is eliminated (Figure 6, Figure 9) (Yao et al., 2007) There are two types of eliminated sequences; breakage-eliminated sequences (BES) and IESs. BES consist of short ( $<50 \mathrm{bp}$ ) regions found to flank 15-bp chromosome breakage sequence (Cbs). BES are deleted and replaced with telomere repeats to effectively produce up to 300 macronuclear chromosomes from the original 5 MIC chromosomes ( Yao \& Monks, 1990). IESs range in size from $\sim 0.5$ to $20 \mathrm{~kb}$ and are found as non-coding repetitive sequences in the MIC considered as "junk" DNA. There are no consensus sequences around or within the IESs that specifically explain how the IESs are targeted for elimination (Mochizuki \& Gorovsky, 2005). However, IESs are found in the form of heterochromatin during development (Figure 9)

(Yao, 1982). Most eukaryotes retain silenced DNA in dense heterochromatin regions, however $T$. Thermophila utilizes an RNA interference (RNAi)-mediated process to remove these sequences (Figure 9) (Mochizuki, Fine, Fujisawa, \& Gorovsky, 2002; Mochizuki \& Gorovsky, 2004b; Mochizuki \& Gorovsky, 2004a). 


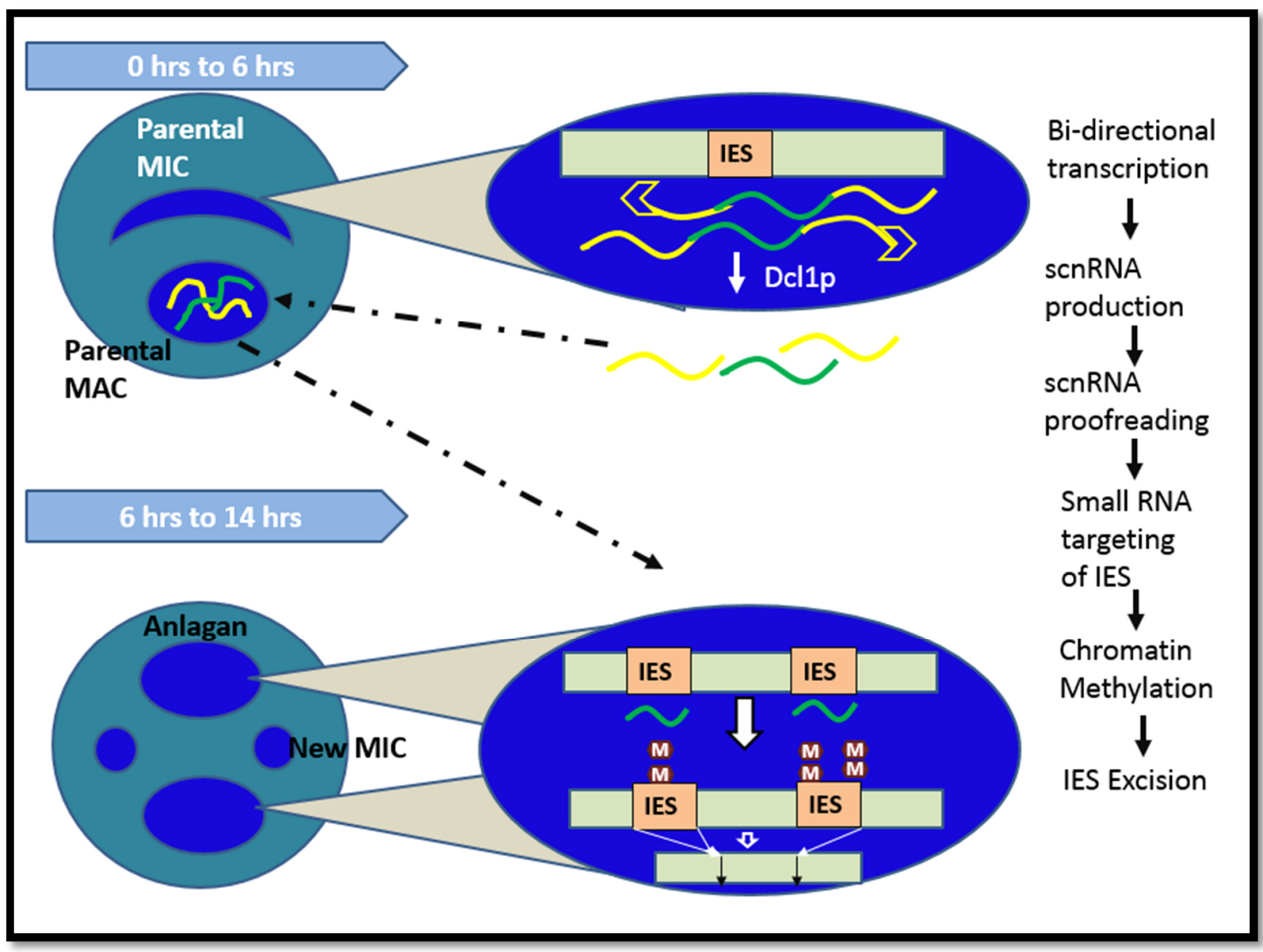

Figure 9: RNAi model of DNA rearrangement. Bi-directional transcription of germlinelimited sequences produces dsRNA that is cleaved by a Dicer-like ribonuclease (DCL1) into 28 NT small RNAs, called scan (scnRNAs). ScnRNAs recognize and target the tri-methylation of lysine 9 and 27 of histone $\mathrm{H} 3$ (H3K9me and H3K27me) on chromatin of the homologous sequence IESs in the developing somatic macronuclei, and signals their elimination.

\subsection{Rationale and objective}

HIRA, UBN, CABIN1, and ASF1 functions as the HUCA complex to deposit H3.3 onto chromatin in a DNA replication-independent manner and is conserved from yeast to humans (Rai et al., 2011). Despite this evolutionary conservation, whether the HUCA complex is present in $T$. Thermophila and its function is not known. More specifically, two potential UBN orthologs have been identified in T. thermophila, TTHERM_00113110(UBN1) and TTHERM_00335810 (UBN2) (Balaji et al., 2009). It is not known if T. thermophila encodes a bona-fide Hir3/ 
CABIN1 homologue. The goal of my research is to determine the presence of the HUCA complex and the function of both CAF-1 and HIRA complexes in T. thermophila through the generation and phenotypic analysis of somatic knockout(KO) strains for potential A] HIRA, B] UBN1, C] UBN2 and D] CAC2 orthologs.

T. thermophila is an interesting model for the study of UBN function in that there are two candidate UBN genes in this organism, similar to humans (Figure 4). From the expression profiles of the two genes through growth and development (retrieved from www.ciliate.org), it can be seen that both are expressed during conjugation but UBN1 seems to be the only one that is transcribed during growth (Figure 10). This suggests that UBN1 has growth specific functions and UBN2 has conjugation specific functions. During time periods Li-Lh corresponding to growing cells, UBN1 seems to be expressed far more than UBN2 (approximately 5000 compared to nearly 0 (Figure 10, Figure 11). This suggests that UBN2 may have a completely different and important function exclusive to conjugation and possibly nuclear development. The relationship between HIRA with the two UBN proteins in T. thermophila is yet to be characterized. It is not known if $\mathrm{H} 3.3$ of $T$. thermophila is deposited onto the DNA by a potential HUCA complex similar to humans. Also if a HIRA or HUCA complex is present, determining the function of the CAF-1 and HIRA/HUCA complex in T. thermophila, will be the focus my work. 


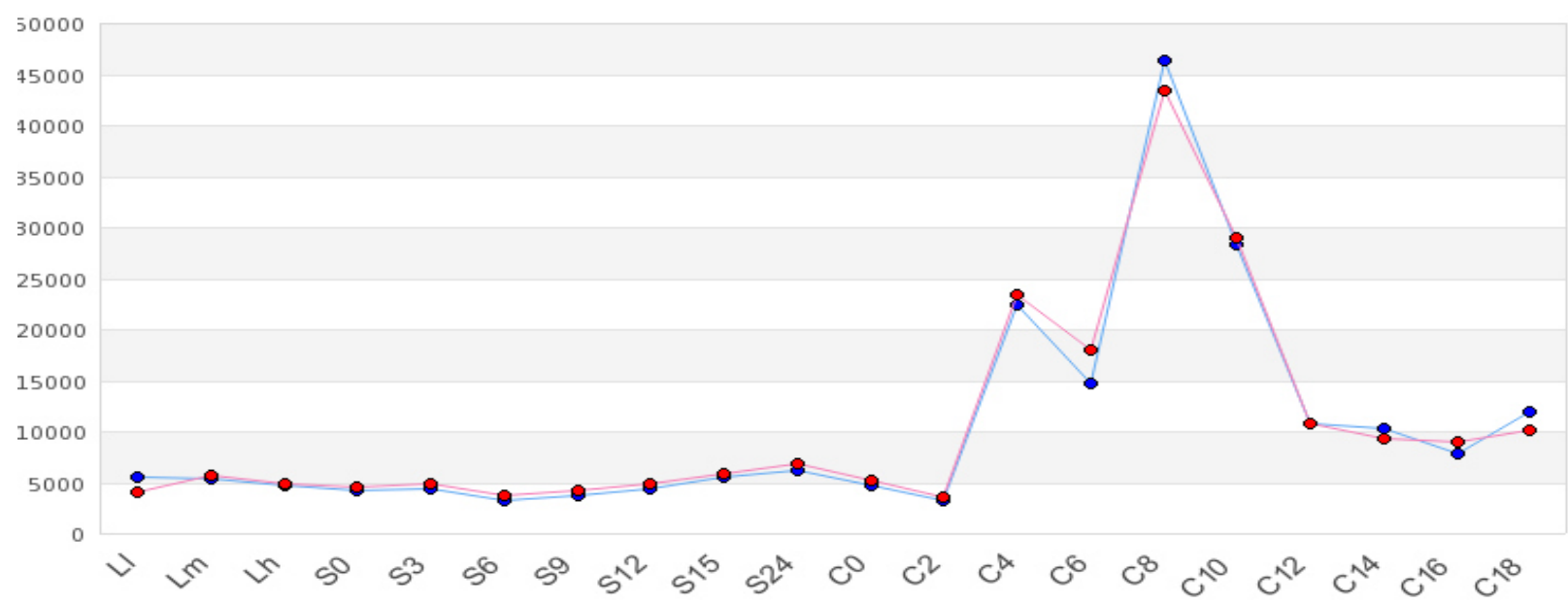

Figure 10: Expression profile for developmentally expressed TTHERM_00113110 (UBN1). For growing cells, L-1, L-m and L-h correspond respectively to $\sim 1 \mathrm{X} 105$ cells $/ \mathrm{ml}, \sim 3.5 \mathrm{X} 105 \mathrm{cell} / \mathrm{s} / \mathrm{ml}$ and $\sim 1 * 106$ cells/ml. For starvation, S-0, S-3, S-6, S-9, S-12, S-15 and S-24, 2X105cells/ml were collected at $0,3,6,9,12,15$ and 24 hours. For conjugation, equal volumes of different mating types- B2086 and CU428 cells were mixed, and samples were collected at 0, 2, 4, 6, 8, $10,12,14,16$ and 18 hours after mixing representing C-0, C-2, C-4, C-6, C-8, C-10, C-12, C-14, $\mathrm{C}-16$ and $\mathrm{C}-18$. Blue and red lines represent the expression values normalized by two different methods from www.ciliate.org. $\mathrm{L}=$ Growth stages, $\mathrm{S}=$ Starvation time points, $\mathrm{C}=$ Conjugation time points (http://tfgd.ihb.ac.cn/search/detail/gene/TTHERM_00113110). 


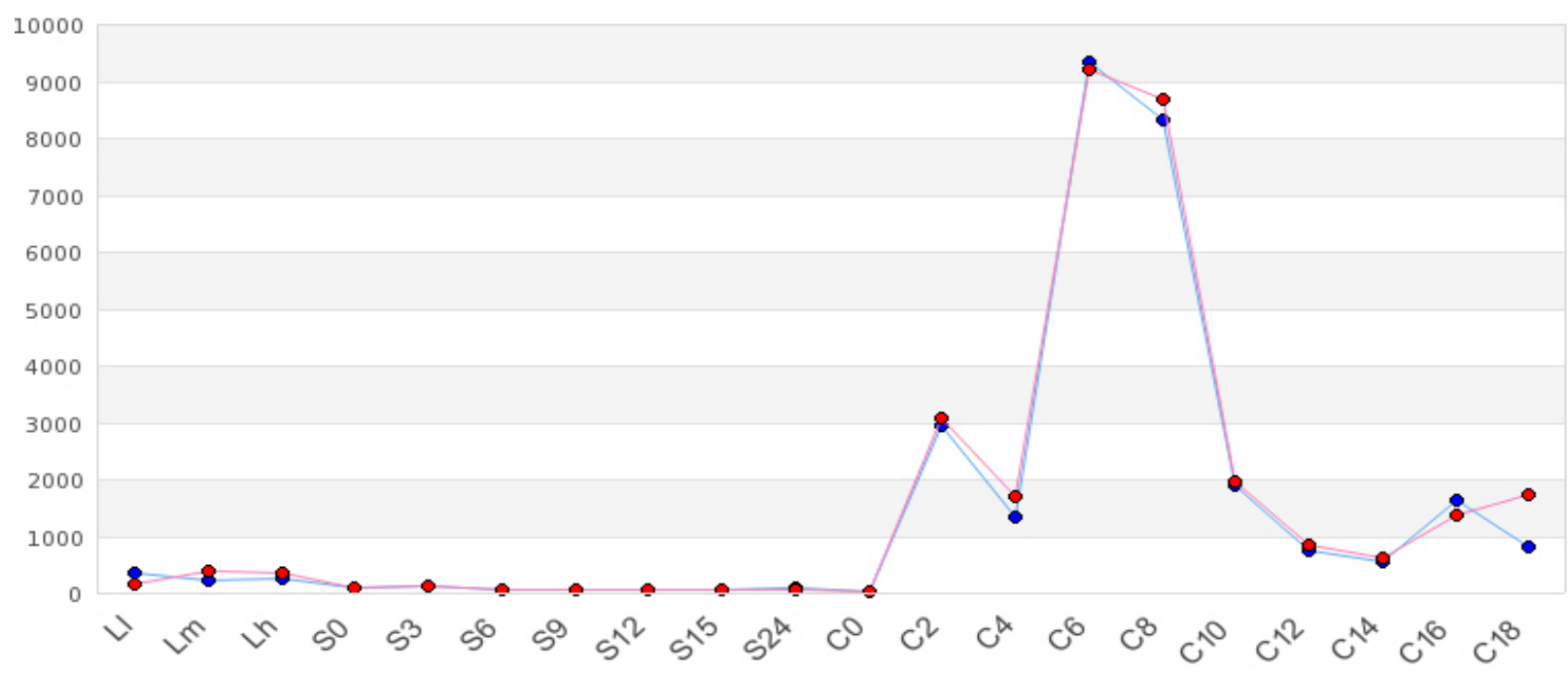

Figure 11:Expression profile for TTHERM_00335810 (UBN2)For growing cells, L-1, L-m and L-h correspond respectively to $\sim 1 \mathrm{X} 105$ cells $/ \mathrm{ml}, \sim 3.5 \mathrm{X} 105$ cells $/ \mathrm{ml}$ and $\sim 1 * 106$ cells $/ \mathrm{ml}$. For starvation, S-0, S-3, S-6, S-9, S-12, S-15 and S-24, 2 X105cells/ml were collected at 0, 3, 6, 9, 12,15 and 24 hours. For conjugation, equal volumes of two different mating types B2086 and CU428 cells were mixed, and samples were collected at 0, 2, 4, 6, 8, 10, 12, 14, 16 and 18 hours after mixing representing C-0, C-2, C-4, C-6, C-8, C-10, C-12, C-14, C-16 and C18. Blue and red lines represent the expression values normalized by two different methods from www.ciliate.org. $\mathrm{L}=$ Growth stages, $\mathrm{S}=$ Starvation time points, $\mathrm{C}=$ Conjugation time points(http://tfgd.ihb.ac.cn/search/detail/gene/TTHERM_00335810). 


\section{Chapter 2: Materials and Methods}

\subsection{Equipment}

All small-scale samples (1.5ml Eppendorf tube) centrifugations at $4{ }^{\circ} \mathrm{C}$ were carried out in a Sorvall Legend Micro 21R refrigerated micro-centrifuge while centrifugations at room temperature used Eppendorf 5424 centrifuge. Larger-scale centrifugations of $15 \mathrm{ml}$ and $50 \mathrm{ml}$ Falcon tubes at room temperature were performed with Centra CL32 (IEC). Polymerase chain reactions (PCR) were performed using a GeneAmp PCR System 9600 (PerkinElmer), GeneAmp PCR System 9700 (Applied Biosystems), or gradient PCR using Eppendorf Mastercycler Gradient.

\subsection{Sequence alignments}

Sequences for all T. thermophila proteins were obtained from the Tetrahymena Genome Database (www.ciliate.org), see Appendix 1for accession numbers. Potential homologues were identified using HomoloGene (http://www.ncbi.nlm.nih.gov/). FASTA sequences were aligned using Basic Local Alignment Search Tool (http://blast.ncbi.nlm.nih.gov/Blast.cgi) and CLUSTALW (http://www.genome.jp/tools/clustalw/). The ALU format for the sequence alignments were taken for similar sequences and shaded using BOXSHADE (http://www.ch.embnet.org/software/BOX_form.html). To help restriction map nucleotide sequences, Webcutter 2.0 was used (http://rna.lundberg.gu.se/cutter2/) and Primer3 (simgene.com/Primer3) to determine optimal primer designs. 


\subsection{Growth conditions}

E. coli transformed with pNEO4 vectors were incubated overnight at $37^{\circ} \mathrm{C}$ on nutrient rich Lysogeny Broth (LB) plates supplemented with ampicillin $(50 \mu \mathrm{g} / \mathrm{ml})$ and stored at $4^{\circ} \mathrm{C}$. For plasmid preparation, samples were inoculated in $3 \mathrm{ml}$ cultures and grown overnight. Plasmid cultures were grown overnight shaking at $250 \mathrm{rpm}$ at $37^{\circ} \mathrm{C}$ in LB supplemented with ampicillin media. Glycerol stocks were prepared for long-term storage by transferring $0.8 \mathrm{ml}$ of overnight liquid culture to $0.8 \mathrm{ml}$ of sterile $50 \%$ glycerol in a $1.8 \mathrm{ml}$ CryoPure cryovial (Sarstedt) and stored at $-80^{\circ} \mathrm{C}$.

T. thermophila were grown as $50 \mathrm{ml}$ cultures in $500 \mathrm{ml}$ flasks with gentle agitation at 80 rpm on a New Brunswick Scientific platform shaker. $100 \mu 1$ of cells from bench cultures are inoculated and grown in the vegetative state overnight in sequestrin proteose peptone (SPP) media at $30{ }^{\circ} \mathrm{C}$. For selection and acceleration of phenotypic assortment, transformed $T$. thermophila strains were grown in 96-well microtitre plates (Sarstedt) where $20 \mu 1$ of sample was passaged to $180 \mu \mathrm{l}$ of SPP supplemented with the appropriate concentration of the antibiotic paromomycin. T. Thermophila transformants were starved by centrifuging $50 \mathrm{ml}$ of culture at $3000 \mathrm{rpm}$ and removing the SPP supernatant and washing the cells in equal volumes of $10 \mathrm{mM}$

Tris- $\mathrm{HCl}, \mathrm{pH}$ 7.4. The log phase cells were centrifuged again, supernatant removed, and then resuspended in $10 \mathrm{mM}$ Tris- $\mathrm{HCl}, \mathrm{pH} 7.4$ overnight $30^{\circ} \mathrm{C}$ without shaking.

\subsection{Media, buffers, solutions}

Recipes of all media, buffers, and solutions used are listed in Appendix 2. 


\subsection{E. coli plasmid DNA mini-preparation}

The pNEO4 plasmid vector used to achieve homologous recombination is detailed in Figure 20.DH5-alpha Competent Escherichia coli (E. coli) containing the pNEO4 plasmid constructs for HIRA, CAC2, UBN1, and UBN2 were grown overnight at $37^{\circ} \mathrm{C}$ in $2 \mathrm{ml}$ of $\mathrm{LB}$ with $0.1 \mathrm{mg} / \mathrm{ml}$ ampicillin. Plasmid DNA from mini-preps was isolated using a modified alkaline lysis mini-preparation method derived from (Birnboim \& Doly, 1979). In a $1.5 \mathrm{ml}$ Eppendorf tube, $1.5 \mathrm{ml}$ of culture was centrifuged at $13,000 \mathrm{rpm}$ for 1 minute at room temperature $\left(\sim 21^{\circ} \mathrm{C}\right)$ and the supernatant was discarded. The pellet was re-suspended in $100 \mu \mathrm{l}$ of mini-prep lysis solution1. Following 5 minute incubation at room temperature, $200 \mu \mathrm{l}$ of mini-prep solution 2 was added to denature the cells. After 5 minute incubation on ice, $200 \mu$ l of mini-prep highly alkaline solution 3 was added. The sample was then centrifuged at 13,000 rpm for 10 minutes to remove cellular debris, and the supernatant was transferred to a new Eppendorf tube. A secondary spin at 13,000 rpm for 2 minutes was performed to eliminate remaining debris and the transfer of supernatant to a new tube. To precipitate DNA, $1 \mathrm{ml}$ of $95 \%$ ethanol was added and the lysate was allowed to stand at room temperature for 10minutes. DNA was first pelleted by centrifugation at 13,000 rpm for 2 minutes at room temperature, followed by aspiration of the supernatant. The DNA pellet was washed with $200 \mu \mathrm{l}$ of $70 \%$ ethanol and repeated once leaving a DNA pellet that was placed in a vacuum desiccator for 20-30 minutes to remove residual ethanol. The dried DNA pellet was solubilised in $50 \mu \mathrm{l}$ of $\mathrm{ddH}_{2} \mathrm{O}$ and treated with $1 \mathrm{ml}$ of RNase.

\subsection{Manual T. thermophila genomic DNA extraction}

Genomic DNA from T. thermophila was isolated from CU427 and CU428 wildtype (WT) and transformant strains as described by (Gaertig, Gu, Hai, \& Gorovsky, 1994). 3 ml 
cultures of T. Thermophila in SPP and penicillin-streptomycin-fungizone (PSF), a bactericidal with activity against both gram negative and positive organisms including yeast and mould was used. Based on confluence, $1 \mathrm{ml}$ of cells were centrifuged at 3,000 rpm for 2 minutes at room temperature in $1.5 \mathrm{ml}$ Eppendorf tubes, and the supernatant was discarded. The cell pellet was resuspended in $500 \mu \mathrm{l}$ Tetrahymena lysis solution (Appendix 2) and mixed until homogenous. To this homogenous solution phenol: chloroform (1:1) extraction was performed twice to remove cellular proteins and lipids. The first $300 \mu \mathrm{l}$ phenol and $300 \mu \mathrm{l}$ chloroform was added to the 600 $\mu l$ cell suspension and mixed until the solution was homogenously white and opaque. The mixture was centrifuged at 13,000 rpm for 1 minute at room temperature where the top aqueous layer $(\sim 600 \mu \mathrm{l})$ was transferred to a new Eppendorf tube and this was done twice. Then $600 \mu 1$ chloroform was added to the $600 \mu$ laqueous layer (1:1) and mixed until the mixture appears white and opaque. The sample was centrifuged at 13,000 rpm for 1 minute at room temperature and the top aqueous layer was again transferred to a new Eppendorf tube. Following this, to precipitate DNA $200 \mu \mathrm{l}$ of $5 \mathrm{M} \mathrm{NaCl}$ was added in addition to $800 \mu \mathrm{l}$ of isopropanol to the $600 \mu \mathrm{l}$ aqueous sample. This was centrifuged at 13,000 rpm for 2 minutes at room temperature and the supernatant was aspirated leaving a small DNA pellet. This DNA pellet was washed twice in 200 $\mu 1$ of $70 \%$ ethanol. The pellet was then dried in a desiccator for half an hour prior to re-

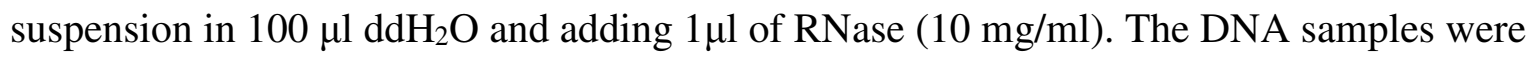
incubated for an hour at $37^{\circ} \mathrm{C}$ then overnight at $4{ }^{\circ} \mathrm{C}$ prior to storage at $-20{ }^{\circ} \mathrm{C}$.

\subsection{Polymerase chain reaction (PCR)}

PCR reagents were added to $0.2 \mathrm{ml}$ thin-walled PCR tubes to set up $20 \mu \mathrm{l}$ reactions as follows: $1 \mu \mathrm{g}$ genomic DNA, $1 \mu \mathrm{l}$ Forward Primer (30 pmol/ $\mu \mathrm{l}), 1 \mu \mathrm{l}$ Reverse Primer (30 pmol/ $\mu \mathrm{l})$, 
$7 \mu \mathrm{lddH} 20,10 \mu \mathrm{l}$ 2x PrimeSTAR Max DNA Polymerase (TaKaRa). Samples were run in the following thermal cycler program (35 cycles) after application in gradient PCR to determine optimal annealing temperature (Eppendorf Mastercycler Gradient) (Table 1).

Table 1: PCR conditions for 2x PrimeSTAR Max DNA polymerase (TaKaRa)

\begin{tabular}{|c|c|c|}
\hline Stage & Temperature & Time \\
\hline Denaturation & $98^{\circ} \mathrm{C}$ & 30 seconds \\
\hline Annealing & $50^{\circ}-60^{\circ} \mathrm{C}$ & 30 seconds \\
\hline Elongation & $72^{\circ} \mathrm{C}$ & $1 \mathrm{~min}$ \\
\hline
\end{tabular}

\subsection{DNA restriction digest/linearization}

Enzymatic restriction digests of both PCR and pNEO4 plasmids with homologous recombination for HIRA, CAC2, UBN1 and UBN2 and PCR product DNA were performed in accordance with manufacturer specifications for KpnI, XhoI, SacII, and SacI enzymatic conditions (New England BioLabs). Digestion reactions were conducted at an enzyme concentration of 4-6 units/ $\mu \mathrm{g}$ of DNA at $37^{\circ} \mathrm{C}$ where small-scale digests were set up in a total reaction volume of $10 \mu 1$ for 2 hours while large-scale digests were set up overnight in a total volume of $200 \mu 1$ to linearize DNA for biolistic applications.

\subsection{Enzymatic cleanup and gel extraction}

Enzymatic cleanups following PCR and digests were performed using an EZ-10 Spin Column PCR and Enzymatic Clean-up Products Purification Kit (Bio Basic). Cleanup of restriction enzyme digested PCR products or plasmids run on agarose gels were performed with 
an EZ-10 Spin Column DNA Gel Extraction Kit (Bio Basic). All handling of DNA was in accordance with manufacturer specifications.

\subsection{DNA electrophoresis}

Agarose gels (1\% w/v) were made with 1 X TBE, stained with ethidium bromide at a concentration of $5 \mathrm{mg} / \mathrm{ml}$ diluted 10000 times prior to solidification for visualization under UV light. Samples are electrophoresed at 100V in 1x TBE buffer. The DNA ladder used for quantification and qualitatively assessing DNA size was GeneDirex $1 \mathrm{~Kb}$ Ready-to-Use Ladder (DM010-R500-FroggaBio). DNA samples were mixed with 6x DNA loading dye $(1 \mu 1$ to $5 \mu 1$ sample). Visualization was achieved using UV light from Alpha Innotech FluorChem system in the Core Molecular Facility at York University.

\subsection{DNA ligation and transformation into competent $E$. coli}

Molecular cloning was carried out using E. coli grown in LB+AMP $(50 \mu \mathrm{g} / \mathrm{ml})$ due to the pNEO4 vectors for HIRA, CAC2, UBN1 and UBN2 containing the ampicillin resistance gene (AmpR). Ligation reactions were performed in $10 \mu$ t total volume set-ups using $1 \mu$ of T4 DNA Ligase (NEB) incubated at room temperature for 2 hours (on bench) using $50 \mathrm{ng}(0.020 \mathrm{pmol})$ vector DNA and $37.5 \mathrm{ng}(0.060 \mathrm{pmol})$ of insert DNA. To this, $25 \mu \mathrm{l}$ high-efficiency DH5-alpha competent $E$. coli cells were added and transformed following the "High Efficiency Transformation Protocol" for "C2987" (New England BioLabs). The cells were incubated on ice for 30 minutes and then heat-shocked in a $42^{\circ} \mathrm{C}$ water bath for 30 seconds. This sudden increase in temperature creates pores in the plasma membrane of the bacteria allowing ingestion of plasmid DNA. To this, $950 \mu \mathrm{l}$ room temperature Super Optimal Broth (SOC) media was added 
and shaken at $\sim 250 \mathrm{rpm}$ for 2 hours at $37{ }^{\circ} \mathrm{C}$ prior to pelleting the bacterial cells via centrifugation at 13,000 rpm for a minute. Cells were plated on LB+AMP plates using aseptic techniques overnight in the $37^{\circ} \mathrm{C}$ incubator.

\subsection{Sequencing}

Sequencing of 5' and 3' homology sequences was performed by Bio Basic International the list of sequencing primers used are in Appendix 3.

\subsection{1. $E$. coli plasmid DNA isolation for sequencing}

DNA for sequencing was isolated from $3 \mathrm{ml}$ cultures of $E$. Coli transformants for pNEO4- HIRA, CAC2, UBN1 and UBN2 grown overnight at $37^{\circ} \mathrm{C}$ using EZ-10 Spin Column Plasmid DNA Minipreps Kit (Bio Basic).

\subsection{DNA purifications}

For T. thermophila biolistic shoots, DNA was purified using an EZ-10Spin Column DNA Gel Extraction Kit (Bio Basic).

\subsection{Plasmid DNA digestion for Biolistic Bombardment}

Plasmid DNA of pNEO4-HIRA, CAC2, UBN1, and UBN2 for T. Thermophila biolistics were digested with KpnI (R0142S) and SacI (R0156S) the two restriction sites that flank the recombinantly inserted $\mathrm{KO}$ genes to release the construct from the bacterial backbone of the vector. This digest was carried out in a total volume of $400 \mu 1$ where $200 \mu 1$ was plasmid DNA and left overnight in the $37^{\circ} \mathrm{C}$ incubator. The digest was purified and precipitated by 
centrifuging at $13000 \mathrm{rpm}$ for 15 minutes at $4^{\circ} \mathrm{C}$ followed by a cold $70 \%$ ethanol wash and repeat centrifugation. The DNA is then resuspended in $20 \mu 1 \mathrm{ddH}_{2} 0$ and ready for biolistics.

\subsection{Construction of the KO cassette}

Primers were designed to amplify $\sim 1 \mathrm{~kb}$ regions immediately upstream of the start codon (3' UTR) and immediately downstream of the stop codon (5'UTR) of the HIRA, CAC2, UBN1 and UBN2 genes (Appendix 3) using T. thermophila genomic DNA as a template and built in KpnI, XhoI (upstream) and SacII, and SacI(downstream) restriction sites. These inserts were then used in two-step directional cloning into the pNEO4 vector. Plasmid insertion was verified by diagnostic restriction enzyme digests followed by subsequent sequencing using primers M13R/ HNIIF which are capable of binding to the promoter region of the cassette for sequencing across the junction into the MTT1 promoter, and the primer M13F which binds the BTU2 region of the cassette for sequencing across the cassette-sequence junction.

\subsection{Biolistic transformation of $T$. thermophila}

Biolistic transformation of $T$. thermophila was conducted by macronuclear exact gene replacement by homologous recombination. This was achieved though particle bombardment as described by Bruns and Cassidy-Hanley (Cassidy-Hanley et al., 1997) using a biolistic PDS1000/He Particle Delivery System (Bio-Rad).

\subsubsection{Preparation of $T$. thermophila cells}

Digested plasmid DNA and T. Thermophila cells were prepared two days before the planned transformation. $50 \mathrm{ml}$ of two different mating types- CU427 or CU428 WT cells in SPP 
at a concentration of $10^{5}$ cells $/ \mathrm{ml}$ were pelleted at $3000 \mathrm{rpm}$ for 3 minutes using IEC centra CL3 desktop centrifuge. The SPP was aspirated and mixed in $50 \mathrm{ml}$ of $10 \mathrm{mM}$ Tris $\mathrm{pH} 7.4$ to induce starvation. Cells were kept in the Tris buffer overnight on a shelf at $30^{\circ} \mathrm{C}$. On the day of the biolistic shoot, the cells were centrifuged again but at 1,000 rpm for 5 minutes at room temperature. All but $1 \mathrm{ml}$ of supernatant was aspirated. Accessories required for biolistic transformation include: stopping screens, 900 PSI rupture disks, microcarrier holders, microcarriers, flying discs all supplied from Bio-Rad.

\subsubsection{Preparation of gold beads}

All gold preparation steps were performed at $4^{\circ} \mathrm{C}$. To prepare $1.0 \mu \mathrm{m}$ gold beads (BioRad) to coat plasmid DNA for transformation, bath sonication was used to separate individual gold particles. Under constant vortexing conditions, constituents were added in the following order: $3 \mu \mathrm{l}$ of linearized (KpnI and SacI digested) KO cassette DNA $(1 \mu \mathrm{g} / \mu \mathrm{l}), 25 \mu \mathrm{l}$ of ice cold 2.5 $\mathrm{M}$ calcium chloride $\left(\mathrm{CaCl}_{2}\right)$, and $10 \mu \mathrm{l}$ of cold $0.1 \mathrm{M}$ spermidine (Sigma) to increase the competency with which the DNA will be delivered to the MAC of T. Thermophila cells. The gold pellets were washed twice (1. $200 \mu \mathrm{l}$ of ice-cold $70 \%$ ethanol, $2.200 \mu \mathrm{l}$ of ice-cold $100 \%$

ethanol) and pulsed down by centrifuge at 13,000 rpm for 5 seconds between each wash. The pellets were re-suspended in $20 \mu \mathrm{l}$ of cold $100 \%$ ethanol (10 $\mu \mathrm{l}$ for each mating strain/gene).

\subsubsection{Preparation of flying discs}

Flying discs were dipped in $95 \%$ ethanol and let to air dry in the laminar hood prior to insertion in the ring holder. The $10 \mu \mathrm{l}$ (per shoot) of prepared gold beads and DNA were bath sonicated, vortexed, and spotted onto the middle of the disc and left in desiccator to dry. 


\subsubsection{Assembly and operation}

All components of the gene gun were washed with $\mathrm{ddH}_{2} \mathrm{O}$ and then $70 \%$ ethanol to sterilize the system. Helium pressure was set to 1,100 PSI with the laminar hood on for sterility. The gene gun was assembled by dipping the 900psi rupture disc in isopropanol and fitted into the holder which to be screwed into place with a torque tool. The flying disc and holder were on top of a stopping screen placed in the flying disc platform. Whattman filter paper and $2 \mathrm{ml}$ of $10 \mathrm{mM}$ Tris $\mathrm{pH} 7.4$ was added to the lid of a Petri plate on top of which the $0.5 \mathrm{ml}$ of prepared $T$. Thermophila cells were spotted and placed in its corresponding slot in the apparatus. Vacuum pressure within the gun was allowed to reach 26 PSI, and the cells were bombarded with the DNA-coated gold beads. The Whattman filter paper and remaining Tris buffer was transferred to $500 \mathrm{ml}$ Erlenmeyer flasks containing $50 \mathrm{ml}$ of pre-warmed $\left(30^{\circ} \mathrm{C}\right) \mathrm{SPP}+\mathrm{PSF}$ to be incubated at $30{ }^{\circ} \mathrm{C}$ for 4 hours with shaking to return cells to vegetative growth conditions.

\subsubsection{Selection}

Cells were cultured in $50 \mathrm{ml}$ volumes and incubated at $30^{\circ} \mathrm{C}$ shaking. Cadmium chloride $\left(\mathrm{CdCl}_{2}\right)$ at concentration $1 \mu \mathrm{g} / \mu \mathrm{l}$ was added $(50 \mu \mathrm{l}) 3$ hours later to induce expression of the MTT1 5' promoter of the pNEO4 cassette. T. thermophila cells that had the pNEO4 cassette transformed exhibited resistance to antibiotics in the neomycin family. An hour after $\mathrm{CdCl}_{2}$ addition, cells were centrifuged in a $50 \mathrm{ml}$ Falcon tube at 1,000rpm for 5 minutes followed by aspiration to leave $15 \mathrm{ml}$. The cells were re-suspended in $12 \mu \mathrm{l}$ of $100 \mathrm{mg} / \mathrm{ml}$ of paromomycin, a final concentration of $80 \mu \mathrm{g} / \mathrm{ml}$. All $15 \mathrm{ml}$ were plated in 96-well microtitre plates by adding 200 $\mu \mathrm{l}$ of cells per well, and incubated at $30{ }^{\circ} \mathrm{C}$ for 72 hours without shaking. Cells that had 
successfully taken up the linearized DNA from the pNEO4 plasmid conferred resistance to this low concentration of drug and were assessed qualitatively by looking for blooming wells.

\subsection{Phenotypic assortment of transformants}

Blooming wells were isolated and subjected to increasing concentrations of paromomycin (increments of $100 \mu \mathrm{g} / \mathrm{ml}$ ) every 3 days to a maximum concentration of $1000 \mu \mathrm{g} / \mathrm{ml}$ (Figure 7).

\subsection{Single-cell cloning to produce pure cell line}

Cells were grown in $3 \mathrm{ml}$ of SPP overnight at $30^{\circ} \mathrm{C}$ shaking. The next morning $2 \mu 1$ of cells were diluted in $200 \mu 1$ droplets of SPP to enable easy picking of single cells. Individual cells were picked using a $2 \mu 1$ pipette and placed in $50 \mu 1$ of SPP and left to grow overnight at $30^{\circ} \mathrm{C}$ without shaking. $20 \mu \mathrm{l}$ were then passaged into $180 \mu \mathrm{l}$ of SPP with $120 \mu \mathrm{g} / \mathrm{ml}$ of paromomycin while another $20 \mu \mathrm{l}$ in $180 \mu \mathrm{l}$ SPP allowing for assortment into a pure KO cell line or back assortment to the original gene if the gene is essential.

\subsection{Verification of correct antibiotic cassette insertion in T. thermophila genome}

In order to determine whether the plasmid integration events mediated by homologous recombination was correctly targeted to the HIRA, CAC2, UBN1, and UBN2 gene, genomic DNA of corresponding transformants and WT CU427 and CU428 was purified and assayed by PCR. PCR primers were used that amplify the modified genome- 1. Up confirmation forward (upstream of the homologous sequence used to generate the KO insert) 2. Up confirmation reverse (in the pNEO4 plasmid (NEO-R)). If the cassette was integrated correctly, amplification 
corresponding to a size fragment greater than $1 \mathrm{~kb}$ should be seen in the $\mathrm{KO}$ transformants and no amplification in WT. A list of primers can be seen in Appendix 3.

Table 2: The PCR programs used for confirmation of correct integration for HIRA, CAC2, UBN1 and UBN2 KOs.

\begin{tabular}{|c|c|c|}
\hline Temperature & Time Duration & \multirow{2}{*}{ Number of Cycles } \\
\hline $98^{\circ} \mathrm{C}$ & $30 \mathrm{sec}$ & \multicolumn{1}{|c|}{} \\
\hline $98^{\circ} \mathrm{C}$ & $10 \mathrm{sec}$ & \multirow{2}{*}{5} \\
\hline $50^{\circ} \mathrm{C}$ & $30 \mathrm{sec}$ & \\
\hline $72^{\circ} \mathrm{C}$ & $2 \mathrm{~min}$ & \\
\hline $98^{\circ} \mathrm{C}$ & $10 \mathrm{sec}$ & \\
\hline $52^{\circ} \mathrm{C}$ & $30 \mathrm{sec}$ & 5 \\
\hline $72^{\circ} \mathrm{C}$ & $2 \mathrm{~min}$ & \\
\hline $98^{\circ} \mathrm{C}$ & $10 \mathrm{sec}$ & \\
\hline $55^{\circ} \mathrm{C}$ & $30 \mathrm{sec}$ & 1 \\
\hline $72^{\circ} \mathrm{C}$ & $2 \mathrm{~min}$ & 1 \\
\hline $72^{\circ} \mathrm{C}$ & $10 \mathrm{~min}$ & \\
\hline $4^{\circ} \mathrm{C}$ & $\infty$ & \\
\hline & & \\
\hline
\end{tabular}

\subsection{Reverse Transcription-PCR (RT-PCR) to determine complete gene replacement}

RT-PCR can be used to qualitatively assess the expression of mRNA from a gene where total RNA is isolated (mRNA, tRNA, and rRNA). If the mRNA for the gene of interest was still 
present in the MAC of transformants, it would have been converted to complimentary DNA (cDNA) and used as a template to amplify sequences between two primers designed flanking at least one intron. This allowed distinction between the desired cDNA amplification (from RNA) versus product from amplification of contaminating genomic DNA. If all copies of the gene in the MAC was not replaced, mRNA for that gene was present allowing for the conclusion of incomplete replacement and gene essentiality after accelerated phenotypic assortment. If all copies of the gene in the MAC were replaced, no mRNA would be present enabling the conclusion of complete gene replacement and gene non-essentiality. Primers can be found in Appendix3. 
Table 3: PCR program used for RT-PCR of HIRA and CAC2.

\begin{tabular}{|c|c|c|c|c|c|}
\hline \multicolumn{3}{|c|}{ CAC2 } & \multicolumn{3}{|c|}{ HIRA } \\
\hline Temperature & Duration & $\begin{array}{c}\text { Number of } \\
\text { cycles }\end{array}$ & Temperature & Duration & $\begin{array}{c}\text { Number of } \\
\text { cycles }\end{array}$ \\
\hline $50^{\circ} \mathrm{C}$ & $30 \mathrm{~min}$ & 1 & $50^{\circ} \mathrm{C}$ & $30 \mathrm{~min}$ & 1 \\
\hline $94^{\circ} \mathrm{C}$ & $2 \min$ & 1 & $94^{\circ} \mathrm{C}$ & $2 \min$ & 1 \\
\hline $94^{\circ} \mathrm{C} 30 \mathrm{sec}$. & $30 \mathrm{sec}$. & \multirow{3}{*}{5} & $94^{\circ} \mathrm{C}$ & $30 \mathrm{sec}$. & \multirow{3}{*}{5} \\
\hline $50^{\circ} \mathrm{C}$ & $30 \mathrm{sec}$. & & $60^{\circ} \mathrm{C}$ & $30 \mathrm{sec}$. & \\
\hline $72^{\circ} \mathrm{C}$ & $1 \mathrm{~min}$ & & $72^{\circ} \mathrm{C}$ & $1 \mathrm{~min}$ & \\
\hline $94^{\circ} \mathrm{C}$ & $30 \mathrm{sec}$. & \multirow{3}{*}{5} & $94^{\circ} \mathrm{C}$ & $30 \mathrm{sec}$. & \multirow{3}{*}{5} \\
\hline $52^{\circ} \mathrm{C}$ & $30 \mathrm{sec}$. & & $62^{\circ} \mathrm{C}$ & $30 \mathrm{sec}$. & \\
\hline $72^{\circ} \mathrm{C}$ & $1 \mathrm{~min}$ & & $72^{\circ} \mathrm{C}$ & $1 \mathrm{~min}$ & \\
\hline $94^{\circ} \mathrm{C}$ & $30 \mathrm{sec}$. & \multirow{3}{*}{25} & $94^{\circ} \mathrm{C}$ & $30 \mathrm{sec}$ & \multirow{3}{*}{25} \\
\hline $55^{\circ} \mathrm{C}$ & $30 \mathrm{sec}$. & & $65^{\circ} \mathrm{C}$ & $30 \mathrm{sec}$. & \\
\hline $72^{\circ} \mathrm{C}$ & $1 \mathrm{~min}$ & & $72^{\circ} \mathrm{C}$ & $1 \mathrm{~min}$ & \\
\hline $72^{\circ} \mathrm{C}$ & $10 \mathrm{~min}$ & 1 & $72^{\circ} \mathrm{C}$ & $10 \mathrm{~min}$ & 1 \\
\hline $4^{\circ} \mathrm{C}$ & \multicolumn{2}{|c|}{$\infty$} & $4^{\circ} \mathrm{C}$ & \multicolumn{2}{|c|}{$\infty$} \\
\hline
\end{tabular}


Table 4: PCR program used for RT-PCR of UBN1 and UBN2.

\begin{tabular}{|c|c|c|c|c|c|}
\hline \multicolumn{3}{|c|}{ UBN1 } & \multicolumn{3}{|c|}{ UBN2 } \\
\hline Temperature & Duration & $\begin{array}{c}\text { Number of } \\
\text { cycles }\end{array}$ & Temperature & Duration & $\begin{array}{c}\text { Number of } \\
\text { cycles }\end{array}$ \\
\hline $50^{\circ} \mathrm{C}$ & $30 \mathrm{~min}$ & 1 & $50^{\circ} \mathrm{C}$ & $30 \mathrm{~min}$ & 1 \\
\hline $94^{\circ} \mathrm{C}$ & $2 \min$ & 1 & $94^{\circ} \mathrm{C}$ & $2 \min$ & 1 \\
\hline $94^{\circ} \mathrm{C}$ & $30 \mathrm{sec}$. & \multirow{3}{*}{5} & $94^{\circ} \mathrm{C}$ & $30 \mathrm{sec}$. & \multirow{3}{*}{5} \\
\hline $55^{\circ} \mathrm{C}$ & $30 \mathrm{sec}$. & & $45^{\circ} \mathrm{C}$ & $30 \mathrm{sec}$. & \\
\hline $72^{\circ} \mathrm{C}$ & $1 \mathrm{~min}$ & & $72^{\circ} \mathrm{C}$ & $1 \mathrm{~min}$ & \\
\hline $94^{\circ} \mathrm{C}$ & $30 \mathrm{sec}$. & \multirow{3}{*}{5} & $94^{\circ} \mathrm{C}$ & $30 \mathrm{sec}$. & \multirow{3}{*}{5} \\
\hline $57^{\circ} \mathrm{C}$ & $30 \mathrm{sec}$. & & $46^{\circ} \mathrm{C}$ & $30 \mathrm{sec}$. & \\
\hline $72^{\circ} \mathrm{C}$ & $1 \mathrm{~min}$ & & $72^{\circ} \mathrm{C}$ & $1 \mathrm{~min}$ & \\
\hline $94^{\circ} \mathrm{C}$ & $30 \mathrm{sec}$. & \multirow{3}{*}{25} & $94^{\circ} \mathrm{C}$ & $30 \mathrm{sec}$ & \multirow{3}{*}{25} \\
\hline $59^{\circ} \mathrm{C}$ & $30 \mathrm{sec}$. & & $47^{\circ} \mathrm{C}$ & $30 \mathrm{sec}$. & \\
\hline $72^{\circ} \mathrm{C}$ & $1 \mathrm{~min}$ & & $72^{\circ} \mathrm{C}$ & $1 \mathrm{~min}$ & \\
\hline $72^{\circ} \mathrm{C}$ & $10 \mathrm{~min}$ & 1 & $72^{\circ} \mathrm{C}$ & $10 \mathrm{~min}$ & 1 \\
\hline $4^{\circ} \mathrm{C}$ & \multicolumn{2}{|c|}{$\infty$} & $4^{\circ} \mathrm{C}$ & \multicolumn{2}{|c|}{$\infty$} \\
\hline
\end{tabular}

\subsection{Viability assay to determine if mating pairs complete or abort conjugation}

After 8 hours post-mixing of two mating types, individual pairs of each KO and WT strains (WT427 (CU427)/WT428(CU428)) were picked and placed in $10050 \mu 1$ droplets of SPP and incubated at $30^{\circ} \mathrm{C}$ for 2 hours. 2 hours later, each droplet was examined to exclude pairs that 
were killed or separated during the picking process. 48 hours later, droplets containing $\geq 50$ pairs were analyzed to determine whether mating pairs completed or aborted conjugation. To determine completion of conjugation, $25 \mu 1$ of each droplet was transferred to $180 \mu \mathrm{LPP}$ with $120 \mu \mathrm{g} / \mathrm{ml}$ of paromomycin and $1 \mu \mathrm{g} / \mathrm{ml} \mathrm{CdCl}_{2}$ while another $25 \mu 1$ to $180 \mu \mathrm{l}$ of SPP with $15 \mu \mathrm{g} / \mathrm{ml}$ of 6-methylpurine (6-mp). The $\mathrm{KO}$ and WT mating pairs were scored for sensitivity in paromomycin and 6-mp (Figure 12 and Figure 13). Completion of conjugation would result in progeny that are 6-mp resistant and paromomycin sensitive. WT427 and WT428 mating types are homozygous recessive for the 6-mp resistant gene in the MAC and therefore sensitive to 6$\mathrm{mp}\left(6-\mathrm{mp}^{+}\right)$. However, WT428 is homozygous for the 6-mp resistant gene (6-mp ${ }^{\mathrm{R}}$ ) while WT427 is homozygous for the 6-mp ${ }^{+}$allele in the MIC. Thus completion of conjugation would result in the fusion of the MIC of both mating types producing a zygote that subsequently divides mitotically twice. The four new nuclei products develop into the new MAC and MIC of the progeny where the MAC would be heterozygous for 6-mp resistance. Also during conjugation, there is the resorption of the old MAC. Therefore, the completion of conjugation should result in progeny that no longer confer resistance to paromomycin in KOs (Figure 13). 
WT427(Cu427)

Mpr+

$\mathrm{Mpr}+$

$\left(p m^{s}, m p^{s}, V I\right)$
WT428(Cu428)

$\underline{\mathrm{Mpr}}$

$\left(p m^{s}, m p^{s}, V I I\right)$

wt

exconjugants

\section{Legend: MIC genotype in above MAC phenotype in bracket}

Figure 12: Genetics of WT 427 and WT428 MIC and MAC. MIC genotypes represented as fractions. MAC phenotypes in brackets. 


\section{KO(Cu427)}

Mpr+

Mpr+

\section{$\left(p m^{s}, m p^{s}, V I\right)$}

\section{$\mathrm{KO}(\mathrm{Cu} 428)$}

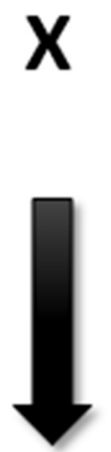

$\underline{M p r}$ $\mathrm{Mpr}$

$\left(p m^{s}, m p^{s}, V I I\right)$
$\mathrm{KO}$

exconjugants

\section{Legend: MIC genotype in above MAC phenotype in bracket}

Figure 13: Genetics of KO transformant 427 and 428 strains MIC and MAC. MIC genotypes represented as fractions. MAC phenotypes in brackets.

\subsection{DAPI staining and microscopy}

For staining the cells with DAPI, $20 \mu \mathrm{l}$ of cells were grown overnight in $3 \mathrm{ml}$ of SPP at $30{ }^{\circ} \mathrm{C}$ shaking overnight. $1.5 \mathrm{ml}$ of culture was transferred to a $1.5 \mathrm{ml}$ Eppendorf tube and spun at $3000 \mathrm{rpm}$ for 1 minute. The supernatant was extracted followed by a wash in $200 \mu \mathrm{l}$ of acetone. A repeat spin at $3000 \mathrm{rpm}$ for 1 minute was done to rid remaining acetone and cells were resuspended in $60 \mu 1$ of water. $20 \mu 1$ of cell were spotted on a glass microscope slide and air-dried. 
The slides were then spotted with $25 \mu 1$ of DAPI mixture and left to air dry prior to viewing. Cells were examined on a Leica DM6000B fluorescent microscope at 10x, 20x, and 40x magnification in vegetative, starved, and conjugating states using DAPI filter.

\section{Chapter 3: Results}

\subsection{Conservation of HUCA complex from yeast to human}

HIRA, UBN, CABIN1, and ASF1 collectively function as the HUCA complex. The HUCA complex is conserved from yeast to humans to deposit H3.3 (humans) and H3 (yeast) onto chromatin in a DNA replication-independent manner (Rai et al., 2011). Despite this evolutionary conservation, presence of the HUCA complex in T. Thermophila and its function is not known. The two potential UBN orthologs identified in T. thermophila acted as the basis for my research (Balaji et al., 2009) (Figure 4). Potential orthologs of HIRA and CAC2 in $T$. thermophila were obtained by performing comparative sequence alignments as outlined in materials and methods using the yeast S.cerevisiae sequences for HIR1 and CAC2 as my starting query sequence. By comparing S.cerevisiae HIR and CAC2 to T. thermophila, H. Sapiens, and M. musculus, I was able to determine the sequence identity scores for these genes in the analyzed species (Table 5). Due to regions beyond the conserved HUN domain of UBN orthologs exhibiting extensive sequence divergence, I utilized the HUN domain of human UBN1 as a query sequence to identify the identity score of $T$. Thermophila UBN1 and UBN2 alongside S.cerevisiae and M. musculus (Table 6). 
Table 5: Sequence identity scores for HIRA, CAC2. Utilizing S.cerevisiae as query sequence: FASTA amino acid residue sequences were obtained from NCBI protein database and comparative sequence analyses were performed using BLASTP from NCBI.

\begin{tabular}{|c|c|c|}
\hline \multirow{2}{*}{ Species } & \multicolumn{2}{|c|}{ Identity Score (\%) } \\
\cline { 2 - 3 } & HIRA & CAC2 \\
\hline S.cerevisiae & 100 & 100 \\
\hline T. thermophila & 93 & 71 \\
\hline H. sapiens & 94 & 76 \\
\hline M. musculus & 94 & 70 \\
\hline
\end{tabular}

Table 6: Sequence identity score of the HUN domain using the HUN domain sequence of $H$. sapiens as query across $T$. thermophila, S.cerevisiae, and M. musculus UBN orthologs. .FASTA amino acid residue sequences were obtained from NCBI protein database and comparative sequence analyses were performed using BLASTP from NCBI.

\begin{tabular}{|c|c|c|c|c|c|c|c|}
\hline \multirow{4}{*}{ Species } & \multicolumn{7}{|c|}{ Identity Score of HUN domain (\%) } \\
\hline & \multicolumn{2}{|c|}{ H. sapiens } & \multicolumn{2}{|c|}{ M. musculus } & \multicolumn{2}{|c|}{ T. thermophila } & \multirow{2}{*}{\begin{tabular}{|c|} 
S.cerevisiae \\
HPC2
\end{tabular}} \\
\hline & UBN1 & UBN2 & UBN1 & UBN2 & $\begin{array}{c}3110 \\
\text { (UBN1) }\end{array}$ & $\begin{array}{c}\mathbf{5 8 1 0} \\
\text { (UBN2) }\end{array}$ & \\
\hline & 100 & 100 & 100 & 100 & 78 & 83 & 100 \\
\hline
\end{tabular}

Sequence alignments were obtained for HIRA, CAC2, and the HUN domain of UBN1 and UBN2 in S.cerevisiae, H. sapiens, M. musculus and T. Thermophila orthologs using CLUSTALW (http://www.genome.jp/tools/clustalw/). The aligned amino acid residues were shaded using BOXSHADE (http://www.ch.embnet.org/software/BOX_form.html). Both BLAST and BOXSHADE indicated that HIRA and CAC2 of T. thermophila contained a conserved WD40 repeat ( $\beta$-propeller) at the $\mathrm{N}$-terminus required for mediating the interaction with ASF1 as 
in yeast and humans (Figure 14 and Figure 15) (Galvani et al., 2008; Balaji et al., 2009). UBN1 and UBN2 of T. Thermophila exhibited the conserved HUN domain in the C-terminus as seen in yeast as opposed to the N-terminus as seen in humans (Figure 16). The HUN domain facilitates the interaction with the N-terminus WD repeats of HIR/ HIRA in yeast and humans to collectively deposit H3.3-H4 onto DNA as the HUCA complex. Also, UBN/HPC2 HUN domain has been identified as the histone tail binding region of the HUCA complex (Balaji et al., 2009). 


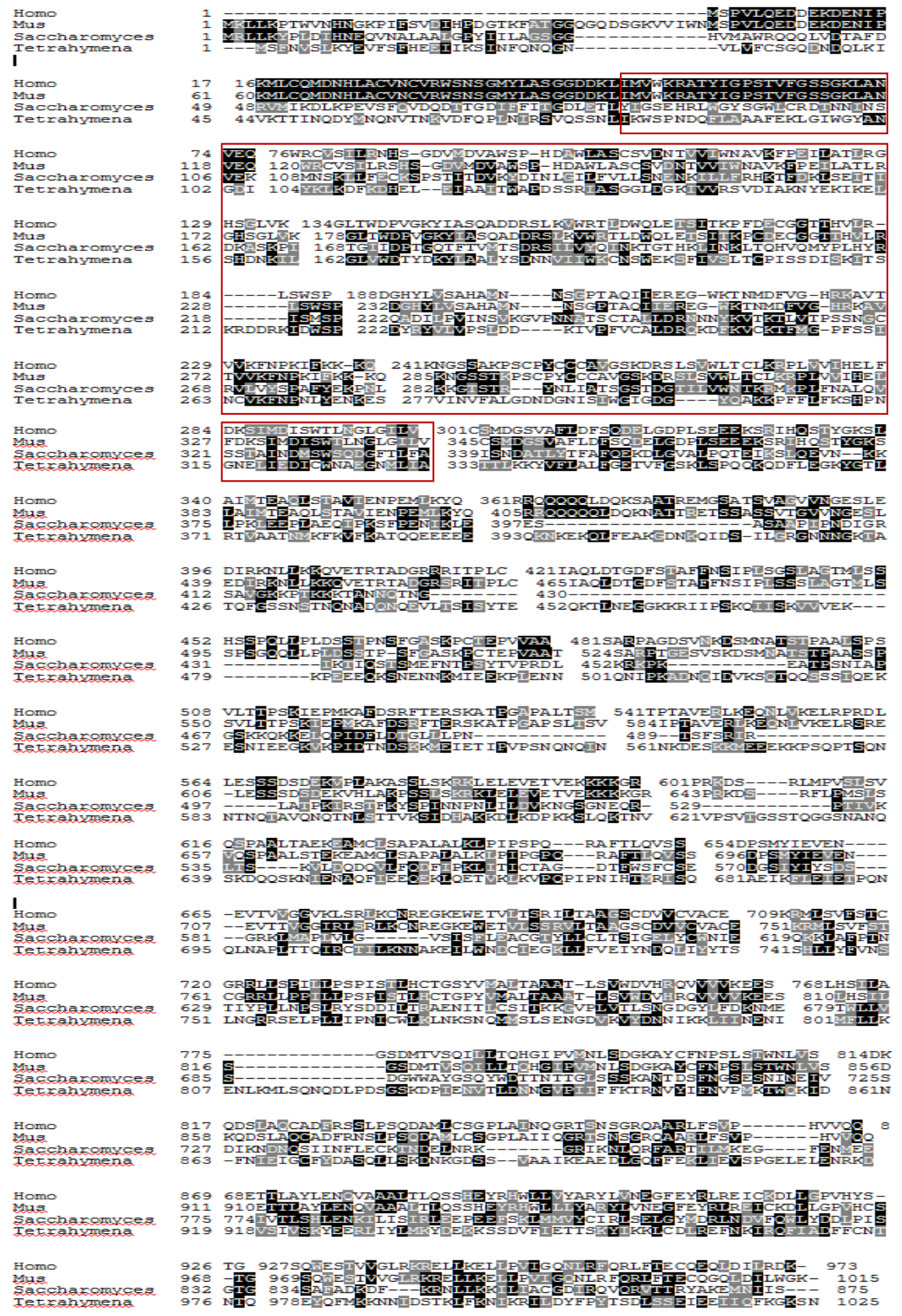

Figure 14: Boxshade results of HIRA. Using S.cerevisiae as query sequence against $H$. sapiens, T. thermophila, and M. musculus to outline degree of similarity. Black: identical amino 
acid residues, Grey: Similar amino acids. Red box outlines the conserved WD40 repeats ( $\beta$ propeller)

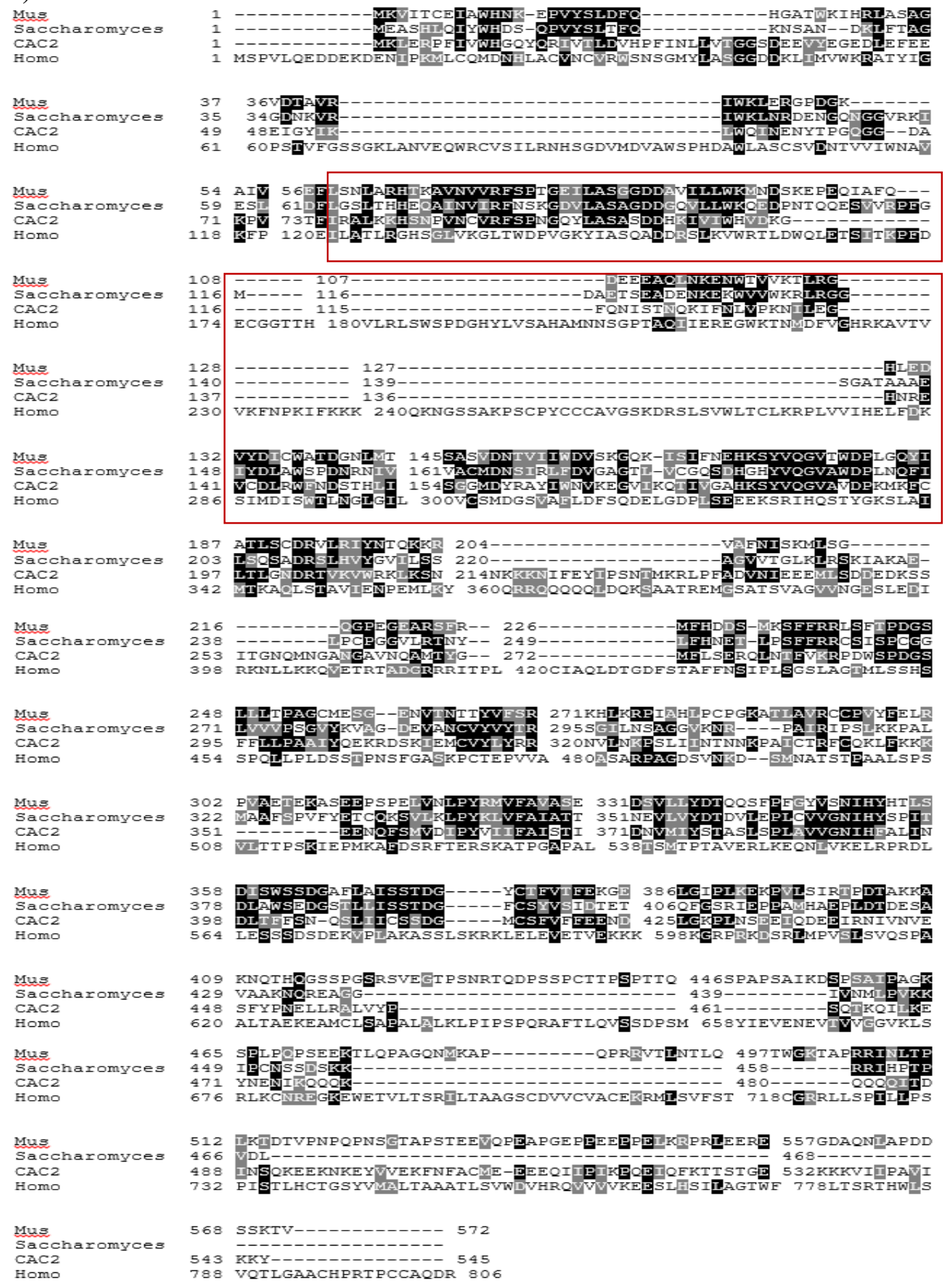

Figure 15: Boxshade results of CAC2. Using S.cerevisiae as query sequence against $H$. sapiens, T. thermophila, and M. musculus to outline degree of similarity. Black: identical amino 
acid residues, Grey: Similar amino acids. Red box outlines the conserved WD40 repeats ( $\beta$ propeller).

JDBN1_[Homo
UBN1_[Mus
UBN2_[Homo
UBN2_[Mus
HPC2
TTHERM_00335810
TTHERM 00113110
consensus

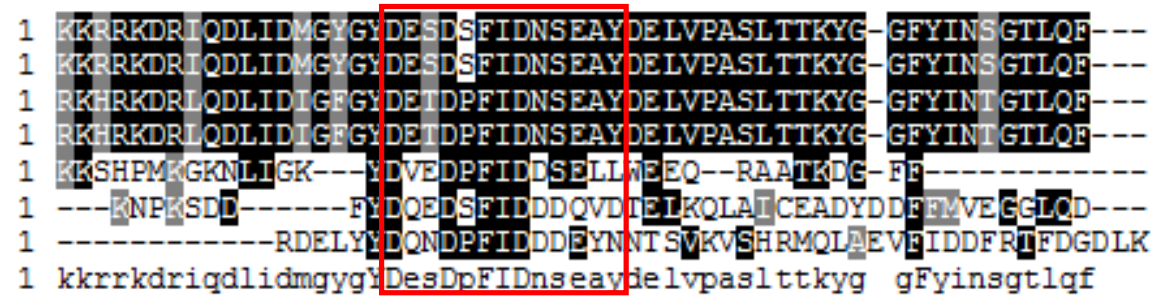

Figure 16: Boxshade results of the HUN domain of UBN orthologs using H. sapiens as query sequence against $T$. thermophila, S.cerevisiae and M. musculus to outline degree of similarity. Black: identical amino acid residues, Grey: Similar amino acids. The red box outlines the conserved acidic residues of the HUN domain following the periodic signature in the form DX2DX3DX2EX2-3[ED] (where X is any amino acid). TTHERM_00113110 appears to have a more conserved periodic signature.

\subsection{Preparation of template DNA for amplification of $T$. thermophila HIRA, CAC2, UBN1 and UBN2}

To amplify homologous regions flanking 1 kb up and down of HIRA, CAC2, UBN1 and UBN2 genes in $T$. thermophila, I prepared genomic DNA from $T$. thermophila to serve as the template (see materials and methods). $1 \mu \mathrm{g}$ of $T$. Thermophila total genomic DNA (standard amount used for all PCR reactions) run out on a 1.0\% agarose gel (Figure 17). 


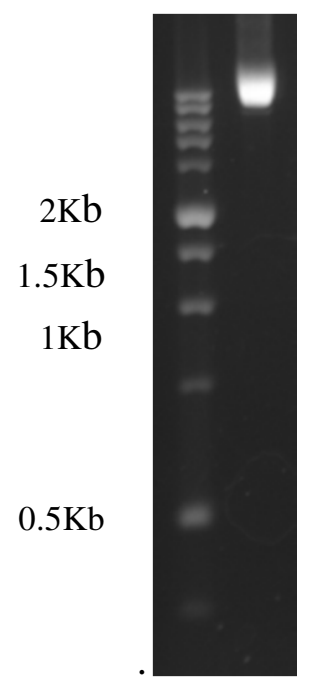

Figure 17: Purified T. thermophila genomic DNA.1 $\mu \mathrm{g}$ of genomic DNA was loaded on a $1.0 \%$ agarose gel made in $1 \mathrm{x}$ TBE buffer with ethidium bromide added for visualization using Alpha Innotech Flour Chem system. 1Kb DNA ladder was obtained by FroggaBio (Appendix4).

\subsection{Amplification and molecular cloning of $\sim 1 \mathrm{~Kb}$ homologous sequences flanking up and down regions of $T$. thermophila HIRA, CAC2, UBN1, and UBN2}

My goal was to KO through exact gene replacement all MAC copies of HIRA, CAC2,

UBN1 and UBN2 and determine whether the genes were essential for survival in Tetrahymena.

In order to generate a MAC KO, two-step directional cloning of 5' and 3' homology sequences of

HIRA, CAC2, UBN1 and UBN2 were amplified to be ligated into the pNEO4 plasmid. I

designed two primer sets to amplify approximately $1 \mathrm{~Kb}$ upstream (UP) and downstream

(DOWN) of the start and stop codon for each of the four target genes. Each of these primer sets

had built in restriction enzyme digest sites corresponding to restriction sites also found within the plasmid polylinker. KpnI and XhoI were chosen for the 5' primer set (UP-F/UP-R) and SacII and SacI for the 3' primer set (DOWN-F/DOWN-R) as seen in the schematic for Figure 18. The 
amplified homologous sequences for the 5' and 3' regions of each of the four genes are shown in Figure 19.

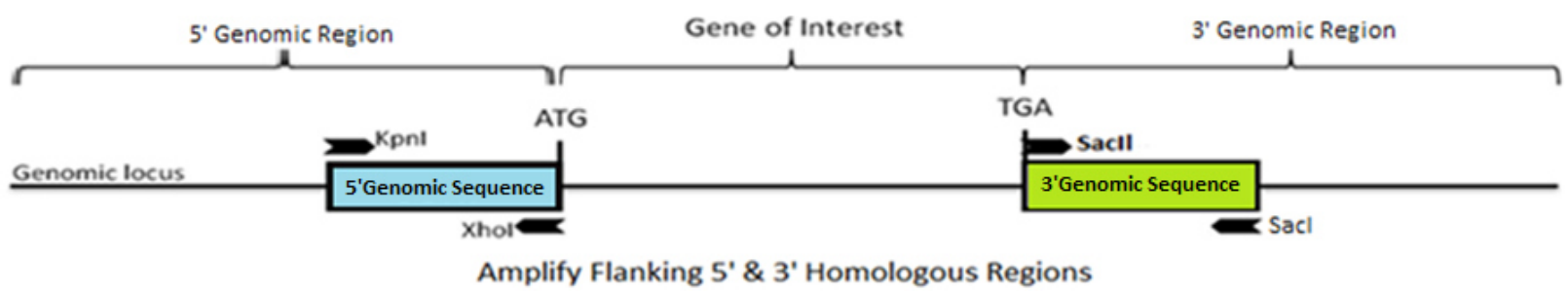

Figure 18: KO strategy outlining amplification of 5' and 3'homologous genomic DNA ( $1 \mathrm{~kb})$ with restriction sites KpnI and XhoI UPSTREAM and SacII and SacI DOWNSTREAM of the start and stop codon respectively.
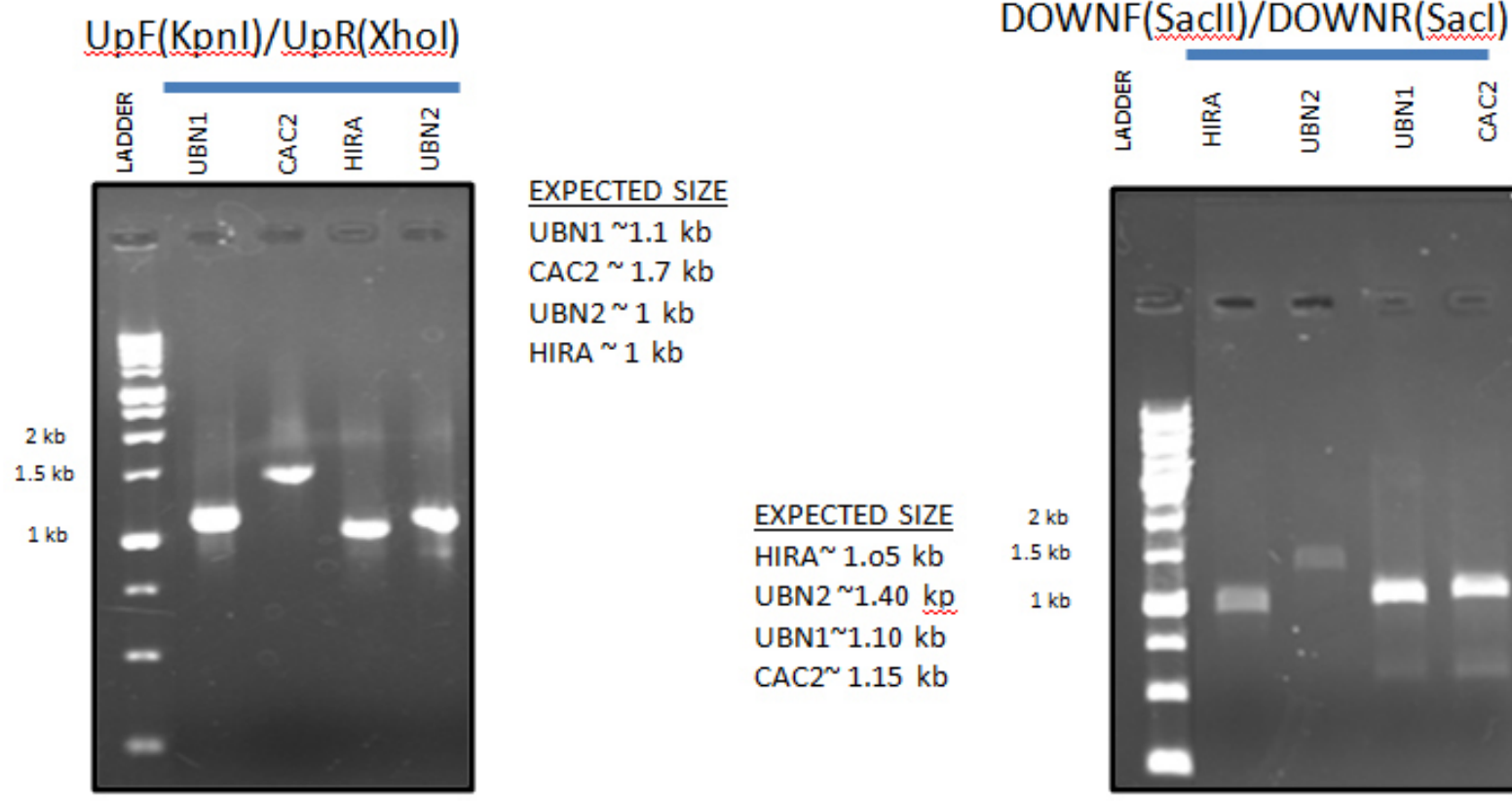

HIRA $1.05 \mathrm{~kb}$ UBN2 $1.40 \mathrm{kp}$ UBN1 $1.10 \mathrm{~kb}$ $\mathrm{CAC2}^{\sim} 1.15 \mathrm{~kb}$

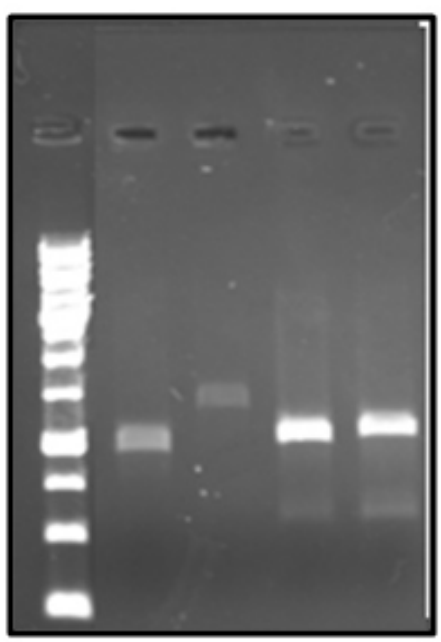

Figure 19: Agarose gel analysis of PCR-amplified T. Thermophila UP and DOWN sequences for HIRA, CAC2, UBN1 and UBN2. 


\subsection{Engineering of HIRA, CAC2, UBN1 and UBN2 KO cassettes}

Designing KO cassettes for HIRA, CAC2, UBN1, and UBN2 consisted of flanking a bacterial transposon (Tn5) derived neomycin resistance gene (neo) with the PCR amplified $\sim 1 \mathrm{~kb}$ UP and DOWN sequences for each of the four genes. Neo encodes for aminoglycosidase $3^{\prime}$ phosphotransferase II which when expressed results in the phosphorylation and inactivation of antibiotics in the neomycin family, including paromomycin (Beck, Ludwig, Auerswald, Reiss, \& Schaller, 1982). Due to the significant difference between the bacterial genome from which the neo gene is derived and the T. Thermophila genome, the pNEO4 plasmid used (Figure 20) was $T$. Thermophila codon optimized (neoTet) (Mochizuki, 2008). Expression of the neoTet gene in the pNEO4 plasmid is directed by 5' cadmium inducible metallothionein-1 (MTT1) promoter. The MTT1 promoter has been demonstrated to improve the efficiency of DNA-mediated biolistic transformation in $T$. Thermophila in addition to permitting controlled expression by varying the amount of cadmium in growth medium. On the 3' end of the neoTet gene is the T. thermophila beta-tubulin gene (BTU2) which contains the transcription termination sequence and poly A addition signal. BTU2 increases the stability of the transcribed molecule (Mochizuki, 2008). The insertion of the $\mathrm{KO}$ cassette disrupts the expression of the endogenous HIRA, CAC2, UBN1 and UBN2 genes. 


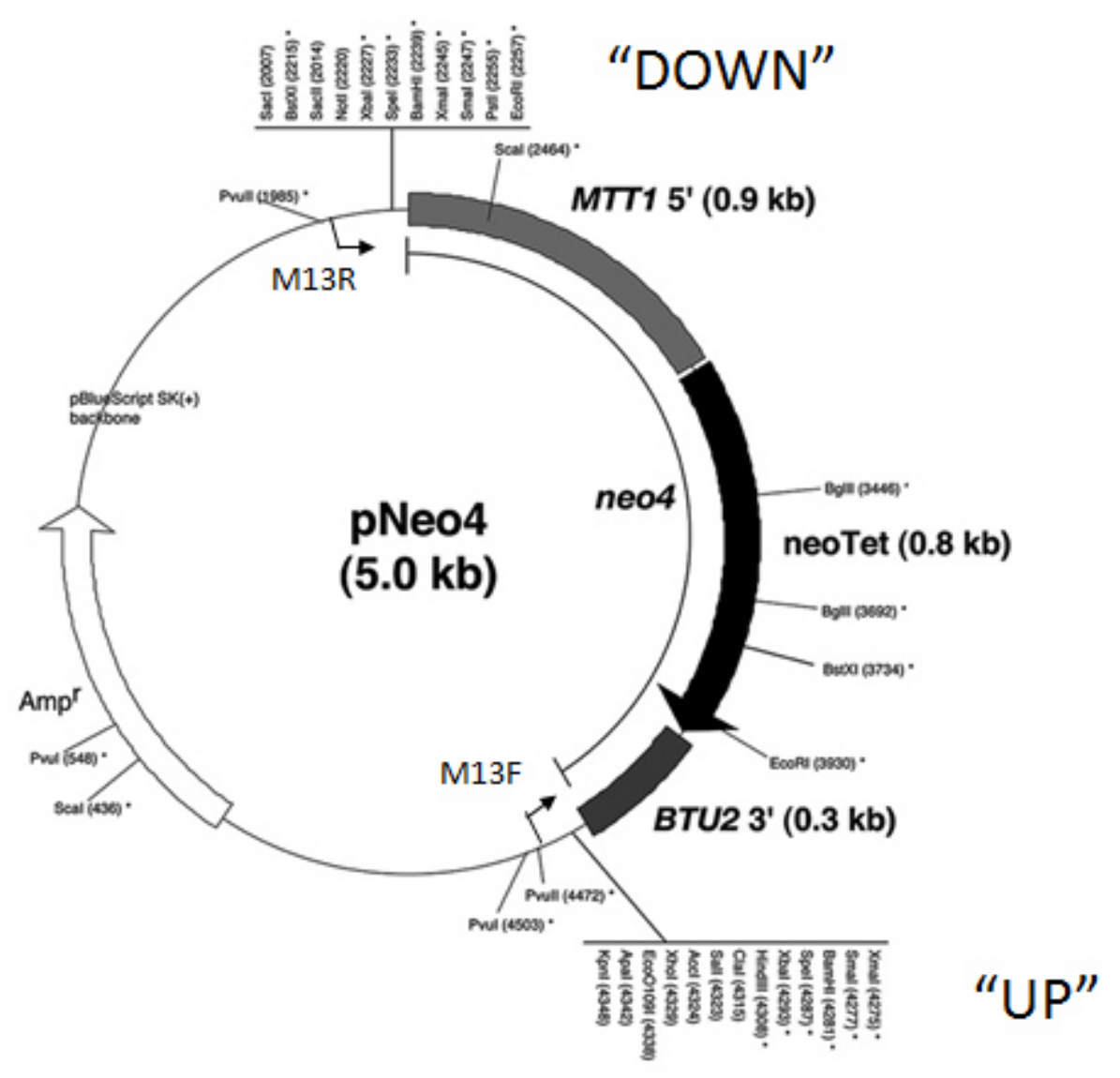

Figure 20: Tetrahymena codon optimized pNEO4 plasmid conferring ampicillin resistance for bacterial cloning and paromomycin for T. thermophila cloning designed by (Mochizuki, 2008). Locations of Primers used for sequencing are labelled M13F and M13R. 


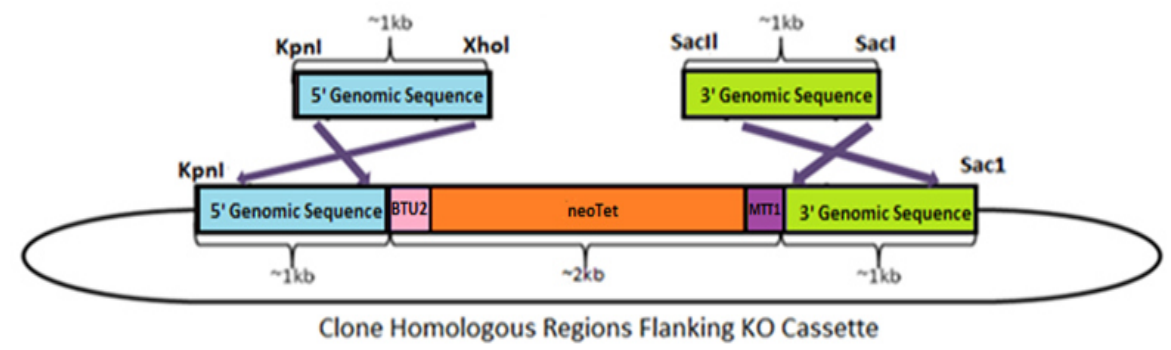

Figure 21: Ligation of 5' and 3' homologous sequences of HIRA, CAC2, UBN1 and UBN2 with pNEO4 plasmid post-digestion of both genomic DNA and pNEO4 plasmid with KpnI and XhoI (5') and SacII and SacI (3').

Amplified UP and DOWN PCR products and pNEO4 plasmid were purified and digested with KpnI, and XhoI (UP), or SacII, and SacI (DOWN). The UP homologous sequences were first ligated with the pNEO4 plasmid and transformed into DH5 alpha E.coli. Successful transformants were isolated based on small scale diagnostics (See Materials and Methods) and sequencing (Figure 22). DNA from successful transformants were digested with SacII and SacI and ligated with the DOWN sequences for HIRA, CAC2, UBN1 and UBN2. The complete plasmids were transformed into E. coli again (Figure 21) prior to re-purification. DNA was extracted from transfomants for small scale diagnostics to determine successful insertion of the DOWN sequences for each gene into the pNEO4 plasmid (Figure 23). Bacterial clones that contained inserts of expected size were subsequently sequenced using M13R or HNIII for 5' homologous sequences and M13F for 3' homologous sequences (Appendix3) at (BioBasicInternational) to ensure $100 \%$ match to the MAC sequence of each gene obtained from ciliate.org. 


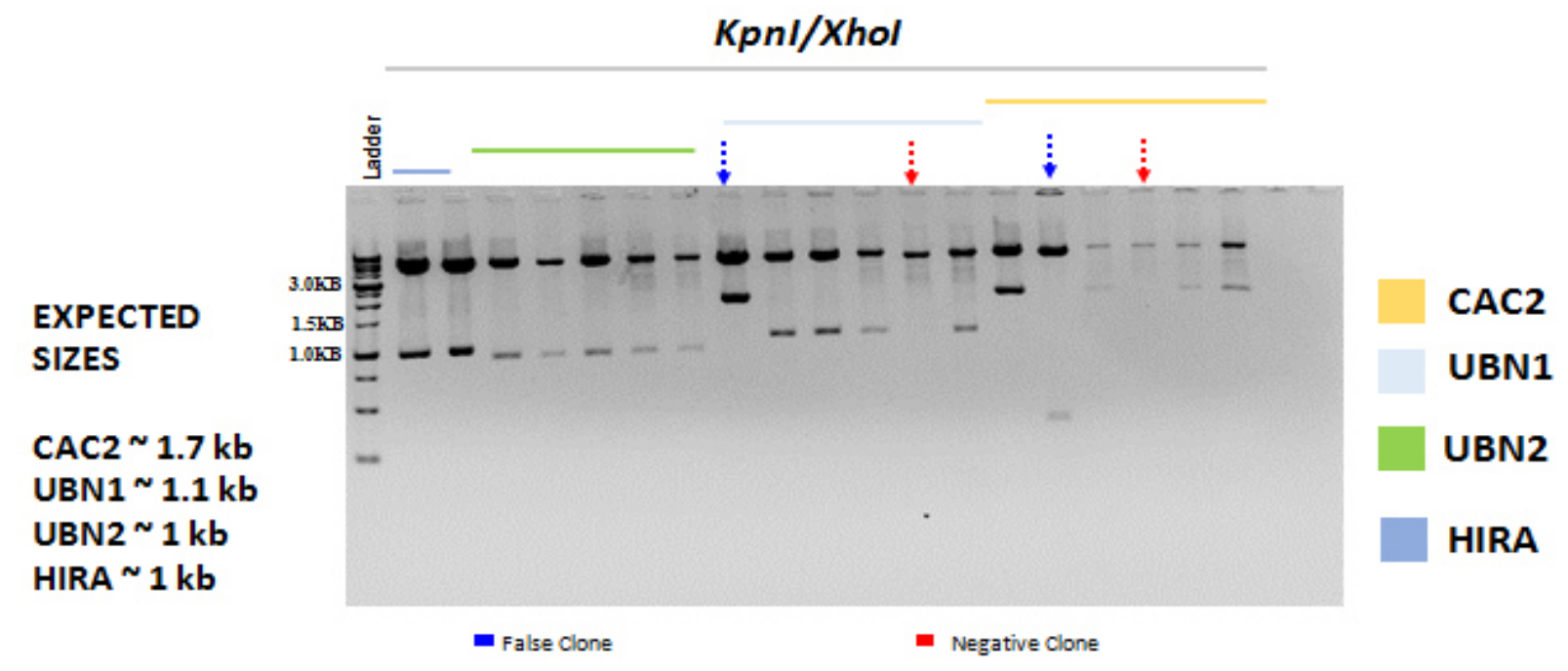

Figure 22: Agarose gel electrophoresis of post-transformation diagnostic restriction enzyme digests of plasmids extracted from bacterial DH5 alpha clones with KpnI and XhoI to release the 5' T. Thermophila UP genomic sequence cloned in for HIRA, CAC2, UBN1, and UBN2.

Samples that released inserts of the expected size were sequenced before proceeding to the next cloning step. 


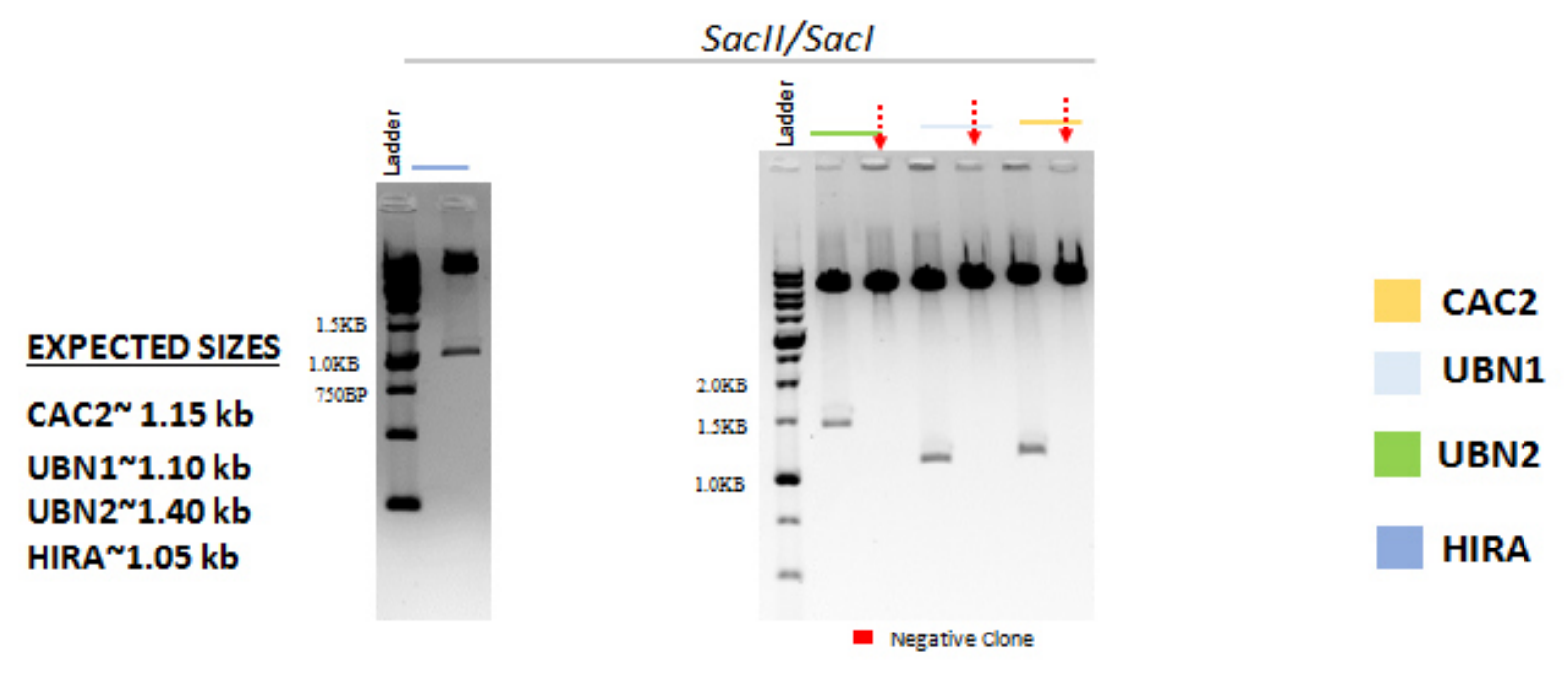

Figure 23: Agarose gel electrophoresis of post-transformation restriction enzyme digests of plasmids extracted from bacterial DH5alpha clones with SacII and SacI to release the 3' DOWN T. Thermophila cloned into pNEO4 for HIRA, CAC2, UBN1, and UBN2. Samples that released inserts of the expected size sequenced before being used in T. Thermophila transformations. 


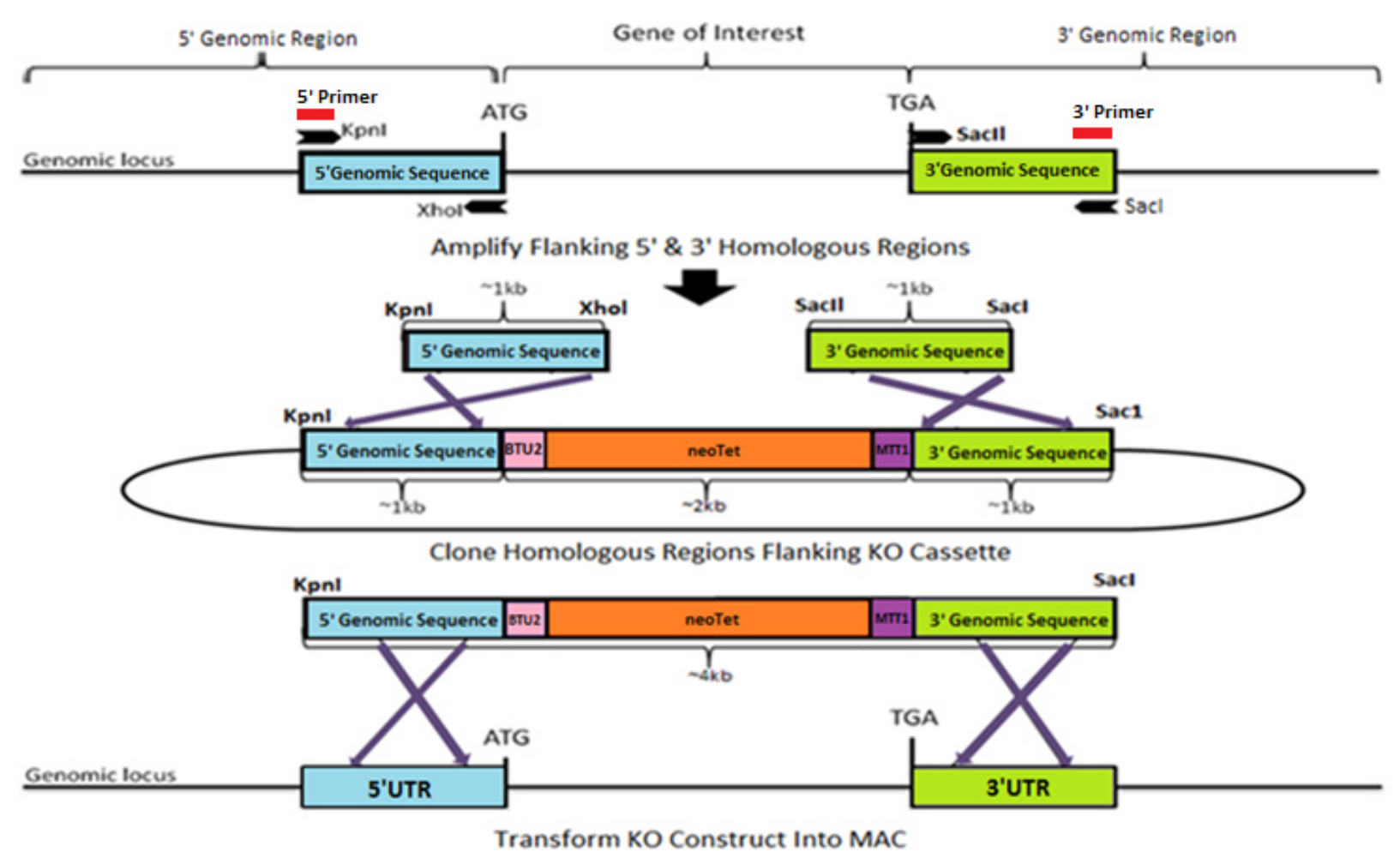

Genomic locus

\begin{tabular}{|l|l|l|l|l|}
\hline 5' Sequence & grvi2 & neotet & 3'Sequence \\
\hline
\end{tabular}

Figure 24: Schematic of MAC KO approach used for all four genes.

\subsection{Linearization of $\mathrm{KO}$ construct for transformation into T. thermophila}

In order to use exact gene replacement mediated by homologous recombination to replace the MAC copies of each of the four genes with their respective KO cassettes, I linearized the complete pNEO4 plasmid containing the UP and DOWN homologous sequences for HIRA, CAC2, UBN1 and UBN2 verified by sequencing. Linearization was achieved by utilizing KpnI and $\mathrm{SacI}$ restriction endonuclease digests that released the $\sim 3.8-4.5 \mathrm{~Kb} \mathrm{KO}$ cassette from the pNEO4 plasmid for each respective gene. Digestion freed the UP and DOWN homologous ends required for transformation into the $T$. thermophila genome (Figure 24). The homologous regions aligned and enabled the KO cassette and replaced the endogenous HIRA, CAC2, UBN1 and 
UBN2 genes in T.thermophila. A small aliquot of the resulting digestion products were electrophoresed on a $1 \%$ agarose gel for confirmation of correct size and completion of RE digestion prior to biolistic transformation of the T. Thermophila MAC following methods outlined by (Cassidy-Hanley et al., 1997) (see Materials and Methods). Upon linearization, samples pNEO4-HIRA, pNEO4-CAC2, pNEO4-UBN1 and pNEO4-UBN2exhibited single bands that ranged in size between $\sim 3.5$ and $4.8 \mathrm{~Kb}$ ((Figure 25) upper band) which represented the $\mathrm{KO}$ cassette. Additionally each of the four plasmid digests showed a $3 \mathrm{~kb}$ signal indicative of the remaining pNEO4 plasmid "backbone (Figure 25-lower band).

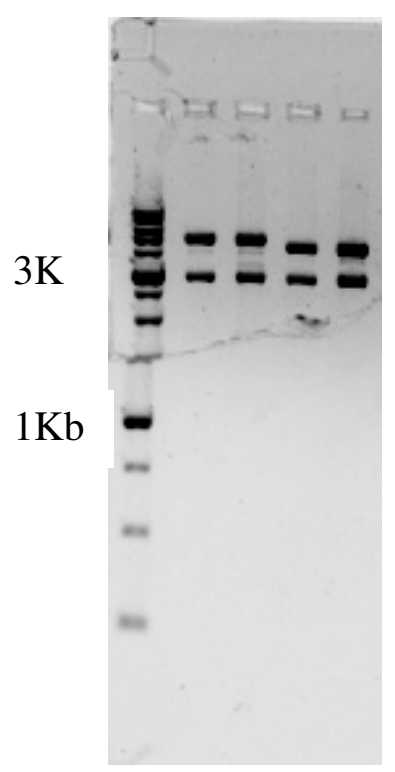

Figure 25:.Agarose gel electrophoresis of linearized KO cassette released from pNEO4 plasmid for HIRA, CAC2, UBN1, and UBN2 digested with KpnI and SacI. $1 \mu 1$ of each sample was run on a $1 \%$ agarose gel at $80 \mathrm{~V}$.

\subsection{Selection and phenotypic assortment of transformed cells}

The two-step cloning of homologous UP and DOWN sequences into pNEO4 was required to ensure correct integration and directionality of the $\mathrm{KO}$ cassette into the $T$. 
Thermophila genome. The 5' (UP) and 3' (DOWN) homology sequences that were PCR amplified flanked the start and the stop codon of the HIRA, CAC2, UBN1, and UBN2 genes and enabled the MAC copy of the respective target gene to be replaced with the KO cassette via recognition of the homologous sequences in the MAC at the correct locations. Paromomycin is an anti-microbial drug that inhibits protein synthesis by binding to ribosomal RNA (Mochizuki, 2008). Therefore if at minimum one wild-type copy of the original gene was replaced with the neoTet containing KO cassette, transformants exhibiting paromomycin resistance was selected is SPP containing paromomycin.

Like other ciliates, $T$. thermophila has two distinct nuclei: a small diploid germ line MIC that is transcriptionally silent during vegetative growth, and a large polyploid ( 45C), transcriptionally active during vegetative growth somatic MAC. The MAC divides amitotically during vegetative growth with no mechanism to ensure equal segregation of alleles such as during mitosis in most eukaryotes. As a consequence of unequal segregation, individual cells that are initially heterozygous often "assort" to one of the two alleles over 100-200 vegetative fissions in a process known as phenotypic assortment (Orias \& Flacks, 1975). Phenotypic assortment in Tetrahymena makes it possible for one of the two daughter cells produced from each cell division to contain more copies of the KO cassette than the endogenous gene. In this study, phenotypic assortment was accelerated using increasing concentrations every two days in paromomycin from initial selection condition of $80 \mu \mathrm{g} / \mathrm{ml}$ to a final concentration $1200 \mu \mathrm{g} / \mathrm{ml}$. The rationale is that if a particular gene is non-essential it should be possible using this strategy to eliminate all copies of the endogenous gene in the polyploid MAC, engineering a complete 
KO (Figure 26).

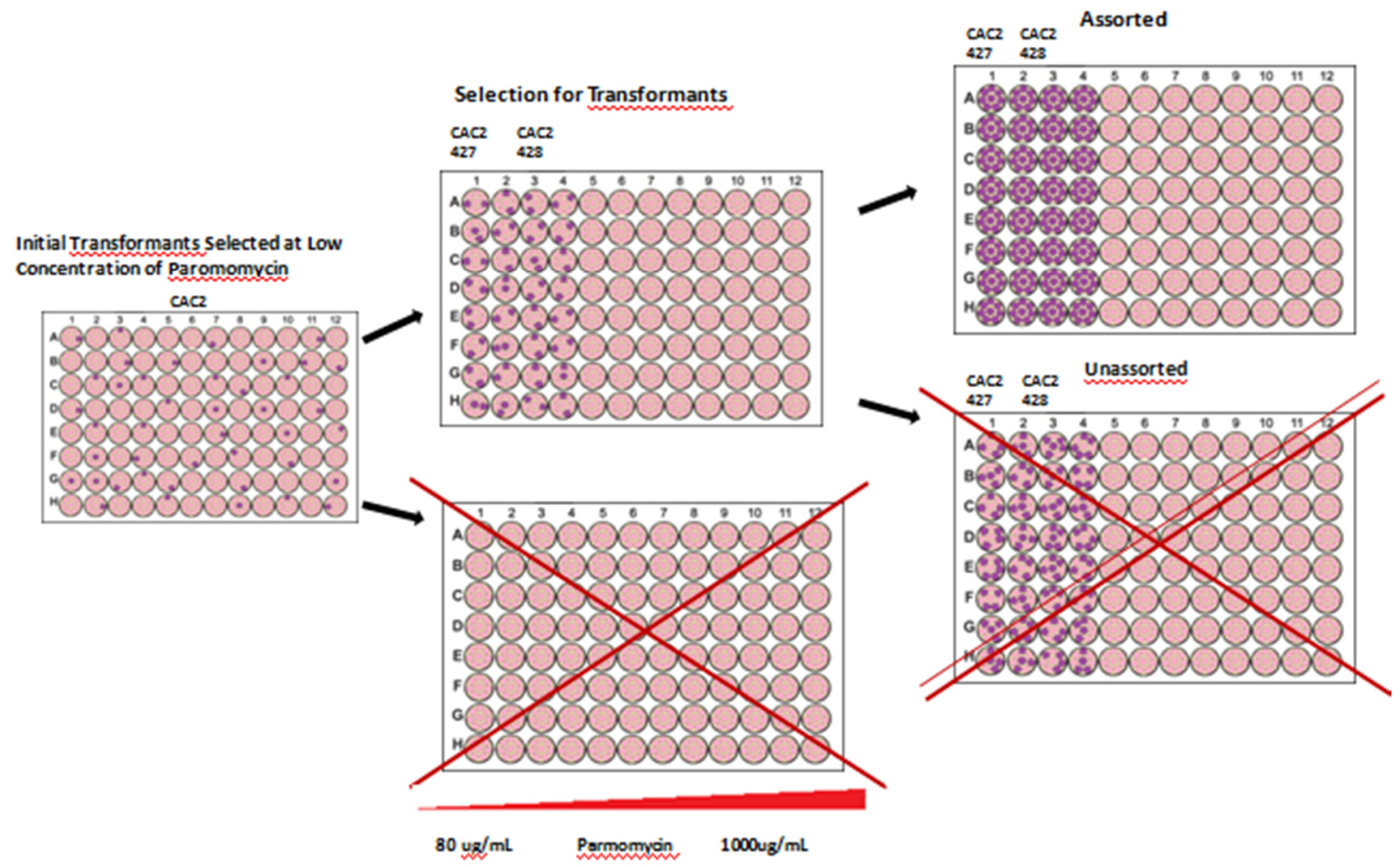

Figure 26: A schematic outlining accelerated phenotypic assortment by gradually increasing the concentration of paromomycin every two days from $80 \mu \mathrm{g} / \mathrm{ml}$ to $1200 \mu \mathrm{g} / \mathrm{ml}$. This is done in attempt to achieve a homozygous MAC for the antibiotic resistant $\mathrm{KO}$ cassette conferring resistance to paromomycin in replacement of HIRA, CAC2, UBN1 and UBN2. Through passaging every two days, transfomants that had greater copies of the KO cassette were able to flourish in SPP with higher concentrations of paromomycin (top plates). Transformants that had fewer copies of the KO cassette died in increasing concentrations of paromomycin (bottom plates).

\subsection{Single cell cloning to produce a pure cell line}

After cells were maintained at $1200 \mu \mathrm{g} / \mathrm{ml}$ of paromomycin for several weeks, single-cell cloning was used to expose lines that were possibly complete KOs as would be expected if all wild type alleles had been assorted during accelerated phenotypic assortment. Ten single cells 
were isolated and clonally propagated for each of the four KOs. The rationale for single-cell cloning was to produce clonal lines that originated from a single cell for further analysis by RTPCR. RT-PCR verified if all MAC copies of the WT gene was replaced by the KO cassette for HIRA, CAC2, UBN1 and UBN2. Single clones were picked and grown in 50 $\mu 1$ SPP droplets. 2 days later, $25 \mu 1$ of droplets containing approximately $\geq 50$ cells were passaged into $180 \mu 1$ of SPP with $100 \mu \mathrm{g} / \mathrm{ml}$ paromomycin to $1200 \mu \mathrm{g} / \mathrm{ml}$ again to ensure the cells that were conferred resistance paromomycin due to increasing copies of the HIRA, CAC2, UBN1 and UBN2 KO cassette.

\subsection{Correct integration of knockout cassette in MAC chromosome}

Colony PCR was used to determine successful integration of the KO cassette in the MAC in place of the HIRA, CAC2, UBN1, and UBN2 genes. Pairing UP-F with a reverse primer designed in the pNEO4 cassette (NEOR) (Appendix 3) (Figure 27) distinguished a transformant from WT. A signal was detected in all T. Thermophila transformants that incorporated the KO cassette, but not WT cells. While this verified the presence of the KO cassette within the cell, it did not establish correct integration. Therefore, to determine both the integration of the pNEO4 cassette and integration at the correct chromosomal loci, I utilized primers designed upstream of the UP-F primer with homology specific to the endogenous genomic DNA for each gene (UpConf-F) instead. This primer was paired with NEOR (

Figure 27).Aberrant insertion of the HIRA, CAC2, UBN1 and UBN2 KO cassettes will not produce signal with UpConf-F and NEOR. 


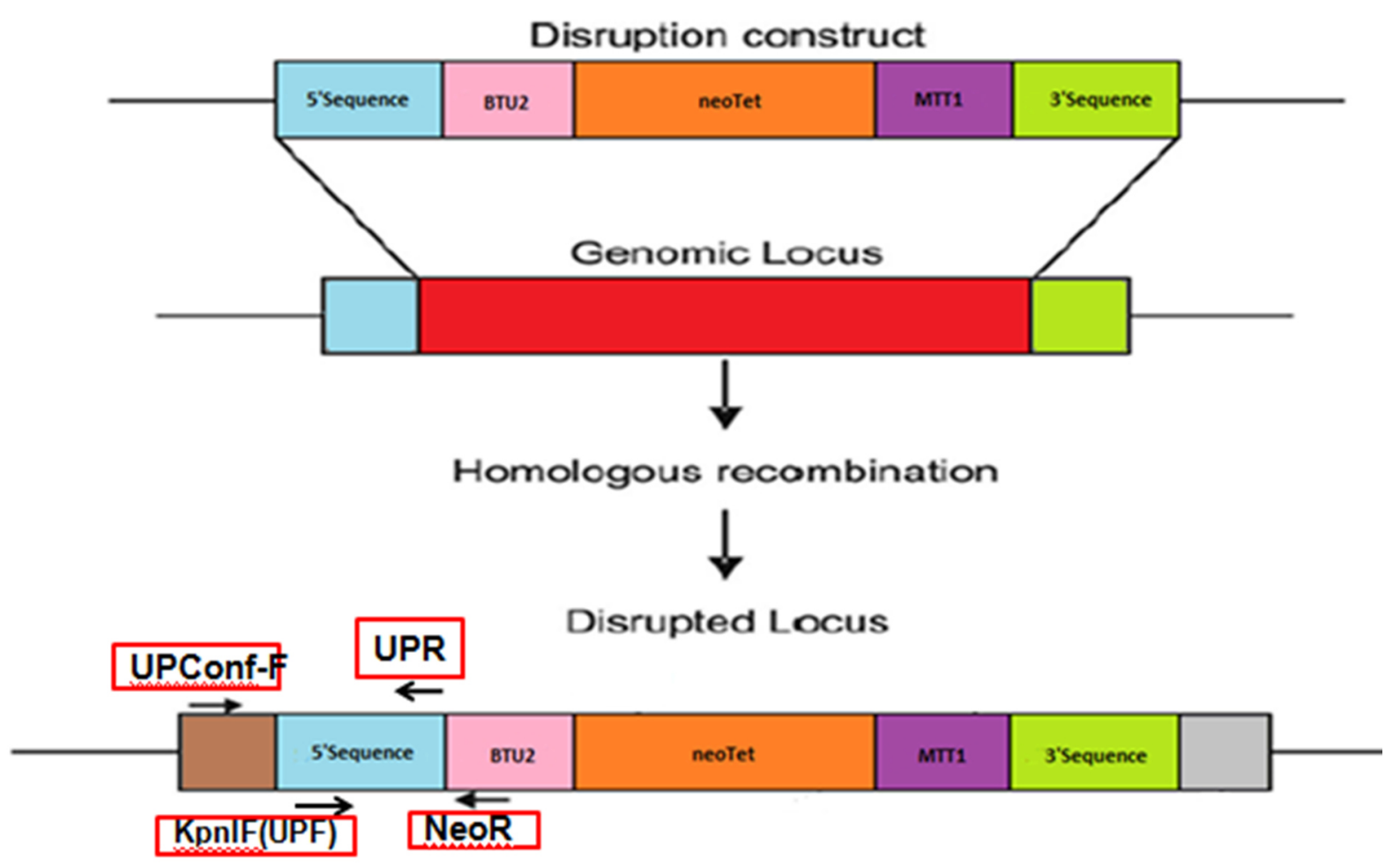

Figure 27: Schematic outlining the primer pairs used to determine whether or not correct integration of the $\mathrm{KO}$ cassette in the T. thermophila MAC genome had occurred for HIRA, CAC2, UBN1, and UBN2. Amplification through the pairing of UP-ConfF with NeoR in the KO transformants indicate correct integration of the $\mathrm{KO}$ cassette in place of original coding sequences of HIRA, CAC2, UBN1, and UBN2.

A) UP-F/NeoR - Signal of $\sim 1 \mathrm{~Kb}$ will be produced in any cells containing the $\mathrm{KO}$ cassette

B) UPConf-F/NeoR-Signal of $>1 \mathrm{~Kb}$ will only be produced in cells with proper integration of the KO cassette at HIRA, CAC2, UBN1 and UBN2 loci

As controls for presence of PCR amplifiable DNA in each experiment, KO transformant DNA for HIRA, CAC2, UBN1, UBN2 and WT (WT427/WT428) were used in PCR reactions with UP-F and UP-R primers. As expected, HIRA, CAC2, UBN1 and UBN2 KOs and WT strains produced a signal of $\sim 1 \mathrm{~Kb}-1.7 \mathrm{~Kb}$ (dependent on the gene) (Figure 28 
Figure 29, Figure 30, and Figure 31-B). PCR analysis of clonal cell lines for HIRA, CAC2, UBN1 and UBN2 KOs produced bands of expected sizes $\sim 1.5-2.5 \mathrm{~Kb}$ (dependent on gene) when the DNA was amplified using the UPConf-F/NEOR primer. This was indicative of successful insertion of the KO cassette into the correct HIRA, CAC2, UBN1 and UBN2 gene loci. As controls WT strains were devoid of signals when paired with UPConf-F/NEOR due to the absence of the KO cassette (Figure 28, Figure 29, Figure 30, and Figure 31-A)
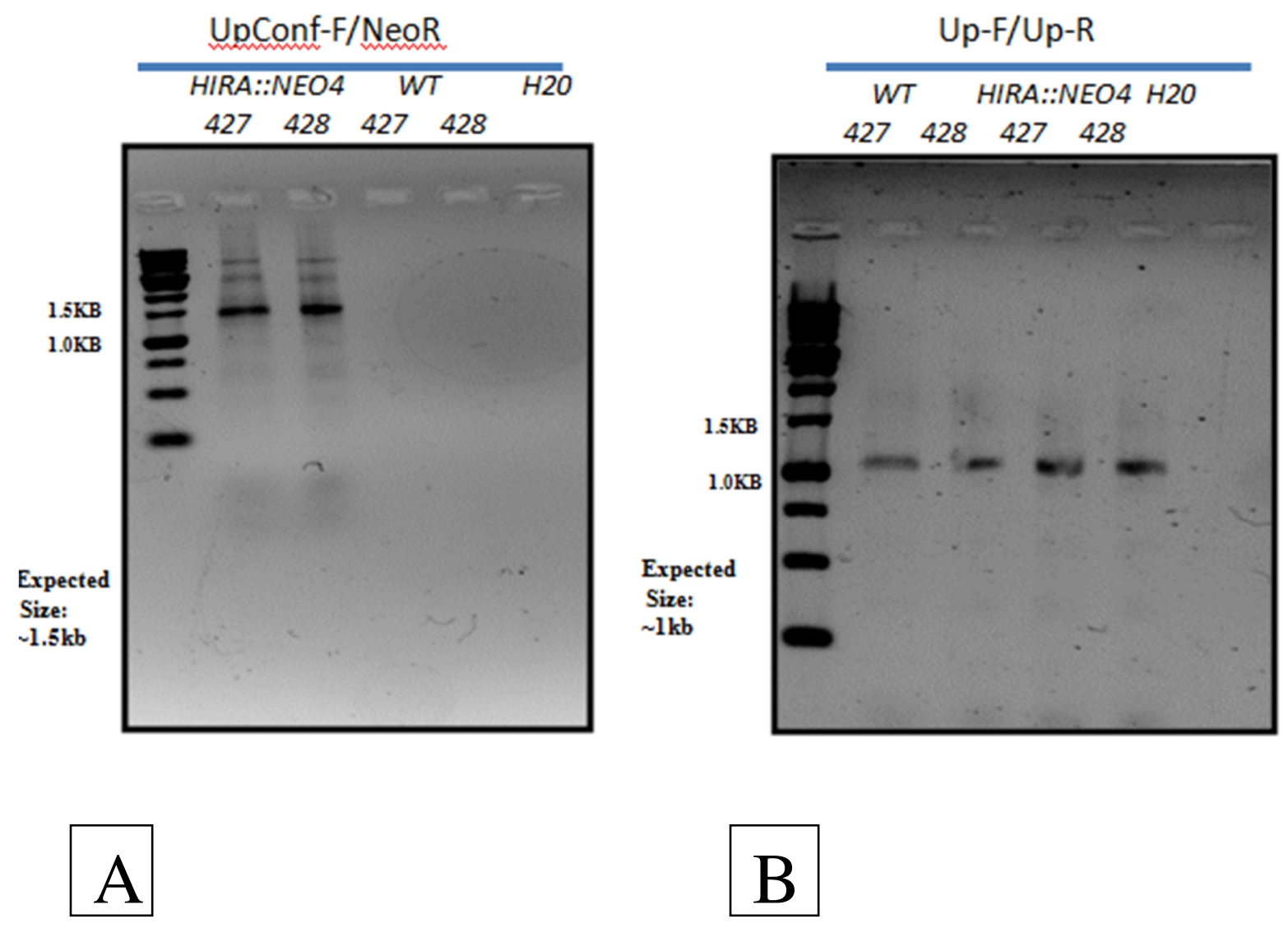

Figure 28: Agarose gel electrophoresis of PCR using HIRA-UPConf-F and NeoR primers. The presence of bands specific for the two HIRA::NEO4 lanes indicates proper integration of KO cassette in place of HIRA gene in T. Thermophila genome of HIRA::Neo4 KOs and no amplification seen in WT 427 and 428(A). The result of the PCR analysis using UP-F with UP-R on DNA purified from both WT and HIRA::Neo4 KOs acted as a loading control to show DNA is present in all sample lanes. No amplification seen in $\mathrm{H}_{2} \mathrm{O}$ indicative of no DNA present (B). 

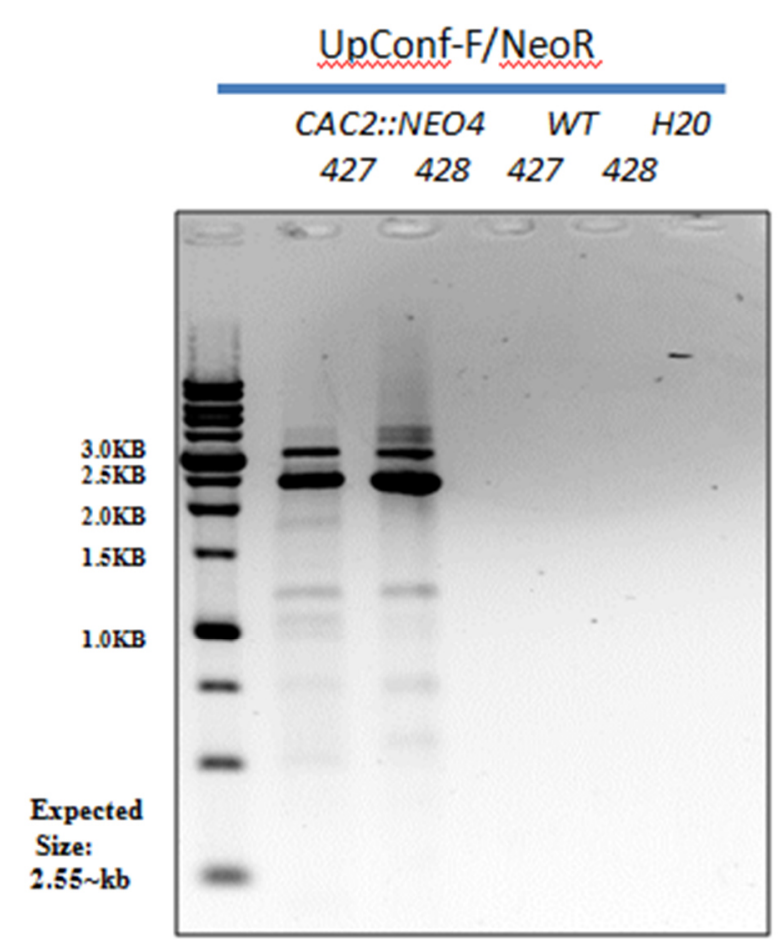

A
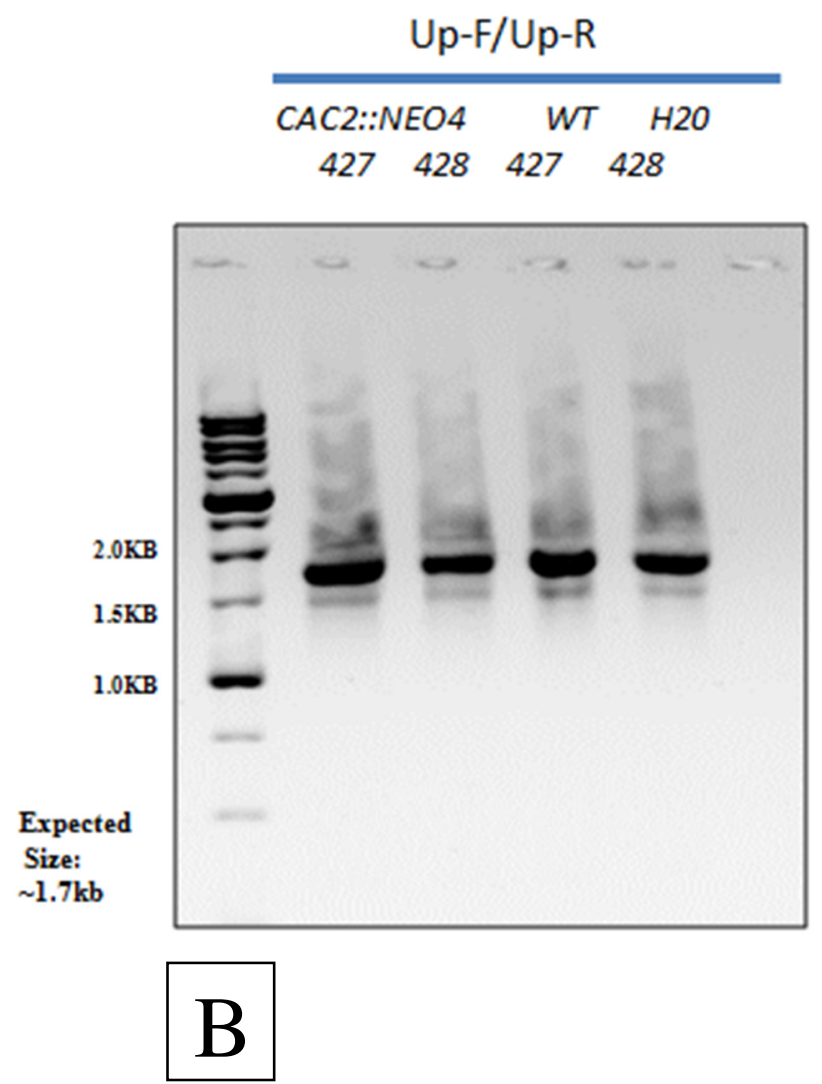

Figure 29: Agarose gel electrophoresis of PCR using CAC2-UPConf-F and NeoR primers. The presence of bands specific for the two CAC2::NEO4 lanes indicates proper integration of $\mathrm{KO}$ cassette in place of CAC2 gene in T. Thermophila genome of CAC2::Neo4 KOs and no amplification seen in WT 427 and 428(A). The result of the PCR analysis using UP-F with UP-R on DNA purified from both WT and CAC2::Neo4 KOs acted as a loading control to show DNA is present in all sample lanes. No amplification seen in $\mathrm{H}_{2} \mathrm{O}$ indicative of no DNA present (B). 

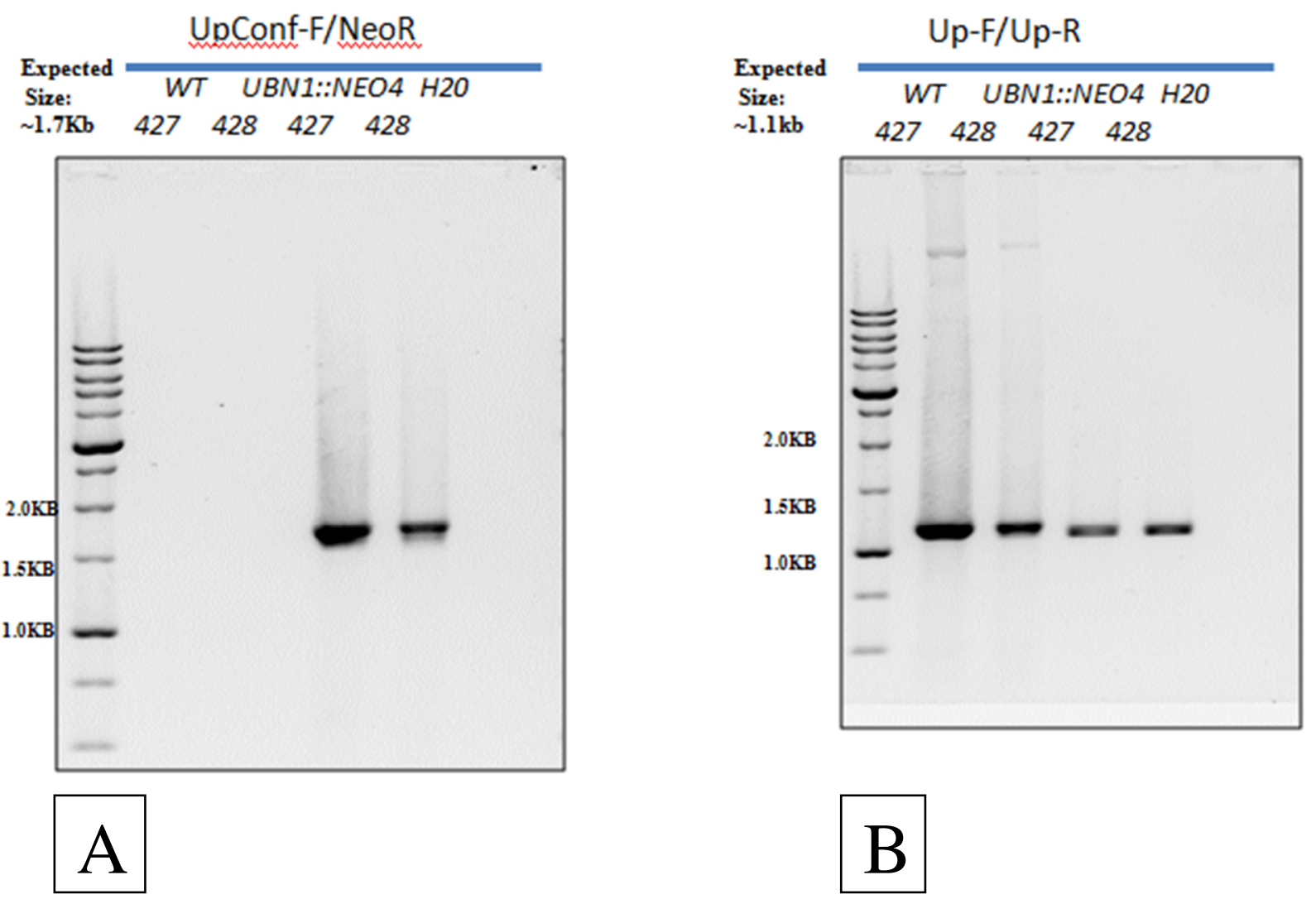

Figure 30: Agarose gel electrophoresis of PCR using UBN1-UPConf-F and NeoR primers. The presence of bands specific for the two UBN1::NEO4 lanes indicates proper integration of KO cassette in place of UBN1 gene in T. Thermophila genome of UBN1::Neo4 KOs and no amplification seen in WT 427 and 428(A). The result of the PCR analysis using UP-F with UP-R on DNA purified from both WT and UBN1::Neo4 KOs acted as a loading control to show DNA is present in all sample lanes. No amplification seen in $\mathrm{H}_{2} \mathrm{O}$ indicative of no DNA present (B). 


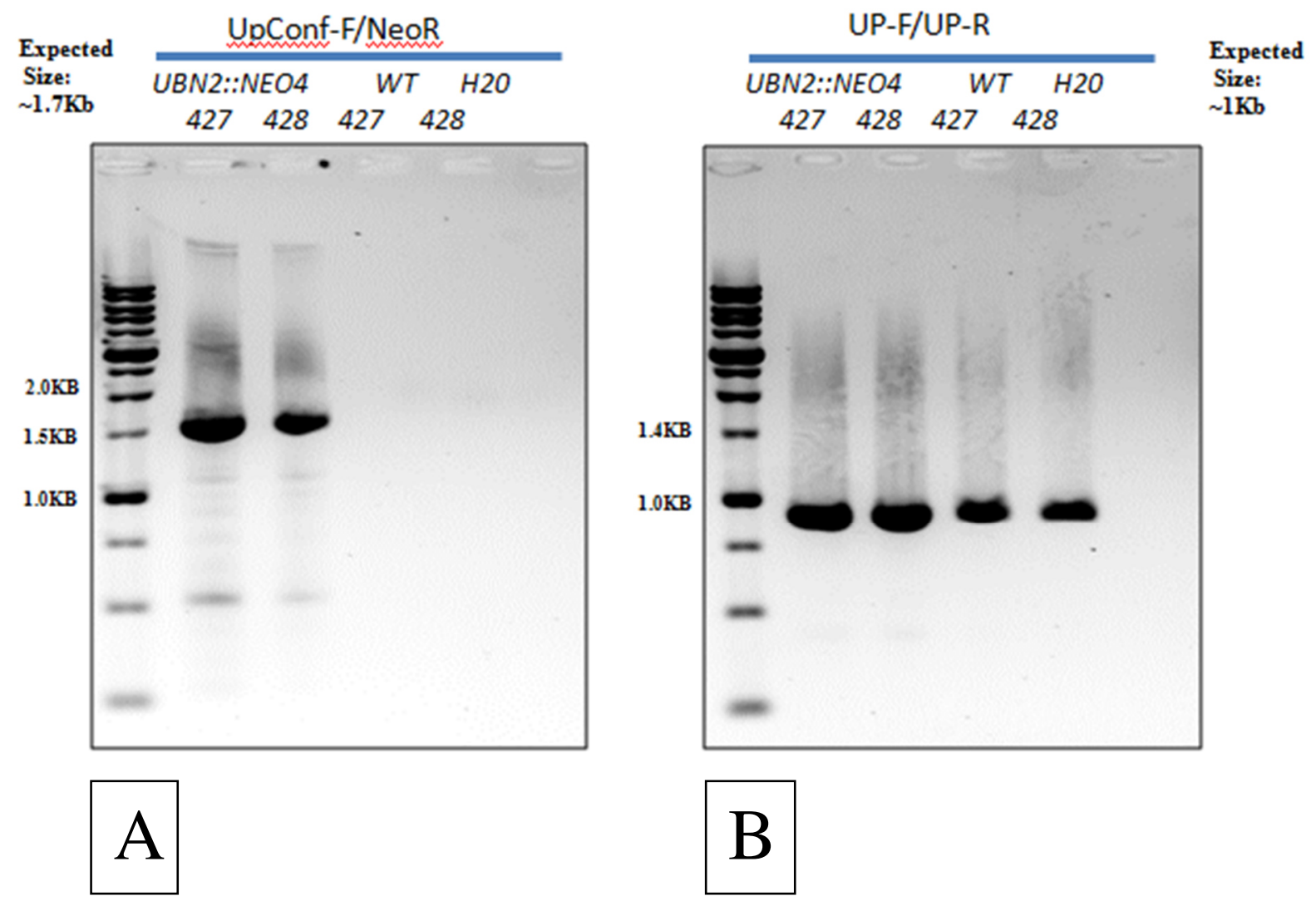

Figure 31: Agarose gel electrophoresis of PCR using UBN2-UPConf-F and NeoR primers. The presence of bands specific for the two UBN2::NEO4 lanes indicates proper integration of KO cassette in place of UBN2 gene in T. Thermophila genome of UBN2::Neo4 KOs and no amplification seen in WT 427 and 428(A). The result of the PCR analysis using UP-F with UP-R on DNA purified from both WT and UBN2::Neo4 KOs acted as a loading control to show DNA is present in all sample lanes. No amplification seen in $\mathrm{H}_{2} \mathrm{O}$ indicative of no DNA present (B). 


\subsection{RT-PCR to determine whether all MAC copies of HIRA, CAC2, UBN1 and UBN2 were replaced as expected if the respective gene is non- essential}

RT-PCR on total RNA (tRNA, rRNA, and mRNA) extracted from HIRA, CAC2, UBN1, and UBN2 KOs as well as WT cells were analyzed with their respective RT-PCR primers flanking at least one intron within the gene sequence (Appendix 3) (Figure 32). Primers were designed flanking introns to avoid detection of contaminating genomic DNA sequences in RNA samples. Introns are spliced during RNA synthesis resulting in a noticeable difference in size of the resulting amplicon from RNA versus DNA. PCR reactions utilizing the gene specific RTPCR UPRT-F/ UPRT-R primers on RNA and genomic DNA produced noticeable size differences for all primer sets (Figure 33 and Figure 34). For UBN2 WT RNA and DNA was extracted from conjugating cells because UBN2 is only developmentally expressed (Figure 11 and Figure 34), This was used as a guide to ensure amplification of gene KO and WT RNA had no genomic DNA contamination in the RT-PCR reactions. RT-PCR on CAC2 KO and WT suggested that all MAC copies of CAC2 were replaced and that the gene was non-essential (Figure 35). Similarly RT-PCR on RNA extracted from conjugating cells of UBN2 KOs and WT suggested that UBN2 was also non-essential during development due to the absence of signal in KOs compared to WT. The absence of signal in UBN2 KO samples versus the presence of a signal in WT RNA lanes suggested that all MAC copies had been replaced (Figure 36). RT-PCR on HIRA and UBN1 KO RNA however exhibited a signal similar to that of WT427 and WT428. This suggested that not all MAC copies of HIRA and UBN1 genes were replaced even after passaging and maintaining the cells at a concentration of $1200 \mu \mathrm{g} / \mathrm{ml}$ of paromomycin for over 3 months. This was indicative of at least one mRNA transcript corresponding to the HIRA and 
UBN1 genes was converted to cDNA via reverse transcriptase and amplified in the RT-PCR reaction. Therefore, HIRA and UBN1 were essential genes and could only be knocked-down (Figure 37 and Figure 38). Cycling conditions for HIRA, CAC2, UBN1 and UBN2 can be seen in (Table 3, Table 4)

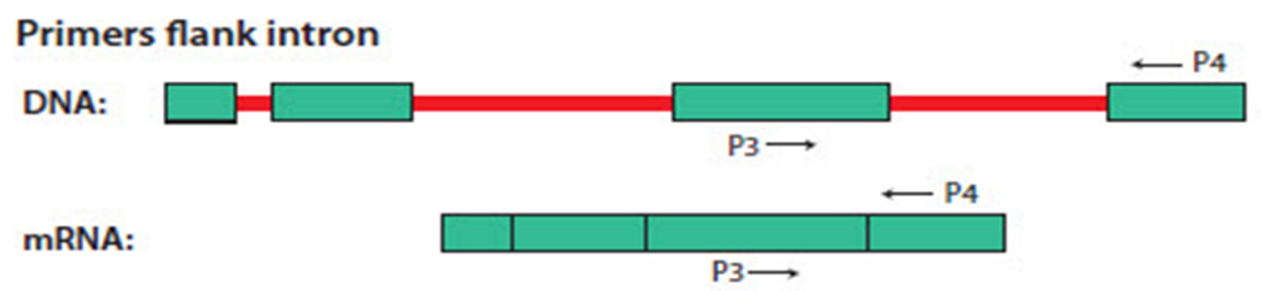

Figure 32: Intron-flanking primers for RT-PCR. Introns are in red and exons are in green. P3 and $\mathrm{P} 4$ will generate a longer PCR product from DNA than RNA templates because the introns are spliced out in RNA samples. 
UnRT-F(HIRA)/UpRT-R

WT(RNA) WT(DNA) H2O

427428427428

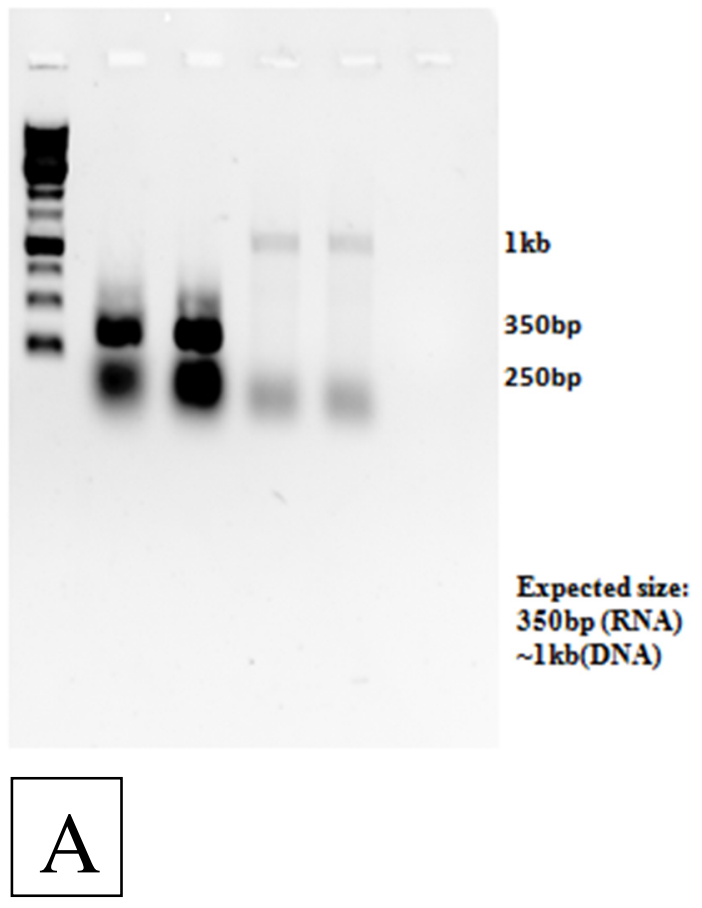

UpRT-F2 (CAC2)-F/UpRT-R2

$427^{\text {WT(RNA) }} 428^{\text {WT(DNA) }} 427^{\text {H2O }}$

Expected size: $\sim 300 \mathrm{bp}$ (RNA) $\sim 500 \mathrm{bp}(\mathrm{DNA})$

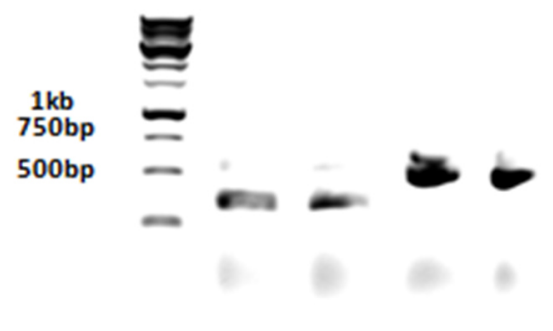

Figure 33: Agarose analysis of PCR for total RNA (tRNA, rRNA, mRNA) and DNA extracted from WT cells utilizing UpRT-F/ UpRT-R primers for HIRA (A) UpRT-F2/UpRT-R2 specific to the $\mathrm{CAC} 2$ gene loci(B). Primers flanked at least one intron and produced a noticeable size difference between RNA and DNA lanes ensuring that the RNA samples were not contaminated with genomic DNA. The water lanes indicate absence of DNA and RNA. 

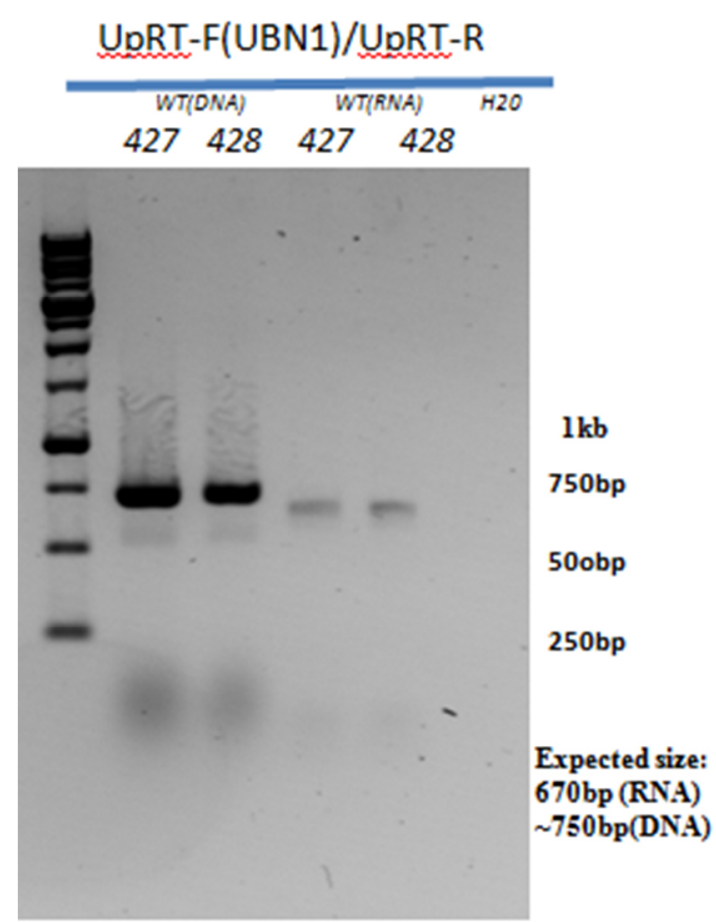

A
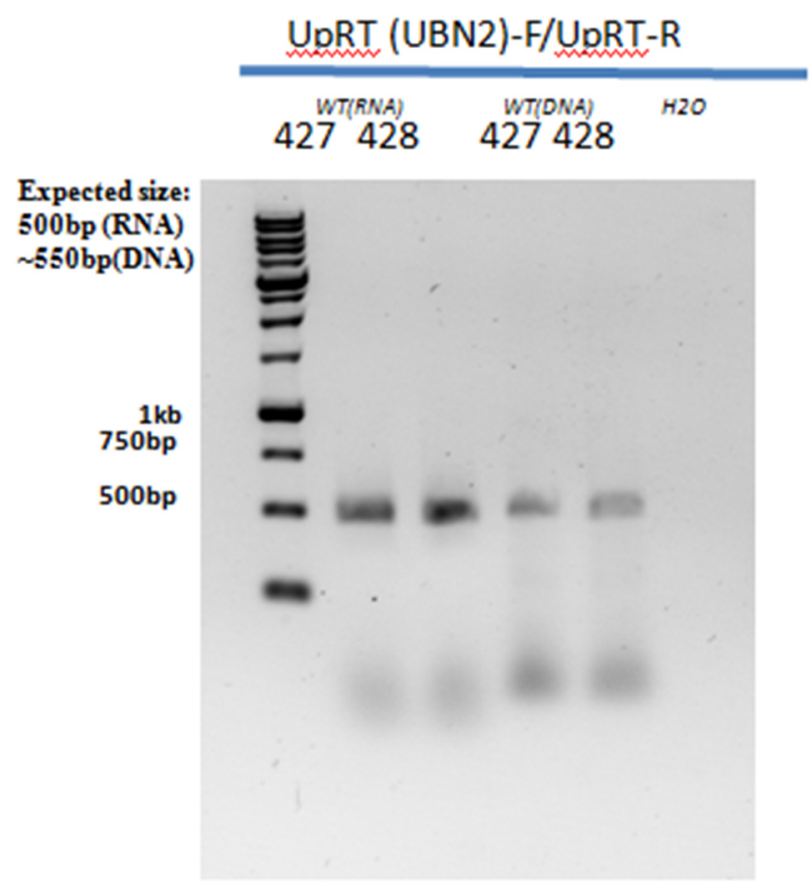

B

Figure 34:Agarose analysis of PCR for total RNA (tRNA, rRNA, mRNA) and DNA extracted from WT cells utilizing UpRT-F/UpRT-R primers for UBN1 (A) and UBN2 gene loci(B). Primers flanked at least one intron and produced a noticeable size difference between RNA and DNA lanes ensuring that the RNA samples were not contaminated with genomic DNA. The water lanes indicate absence of DNA and RNA. 

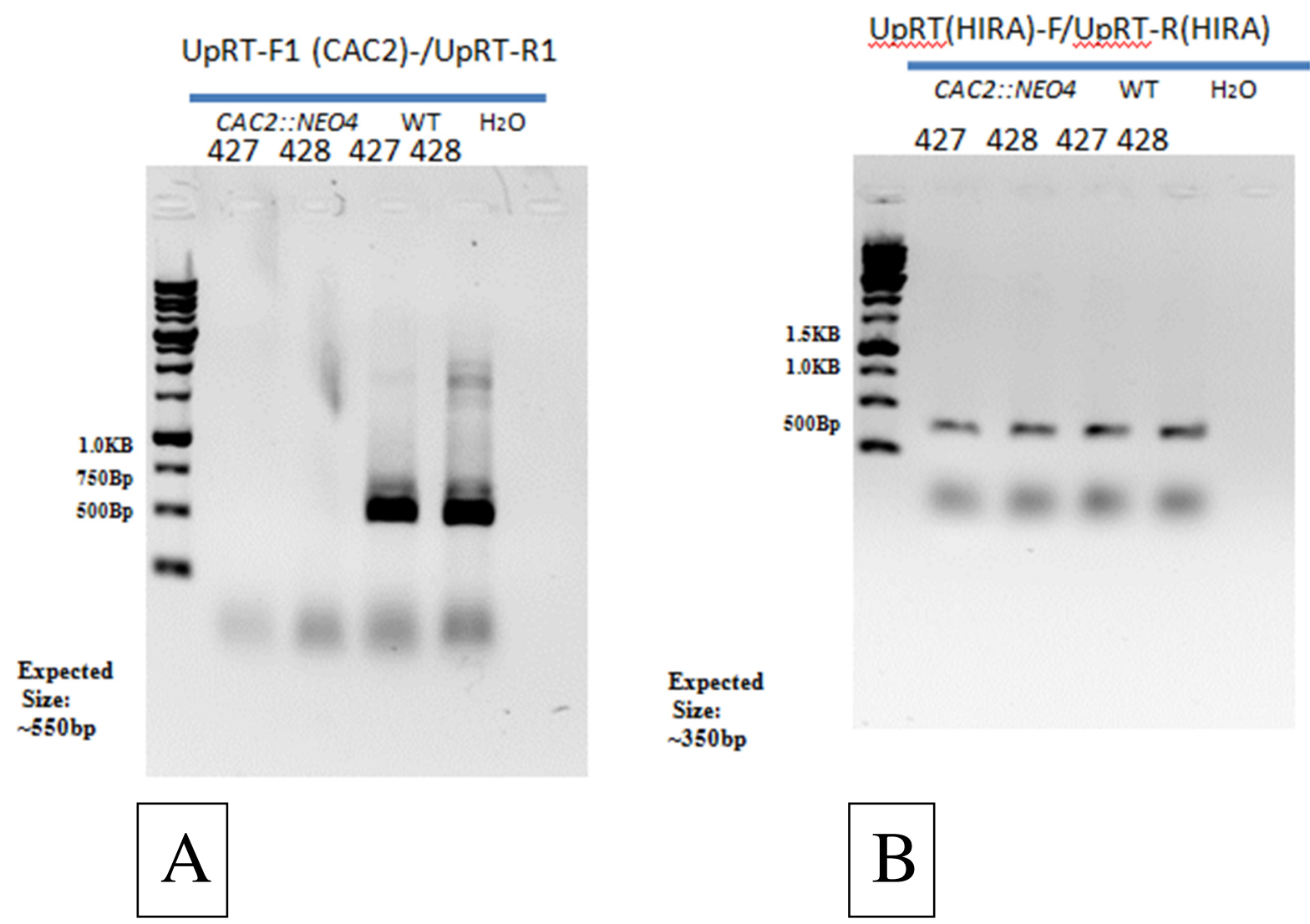

Figure 35: RT-PCR on total RNA (tRNA, rRNA, and mRNA) extracted from CAC2 KOs analyzed with respective RT-PCR primers flanking at least one intron within the gene sequence on CAC2::Neo4 427 and 428 KOs and WT 427 and 428 to determine complete replacement of all MAC copies of the CAC2. CAC2 exhibited complete absence of signal but both WT427 and WT428 exhibited a signal of approximately $0.270 \mathrm{~Kb}$. This suggested that phenotypic assortment resulted in all MAC copies of the CAC2 had been replaced (left). HIRA RT primers were used on CAC2 KOs and WT as a loading control to ensure RNA present in all lanes (right). 


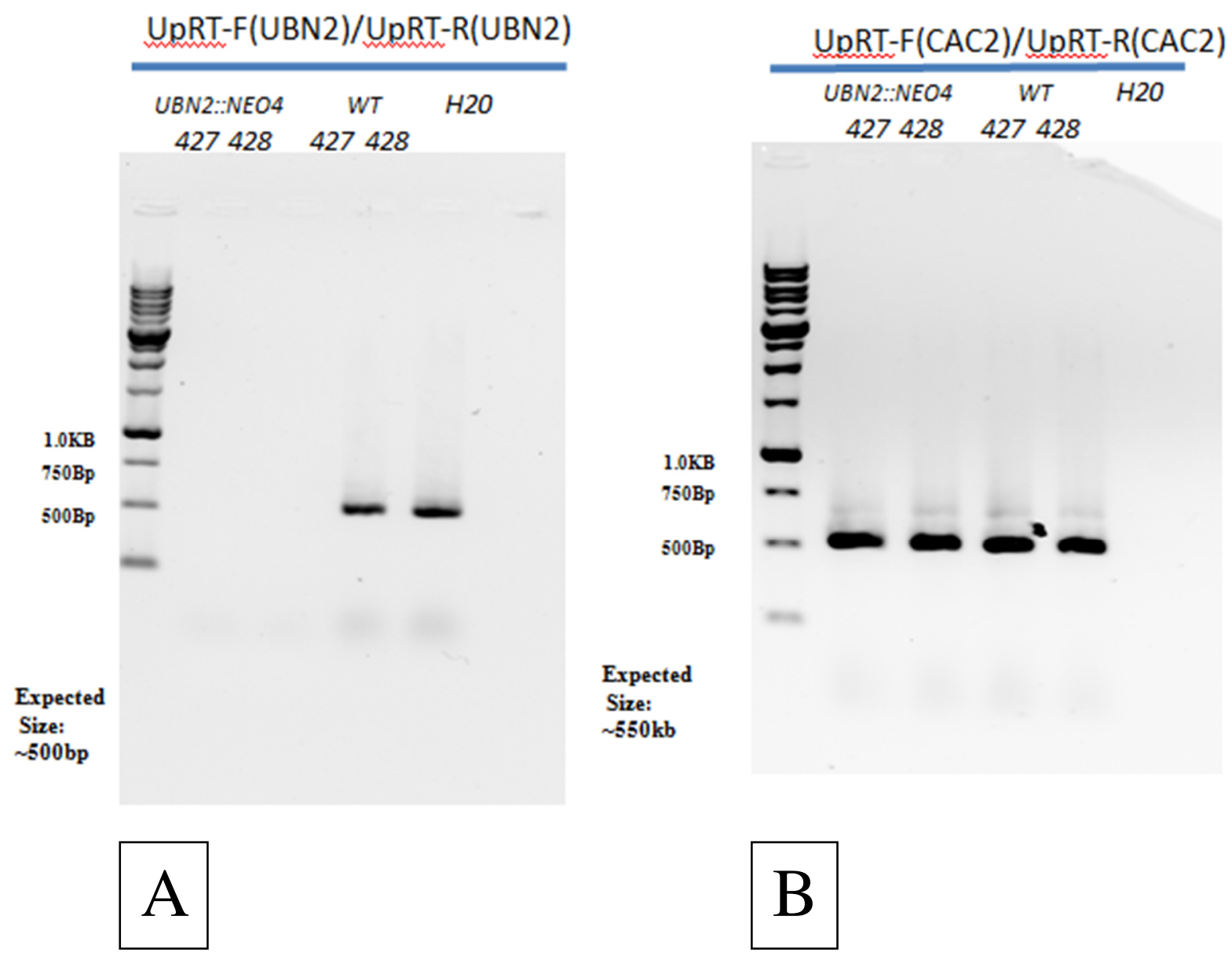

Figure 36: RT-PCR on total RNA (tRNA, rRNA, and mRNA) extracted from UBN2 KOs analyzed with respective RT-PCR primers flanking at least one intron within the gene sequence on UBN2::Neo4 427 and 428 KOs and WT 427 and 428 to determine complete replacement of all MAC copies of the UBN2. UBN2 exhibited complete absence of signal but both WT427 and WT428 exhibited a signal of approximately $0.5 \mathrm{~Kb}$. This suggested that phenotypic assortment resulted in all MAC copies of the UBN2 had been replaced (left). CAC2 RT primers were used on UBN2 KOs and WT as a loading control to ensure RNA present in all lanes (right). 

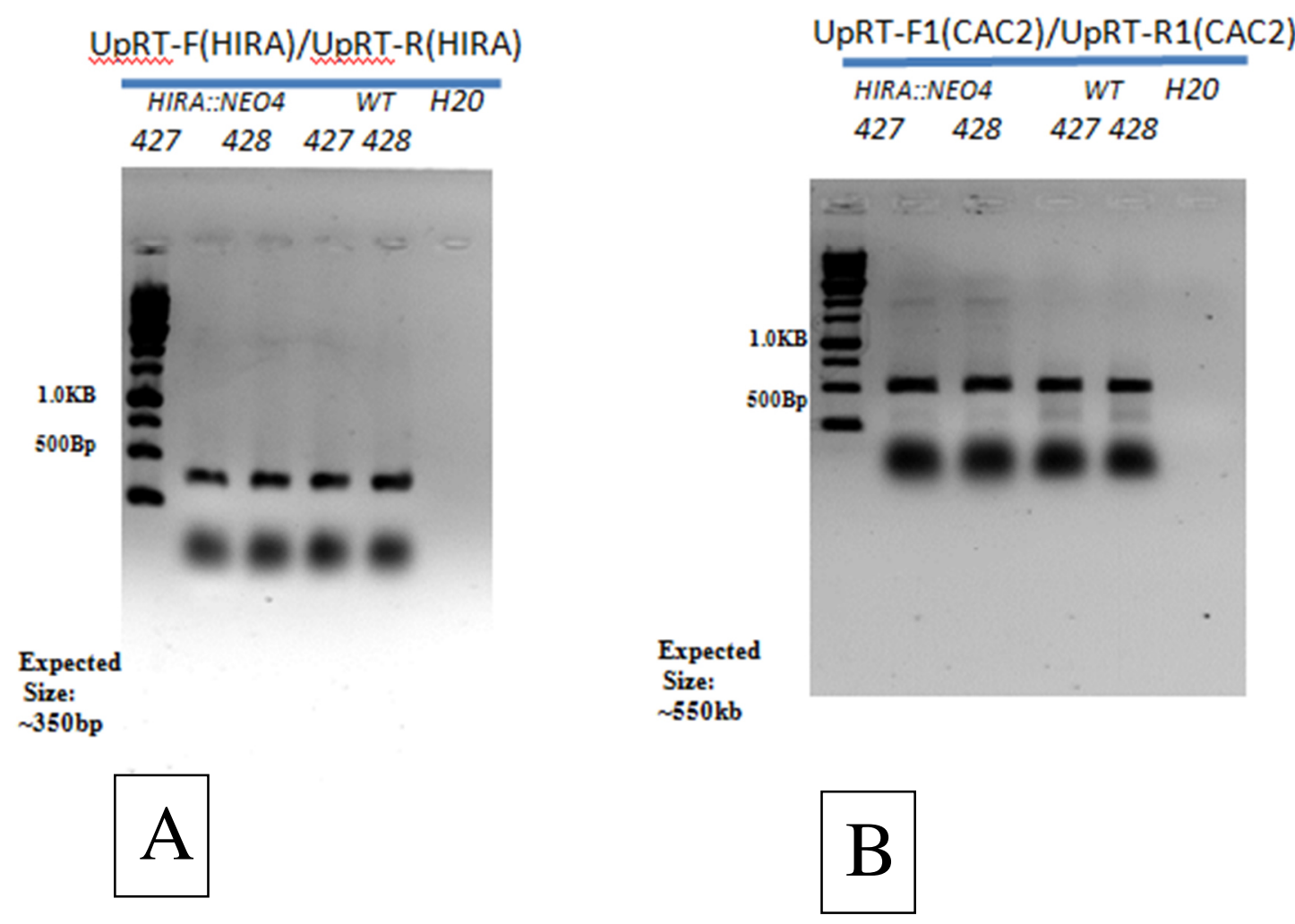

Figure 37: RT-PCR on total RNA (tRNA, rRNA, and mRNA) extracted from HIRA KOs analyzed with respective RT-PCR primers flanking at least one intron within the gene sequence on HIRA::Neo4 427 and 428 KOs and WT 427 and 428 to determine complete replacement of all MAC copies of the HIRA. HIRA KOs exhibited a signal equivalent to both WT427 and WT428 of approximately $0.350 \mathrm{~Kb}$. This suggested that phenotypic assortment resulted in not all MAC copies of HIRA can be replaced (left). CAC2 RT primers were used on HIRA KOs and WT as a loading control to ensure RNA present in all lanes (right). 

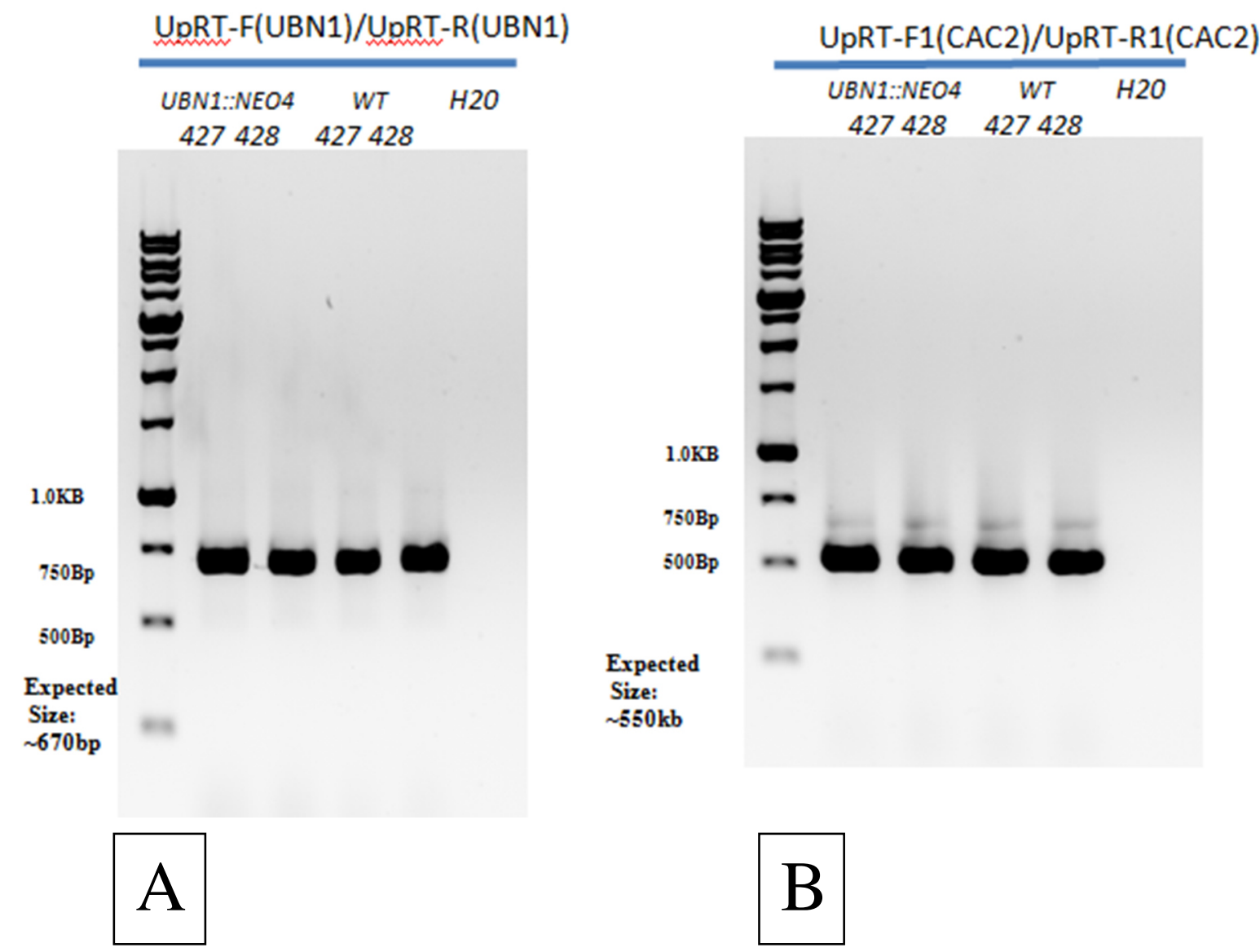

Figure 38: RT-PCR on total RNA (tRNA, rRNA, and mRNA) extracted from UBN1 KOs analyzed with respective RT-PCR primers flanking at least one intron within the gene sequence on UBN1::Neo4 427 and 428 KOs and WT 427 and 428 to determine complete replacement of all MAC copies of the UBN1. UBN1 KOs exhibited a signal equivalent to both WT427 and WT428 of approximately $0.650 \mathrm{~Kb}$. This suggested that phenotypic assortment resulted in not all MAC copies of UBN1 can be replaced (left). CAC2 RT primers were used on UBN1 KOs and WT as a loading control to ensure RNA present in all lanes (right). 


\subsection{Cell pairing level during conjugation}

The effect of replacing HIRA, CAC2, UBN1 and UBN2 with the KO cassette on cell pairing during conjugation was assessed by counting the number of mating pairs 3 hours postmixing of two different mating types for each gene and WT427 with WT428. All KO mating pairs had similar pairing efficiencies to that of WT. Pairing efficiencies were greater than $90 \%$ on average 3 hours post-mixing for 100 cells for each trial. Three replicates were conducted for each mating pair and then an average was determined (Table 7). Together this suggests that the respective KOs did not affect the ability of the cells to initiate conjugation.

Table 7: Number of mating pairs in a 100 cell sample to determine conjugation pair efficiency 3 hours post-mixing of two different mating types.

\begin{tabular}{|l|l|l|l|l|l|}
\hline $\begin{array}{l}\text { Trial } \\
(\mathbf{1 0 0} \text { cells) }\end{array}$ & $\begin{array}{l}\text { WT427XWT4 } \\
\mathbf{2 8}\end{array}$ & $\begin{array}{l}\text { HIRAKO::427 } \\
\mathbf{X} \\
\text { HIRAKO::428 }\end{array}$ & $\begin{array}{l}\text { CAC2KO::427 } \\
\mathbf{C}\end{array}$ & $\begin{array}{l}\text { UBN1KO::427 } \\
\mathbf{X} \\
\text { CAC2K::428 }\end{array}$ & $\begin{array}{l}\text { UBN2KO::427 } \\
\mathbf{X}\end{array}$ \\
\hline $\mathbf{1}$ & 98 & 93 & 95 & 92 & 94 \\
\hline $\mathbf{2}$ & 90 & 94 & 94 & 94 & 94 \\
\hline $\mathbf{3}$ & 94 & 93 & 93 & 93 & 93 \\
\hline Average \% & 94 & 93 & 94 & 93 & 94 \\
\hline
\end{tabular}

\subsection{Drug screening assay for $6 \mathrm{mp}$ resistance and paromomycin sensitivity}

Cells were picked at the $8^{\text {th }}$ hour mark because mating pairs are believed to be committed to completing conjugation 5.25 hours after conjugation initiation. After this time point, mating pairs commit to termination of the parental genome and survival of the new 
recombinant zygotic nucleus (Cole \& Sugai, 2012). HIRA, CAC2, UBN1 and UBN2 KOs were similar to WT. KO mating pairs completed conjugation and conferred resistance to 6-mp and sensitivity to paromomycin at an average similar to that of WT. The number of wells that were flourishing in 6-mp and paromomycin were scored for each $\mathrm{KO}$ and WT mating set for 3 repeats and can be found in (Table 8). The wells that did not follow 6-mp resistance and paromomycin sensitivity can be assumed to be due to picking individual cells or separation of a mating pair during the picking process.

Table 8: The average of individual mating pairs conferring resistance to 6-mp and parmomycin sensitivity for 3 different trials. 90 mating pairs for HIRA, CAC2, UBN1, UBN 2 KOs, and WT427 crossed with WT428 were scored for each repeat.

\begin{tabular}{|c|c|c|c|c|c|c|c|c|c|c|}
\hline $\begin{array}{c}\text { Trials } \\
(90 \\
\text { mating } \\
\text { pairs })\end{array}$ & \multicolumn{2}{|c|}{$\begin{array}{c}\text { WT427 } \\
\text { X } \\
\text { WT428 } \\
(\%) \\
\end{array}$} & \multicolumn{2}{|c|}{$\begin{array}{c}\text { HIRAKO::427 } \\
\text { X } \\
\text { HIRAKO::428 } \\
(\%)\end{array}$} & \multicolumn{2}{|c|}{$\begin{array}{c}\text { CAC2KO::427 } \\
\text { X } \\
\text { CAC2KO::428 } \\
(\%)\end{array}$} & \multicolumn{2}{|c|}{$\begin{array}{c}\text { UBN1KO::427 } \\
\text { X } \\
\text { UBN1KO::428 } \\
(\%)\end{array}$} & \multicolumn{2}{|c|}{$\begin{array}{c}\text { UBN2KO::427 } \\
\text { X } \\
\text { UBN2KO::428 } \\
(\%)\end{array}$} \\
\hline Drug & 6- $m p^{\mathrm{R}}$ & Paro & $6 m p^{R}$ & Paro $^{+}$ & 6- $m p^{R}$ & Paro $^{+}$ & 6- $m p^{R}$ & Paro $^{+}$ & 6- $m p^{R}$ & Paro $^{+}$ \\
\hline 1 & \multicolumn{2}{|c|}{97} & \multicolumn{2}{|c|}{94} & \multicolumn{2}{|c|}{92} & \multicolumn{2}{|c|}{93} & \multicolumn{2}{|c|}{97} \\
\hline 2 & \multicolumn{2}{|c|}{98} & \multicolumn{2}{|c|}{93} & \multicolumn{2}{|c|}{92} & \multicolumn{2}{|c|}{94} & \multicolumn{2}{|c|}{94} \\
\hline 3 & \multicolumn{2}{|c|}{94} & \multicolumn{2}{|c|}{94} & \multicolumn{2}{|c|}{91} & \multicolumn{2}{|c|}{94} & \multicolumn{2}{|c|}{93} \\
\hline $\begin{array}{c}\text { Average } \\
(\%)\end{array}$ & \multicolumn{2}{|c|}{96} & \multicolumn{2}{|c|}{94} & \multicolumn{2}{|c|}{92} & \multicolumn{2}{|c|}{94} & \multicolumn{2}{|c|}{95} \\
\hline
\end{tabular}

\subsection{DAPI staining for preliminary phenotypic analysis during vegetative growth and starvation}

The MAC and MIC structures of CAC2 KOs in their starved and vegetative states were stained with DAPI. The MAC of CAC2 KOs of vegetative cells appeared to be larger in size 
than the MAC of WT cells (Figure 39). The MACs of 40 CAC2 KOs were measured using Image $\mathrm{J}$ of vegetative and starved cells (Table 9). At 40X the total picture width is equivalent to $360 \mu \mathrm{m}$. On Image $\mathrm{J}$, the diameters of the CAC2 KO MACs were measured in micrometers. The MAC of CAC2 KOs is larger than the MACs of WT.

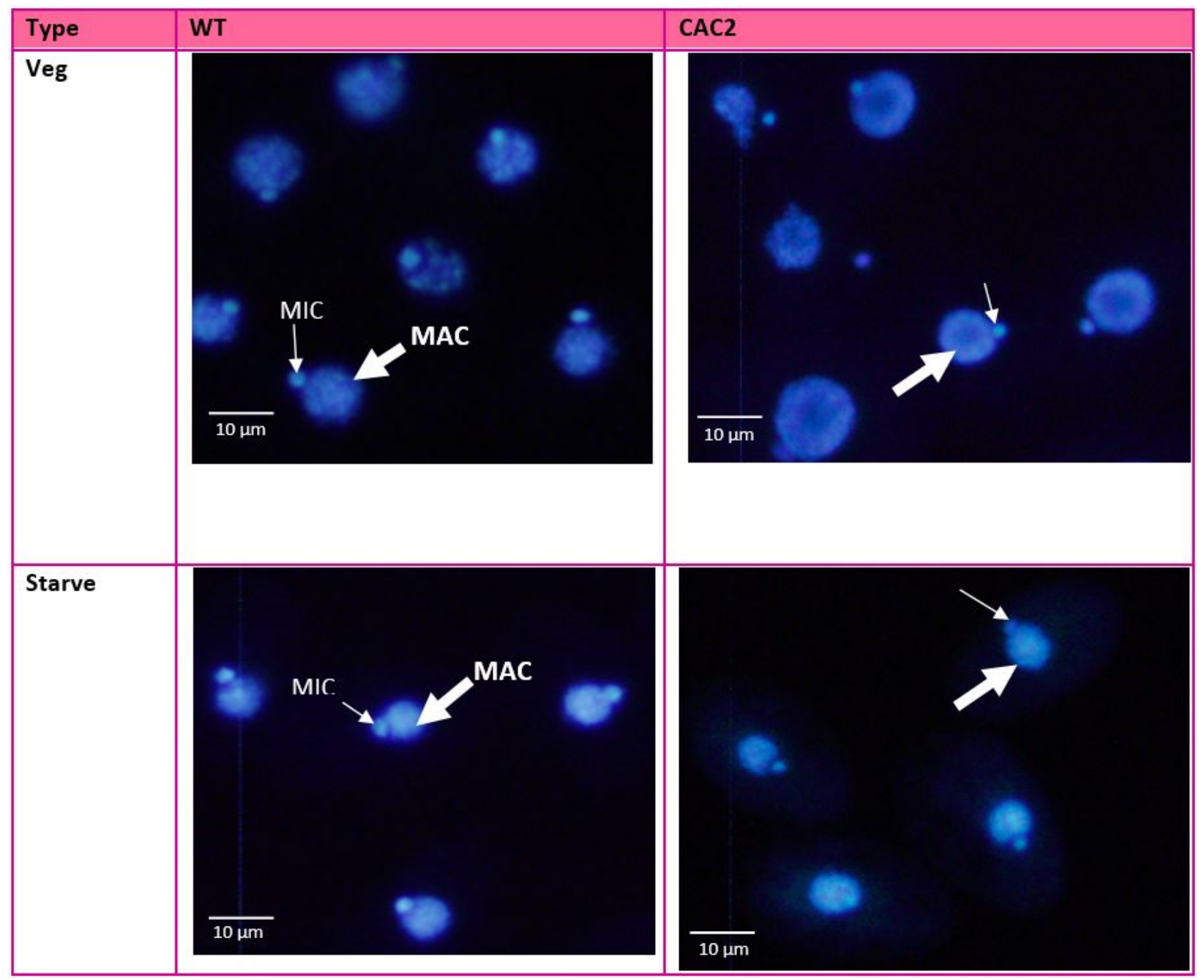

Figure 39: Fluorescence of vegetative and starved CAC2, KOs compared to WT using DNAspecific dye DAPI to capture the nuclear structures of MAC and MIC. The MAC of vegetative CAC2 KOs is enlarged compared to WT vegetative MACs. Images were taken at 40X magnification in a 1360x1024 frame. 
Table 9: Image J results for the mean diameter of CAC2 KO MACs compared to WT. Diameters were measured in micrometers. Images used were taken at $40 \mathrm{X}$ magnification in a 1360x 1024 frame. Field of view at 40X was 360 micrometers.

\begin{tabular}{|l|r|c|r|r|}
\hline Mean Diameter of MAC in $\boldsymbol{\mu m}$ \\
\hline Type & WT & \multicolumn{1}{l|}{ SD } & \multicolumn{1}{l|}{ CAC2 } & \multicolumn{1}{l|}{ SD } \\
\hline Starve & 12.60 & \pm 1.80 & 14.26 & \pm 1.73 \\
\hline Veg & 17.86 & \pm 1.37 & 20.38 & \pm 2.52 \\
\hline
\end{tabular}

\subsubsection{DAPI staining for preliminary phenotypic analysis during conjugation}

To determine if knocking out HIRA, CAC2, UBN1 or UBN2 had an influence on chromatin structure within the MAC and/or the MIC, samples were collected at distinct time points of conjugation (Figure 40) and stained with DAPI. Close analysis of the respective gene KO pairs with WT mating pairs showed no significant difference in the MAC and MIC structures from WT. All mating pairs seemed to undergo pair formation around 1.5 hours. The MIC undergoes meiosis forming a crescent and then 4 haploid nuclei products between the $3^{\text {rd }}$ $5^{\text {th }}$ hour. One of the haploid nuclei products were selected while the other 3 disintegrated enabling crossing-over to take place by the $5^{\text {th }}$ hour. Mitotic division of functional meiotic products yields genetically identical migratory (anterior) and stationary (posterior) gamete pronuclei. The anterior pronuclei of mating pairs were reciprocally exchanged, and fused with the stationary pronuclei of the recipient cell pair, forming the diploid zygote. The zygotic diploid nucleus undergoes two mitotic divisions, giving rise to 4 diploid nuclei. The anterior two products differentiate into macronuclei, while posterior products became the new MICs. After the $9^{\text {th }}$ hour the old MAC was reabsorbed just like in WT mating pairs (Figure 40). 


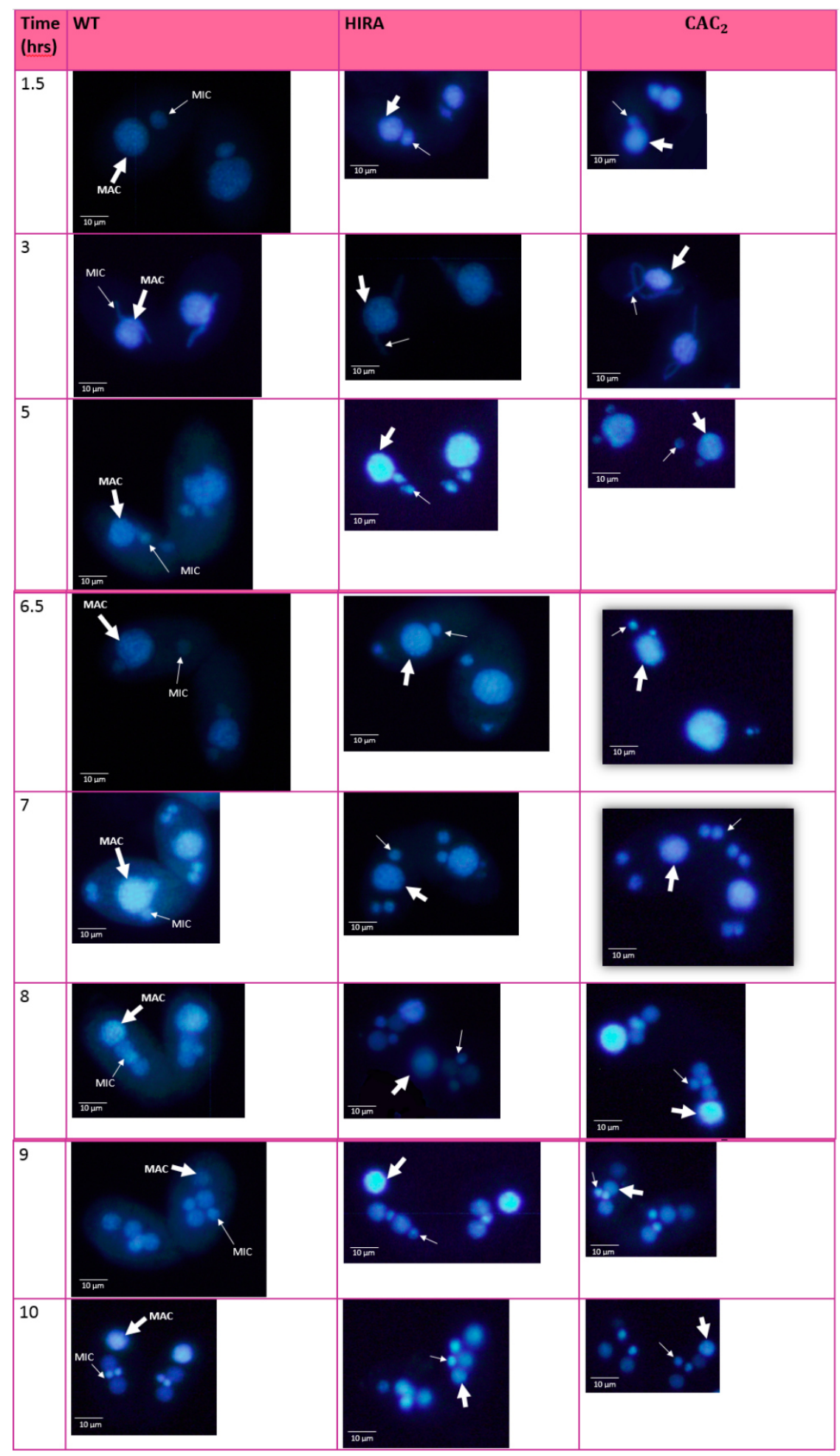




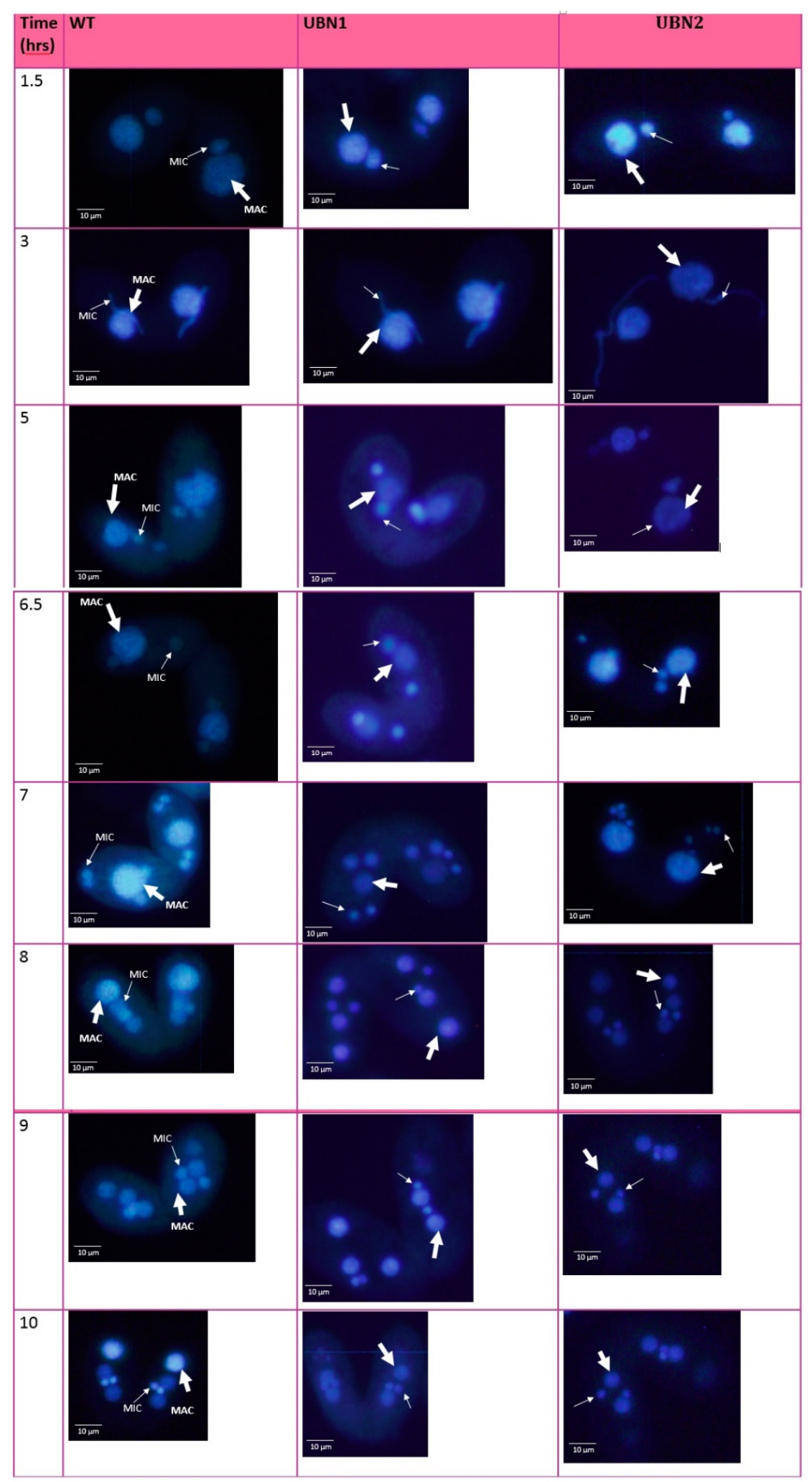

Figure 40: Fluorescence of conjugating CAC2, HIRA, UBN1 and UBN2 KOs compared to WT using DNA-specific dye DAPI to capture the nuclear integrity of MAC and MIC. Images were taken at 40X magnification in a 4080x3072 frame. 


\section{Chapter 4: Discussion}

As mentioned in the introduction, replication-dependent nucleosome assembly starts with newly synthesized histone H3-H4 dimers that are imported into the nucleus through the ASF1H3-H4 complex. ASF1 transfers $\mathrm{H} 3-\mathrm{H} 4$ to the CAC2 subunit of CAF-1 in yeast and humans. Transfer of $\mathrm{H} 3-\mathrm{H} 4$ dimers to $\mathrm{CAC} 2$ enables tetramerization and subsequent deposition onto newly synthesized DNA. Replication-independent nucleosome assembly consists of the transfer of $\mathrm{H} 3.3-\mathrm{H} 4$ dimers to HIRA in humans to promote $\mathrm{H} 3.3-\mathrm{H} 4$ deposition onto DNA (Burgess \& Zhang, 2013). Yeast only has one form of $\mathrm{H} 3$ that is deposited in both replication-dependent and independent nucleosome assembly by CAF-1 and HIR respectively(Tagami et al., 2004).The HIR and CAF-1 complex interact in S. Cerevisiae suggesting that the HIR/CAF-1 complex provides functional backup for nucleosome deposition and assembly (Sharp, Franco, Osley, \& Kaufman, 2002). Deletion of HIR1/HIRA and subunits of CAF-1 produced viable progeny but resulted in decreased rates of histone $\mathrm{H} 3$ exchange in yeast and reduced nucleosome assembly in humans (Ray-Gallet et al., 2011; Sharp et al., 2002; Kaufman, Cohen, \& Osley, 1998). In HeLa cells when CAF-1 is knocked-down, HIRA assembles nucleosomes during replication reinforcing a functional overlap between HIRA and CAF-1 in human cells as well (Ray-Gallet et al., 2011). My results suggest similar functional overlaps between HIRA, CAC2, UBN1 and UBN2 in T. thermophila.

\subsection{Expression of $\mathrm{CAC} 2$ is non-essential for growth}

RT-PCR on CAC2 KO and WT suggested that all MAC copies of CAC2 were replaced (Figure 35). This is very similar to yeast where genes encoding CAF-I subunits are not essential for viability. Some species exhibit the apparent loss of the CAC2 ortholog (Guillardia) 
yet continue to survive. This suggests there must be a continued functional overlap between CAC2 and other related orthologs (Balaji et al., 2009). CAC2 in T. thermophila is non-essential for growth and the production of viable progeny similar to yeast. The non-essentiality of CAC2 suggests alternative chromatin assembly mechanisms must function to compensate chromatin assembly processes mediated by CAF-1 in T. thermophila similar to yeast and humans.

\subsection{Expression of HIRA and UBN1 are essential for growth}

RT-PCR on HIRA and UBN1 KO RNA suggested that all MAC copies of HIRA and UBN1 genes were not replaced. The RT-PCR results suggested that at least one mRNA transcript corresponding to HIRA and UBN1 genes was converted to cDNA via reverse transcriptase and amplified in the RT-PCR reaction. Therefore, HIRA and UBN1 are essential genes and could only be knocked-down (Figure 37 and Figure 38). This is in contrast to previous studies in yeast that demonstrated deletion of HIR subunits (HIR1, HIR2, HIR3 and HPC2) is not essential for growth (Kaufman et al., 1998). However, HIRA has been reported to be essential for normal embryogenesis in mouse models and essential for chromatin assembly in the male pronucleus of Drosophila (Loppin et al., 2005; Roberts et al., 2002; Bonnefoy, Orsi, Couble, \& Loppin, 2007). UBN1 functions in conjunction with human HIRA (Banumathy et al., 2009).This could be similar in T. Thermophila and possibly explain why both HIRA and UBN1 are essential for growth. 


\subsection{UBN1 of T. thermophila follows the periodic signature of the HUN domain similar to yeast and human}

The two UBN hypothetical orthologs in T. thermophila contain the HUN domain at the C-terminus more similar to S.cerevisiae as opposed to the $\mathrm{N}$-terminus similar to $H$. sapiens. The HRD region appears to be more conserved in hypothetical UBN1 than UBN2 of T. thermophila. UBN1 of $T$. thermophila contains the characteristic conserved acidic residues of the HUN domain and follows the periodic signature in the form DX2DX3DX2EX2-3[ED] (where X is any amino acid) similar to that of human UBN1 and S.cerevisiae HPC2 (Figure 16). This suggests that it may be UBN1 of $T$. Thermophila that functions in conjunction with HIRA in $T$. thermophila similar to humans. UBN1 may be more likely to form the contiguous negatively charged ridge required for binding with HIRA (Balaji et al., 2009). Hypothetical UBN2 in $T$. thermophila lacks the conserved EX2 of the periodic signature.

\subsection{Maternal expression of $\mathrm{CAC} 2$ and $\mathrm{UBN} 2$ are not required for Tetrahymena to complete conjugation.}

The absence of CAC2 and UBN2 had no effect on the pairing efficiencies (Error! Reference source not found.) during or the completion of conjugation as seen by DAPI (Figure 40). On average greater than $90 \%$ of cells sampled initiated conjugation by forming pairs in the first 3 hours. This is seen in developmentally expressed UBN2 KOs as well. The MIC of CAC2 and UBN2 KO conjugating cells completed meiosis and produced four haploid nuclei. Three were degraded and one was selected to divide and produce two pronuclei. Reciprocal nuclear exchange was observed around 4-5 hours and resulted in the fusion of the two haploid pronuclei. 
The diploid zygote divided and formed four nuclei. Two of the nuclei developed into new MACs and two into new MICs. After the cells were re-fed, the pairs separated producing viable progeny (Figure 40).

\subsection{Deletion of CAC2 appears to affect the nuclear integrity of the MAC}

CAC2 and UBN2 are non-essential genes while HIRA and UBN1 are essential. This suggests that UBN1 may associate with HIRA in T. thermophila. DAPI staining suggests that the nuclear integrity of the MACs is affected in the absence of CAC2 in vegetative growing cells. This is seen in the ImageJ results that measured the mean diameter of the MACs of CAC2 KOs in comparison to WT. CAC2 is a subunit of CAF-1 mediated in replication-dependent chromatin

assembly. The enlarged MACs of CAC2 KO cells are probably due to greater histone turnover of $\mathrm{H} 3.3-\mathrm{H} 4$ in place of $\mathrm{H} 3-\mathrm{H} 4$ during transcription and repair resulting in increased nucleosome instability. Also, CAC2 KOs could have enlarged MACs due to reduced histone $\mathrm{H} 3-\mathrm{H} 4$ deposition (Figure 39).

\subsection{Conclusion and future directions}

I have successfully engineered the tools required for the analysis of replication-dependent and independent chromatin assembly pathways in $T$. thermophila. CAC2 appears to be a nonessential gene similar to yeast where the deletion of CAC2 still produces viable progeny. Based on the preliminary phenotypic analysis conducted on $\mathrm{CAC} 2 \mathrm{KOs}, \mathrm{CAC} 2$ seems to function in the maintenance of the chromatin structure in the MACs of vegetatively growing cells. With these tools, we can assess if HIRA in Tetrahymena forms a protein complex and interacts with UBN1 or UBN2 or both. This can be shown through Epitope tagging of HIRA and analysis of interacting proteins via affinity purification and mass spectrometry (AP-MS). Analysis in 
vegetative cells should indicate whether HIRA and UBN1 interact as expected because both genes appear to be essential for growth and is consistent with results in yeast and humans.

If through epitope tagging of HIRA, UBN1 and/or UBN2 are not found to interact with HIRA we can assess the functions of UBN1 and UBN2 through epitope tagging of UBN1 and UBN2. Tagging studies would provide information on major UBN1 and UBN2 interacting proteins using AP-MS. This can be done on vegetative and conjugating cells. Epitope tagged lines of UBN1 and UBN2 can be utilized in indirect immunofluorescence studies to determine cellular localizations. Nabeel has found that HIRA localizes to the MAC in growing cells. If UBN1 localizes to MIC as opposed to the MAC in vegetative cells, UBN 1would not likely be a HIRA-interacting protein and could be postulated to function in some MIC-specific function instead. If UBN1 does localize with HIRA in the MAC of vegetative cells, it would suggest that UBN1 is the key player in the HIRA-UBN complex in T. Thermophila similar to humans. It would also be interesting to determine the localization signal of CAC2 and UBN2 due to both genes appearing to be non-essential.

Since HIRA was found to be essential precluding its functional analysis, conditional RNAi could be used to analyze the function of HIRA in Tetrahymena. RNAi is a method that inducibly expresses double-stranded RNA hairpins and results in gene silencing through targeted mRNA degradation. RNA hairpins causes up regulation of Dicer like proteins (DCL1) that respond to the small double stranded RNA that are 23- to 24-nucleotide (nt) in length. This technique allows for gene silencing in $T$. Thermophila through targeted mRNA degradation by an RNA-induced silencing complexes (Howard-Till \& Yao, 2006). In yeast and humans HIRA negatively regulates expression of core histone genes. It is possible that because Tetrahymena is highly polyploid that Tetrahymena is more sensitive to changes in histone dosage. This can be tested via 
producing the RNAi strain for HIRA and inducing the expression of siRNA. A northern blot can be done with siRNA and probe against histone HTA1 which is involved in the repression of core histones. This will provide insight into if $T$. Thermophila HIRA functions similarly to yeast and humans in the repression of core histones.

To determine the mechanism behind the larger MACs in vegetative CAC2 KO cells we can determine the level of acetylation observed on MAC histones. CAF-1 mediated chromatin assembly in yeast and human cells is associated with H4K5ac, H4K12ac, and H3K56ac. Indirect immunofluorescence (IF) on WT versus CAC2 KO cells using anti-acetyl histone antibodies or histone $\mathrm{H} 3$ antibodies will show if the less condensed MACs are due to reduced acetylation or fewer core histone H3deposition. 


\section{Appendices}

\section{Appendix 1 - Accession numbers}

T. thermophila accession numbers

\begin{tabular}{|l|l|}
\hline Gene & TTHERM accession number \\
\hline CAC2 & TTHERM_00219420 \\
\hline HIRA & TTHERM_00046490 \\
\hline UBN1 & TTHERM_00113110 \\
\hline UBN2 & TTHERM_00335810 \\
\hline
\end{tabular}




\section{Appendix 2 - Composition of all media, buffers, and solutions used}

\begin{tabular}{|c|c|}
\hline Item & $\begin{array}{r}\text { Composition } \\
\end{array}$ \\
\hline$\%$ Agarose Gel(w/v) $(50 \mathrm{ml})$ & $\begin{array}{l}0.5 \mathrm{~g} \text { agarose } \\
50 \mathrm{ml} 1 \mathrm{xTBE} \\
5 \mu \mathrm{l} \text { ethidium bromide }(\mathrm{EtBr}) \\
(10 \mathrm{mg} / \mathrm{ml})\end{array}$ \\
\hline $1 \mathrm{M} \mathrm{CaCl}_{2}(1 \mathrm{~L})$ & To 1 mole of $\mathrm{CaCl}_{2}$ add $\mathrm{ddH}_{2} 0$ to $1 \mathrm{~L}$ \\
\hline Miniprep Solution 1 (400ml) & 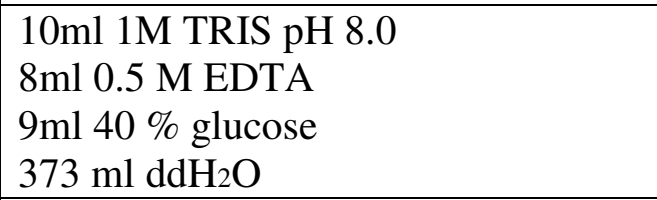 \\
\hline Miniprep Solution $2(10 \mathrm{ml})$ & 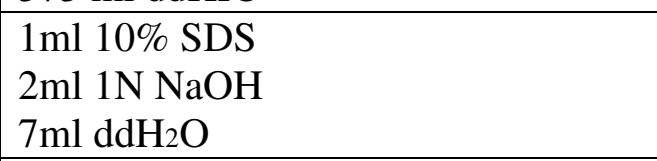 \\
\hline Miniprep Solution 3 (500ml) & $\begin{array}{l}147.2 \mathrm{~g} 3 \mathrm{M} \text { potassium acetate } \\
120.1 \mathrm{~g} \text { acetic acid } \\
500 \mathrm{ml} \mathrm{dd}_{2} \mathrm{O}\end{array}$ \\
\hline $5 \mathrm{M} \mathrm{NaCl}(500 \mathrm{ml})$ & $\begin{array}{l}146.1 \mathrm{~g} \mathrm{NaCl} \\
\text { ddH20 to } 500 \mathrm{ml}\end{array}$ \\
\hline SPP (1L) & $\begin{array}{l}\text { 60mg sequestrin (Sigma) } \\
2 \mathrm{~g} \text { bacto yeast extract } \\
20 \mathrm{~g} \text { proteose peptone } \\
4 \mathrm{~g} \text { glucose } \\
\text { ddH20 to } 1 \mathrm{~L}\end{array}$ \\
\hline $\begin{array}{l}\text { SPP+PSF } \\
\text { (Penicillin/Streptomycin/Fungizone) (1L) }\end{array}$ & $\begin{array}{l}\text { 1L SPP } \\
500 \mu \mathrm{PSSF}(100 \mathrm{x})\end{array}$ \\
\hline Tetrahymena Lysis Solution (500ml) & $\begin{array}{l}210 \mathrm{~g} \text { urea } \\
35 \mathrm{ml} 5 \mathrm{M} \mathrm{NaCl} \\
5 \mathrm{ml} 1 \mathrm{M} \text { Tris } \mathrm{pH} 7.4 \\
10 \mathrm{ml} 0.5 \mathrm{M} \text { EDTA } \\
50 \mathrm{ml} 10 \% \text { SDS } \\
\mathrm{ddH}_{2} \mathrm{O} \text { to } 500 \mathrm{ml}\end{array}$ \\
\hline $1 \mathrm{M}$ Tris-HCl pH $8.0(500 \mathrm{ml})$ & $\begin{array}{l}60.55 \mathrm{~g} \text { Tris } \\
\text { ddH20 to } 500 \mathrm{ml}, \mathrm{pH} \text { to } 8.0\end{array}$ \\
\hline $10 \mathrm{mM}$ Tris $\mathrm{pH} 7.4(1 \mathrm{~L})$ & $\begin{array}{l}1.21 \mathrm{~g} \text { Tris } \\
\mathrm{dd}_{2} \mathrm{O} \text { to } 1 \mathrm{~L}, \mathrm{pH} \text { to } 7.4\end{array}$ \\
\hline YT Media (1L) & 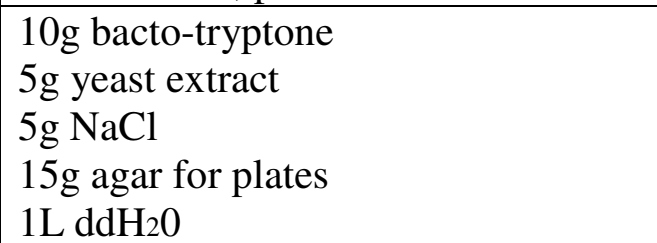 \\
\hline YT+Ampicillin $(50 \mu \mathrm{g} / \mathrm{ml})$ & 400ml YT - $2 \mathrm{ml}$ ampicillin $(10 \mathrm{mg} / \mathrm{ml})$ \\
\hline
\end{tabular}




\section{Appendix 3 - Primers}

\subsection{Sequencing primers}

M13F 5'-TGTAAAACGACGGCCAGT-3'

HN111 5'-TATCATCATCATCTTTGTAATCAATATC-3'

M13R 5'-CAGGAAACAGCTATGAC-3'

3.2. PCR primers to amplify gene sequences for molecular cloning

HIRA:

Upstream Forward: 5' CCCGAATTAGCATAAAAAAGAAAGCTTGAATAG 3'

Upstream Reverse: 5'CCCCTATCTTCAACTAATCGTTATCCTAGCCAC 3'

Downstream Forward: 5'CCCATAGAAGAAATCATTTAATTTAAAGGAAAATCTAAT 3'

Downstream Reverse: 5'CCCTGCAAAATAAATATATCGGGTTTATTTCTTTAACAA 3'

CAC2:

Upstream Forward: 5' CCCATATATTTTTCTATTTTTAATTTAGCAACATTTTAC 3'

Upstream Reverse: 5'CCCGGTCTTTCTAACTTCATTTCTATTGCTAATAATTTT 3'

Downstream Forward: 5'CCCAAAGTAATTATTCCTGCAGTTATTAAGAAATAC 3'

Downstream Reverse: 5' CCCCAAAGGAATTATTTCATGATAATTCTTCTATTTTAG 3'

UBN1: 
Upstream Forward: 5' CCCGATGCAATTTAAAAAAGCATTTTATAACC 3'

Upstream Reverse: 5'CCCTTCCCCCTCATCATCAAGACA 3'

Downstream Forward: 5'CCCCCCCCAAGCAATCCAGCAATATCATCTTC 3'

Downstream Reverse: 5'CCCGTGTATTTTATGAAGGATCATCATCAT 3'

UBN2:

Upstream Forward: 5' CCCCTTAAACTTTGAAATTGGTTA 3'

Upstream Reverse: 5' CCCCATGCTCTTCATCATGGCTTTGCTCATCAT3'

Downstream Forward: 5'CCCGATATAGCTGAGGAGGCAAACATAATAGCT3'

Downstream Reverse: 5' CCCATTGGATATTTCTCATTTCTAATATATTTTGCT3'

\subsection{Primers for PCR verification of correct integration}

HIRA: Upstream Conformation Forward

(UPConf_F):5’ATTCTCAAAGTGCAAAAAATTAAACGA 3'

CAC2: Upstream Conformation Forward (UPConf-F):5' CATAGTTTCAATCATGATGGA 3'

UBN1: Upstream Conformation Forward (UPConf-F):5' CCTCACATCTGTCTACTG 3'

UBN2: Upstream Conformation Forward (UPConf-F):5' GCTCCTCAAGCTCATCAGACTCT $3^{\prime}$

NEOR: Upstream Conformation Reverse (NEO-R2): 5'CCTCTTCACATACATGTTAGC 3'

NEOR: Upstream Conformation REVERSE (NEO-R3): 5'ACGTATCGCCTTCTATCGTCT 3' 


\subsection{Primers for RT-PCR}

HIRA: RT-F: 5'GGAAGTGTAATTCATGGGAAAAGTCATTTATTGTTTCT 3'

HIRA: RT-R: 5'GGTAACCATCTCCTATACCCCAAATTGATA 3'

CAC2: RT-F1: 5'ATGAAGGAGAAGATTTAGAATTTG 3'

CAC2: RT-R1: 5'TGCATCTCCACCTTAGCCTGGTGT 3'

CAC2: RT-F2: 5'GATGATGGAGATAAATCAAGTATTACAGGA 3'

CAC2: RT-R2: 5' GTATTTCTTAATAACTGCAGGAATAATTAC 3'

UBN1: RT-F: 5'CAAAATCAGTCAAAGCGTGTAAATGGATGT3'

UBN1: RT-R: 5' TTTTTCCACATCAGCCTGTAGCTTTC 3'

UBN2: RT-F: 5'CACTCATAGATATAGTGAATCTAG 3'

UBN2: RT-R: 5'CTACTTTTAACTAAATCT 3' 


\section{Appendix 4 - DNA ladder}

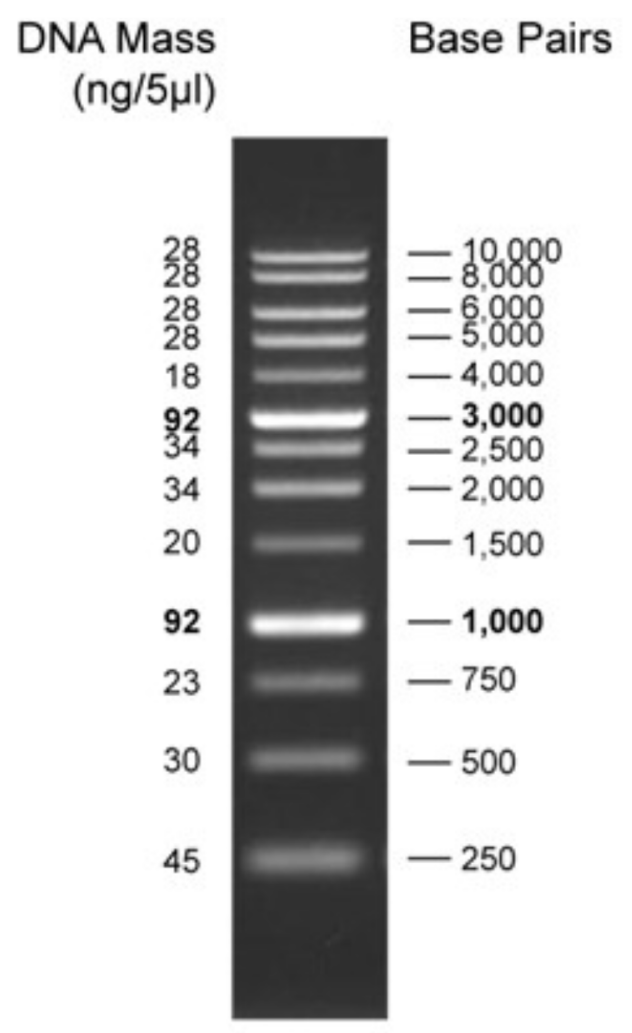

$1 \%$ TAE agarose gel

1kb DNA ladder scale (Frogga Bio) 


\section{References}

1Ahmad, K., \& Henikoff, S. (2002). Histone H3 variants specify modes of chromatin assembly. Proceedings of the National Academy of Sciences of the United States of America, 99 Suppl $4,16477-16484$.

2Annunziato, A. (2008). DNA packaging: Nucleosomes and chromatin. Nature Education, 1(1), 26.

3Antczak, A. J., Tsubota, T., Kaufman, P. D., \& Berger, J. M. (2006). Structure of the yeast histone H3-ASF1 interaction: Implications for chaperone mechanism, species-specific interactions, and epigenetics. BMC Structural Biology, 6, 26.

4Austin, C. P. Chromatin. Retrieved 09/10, 2014, from www.genome.gov/glossary/index.cfm?id=32

5Avvakumov, N., Nourani, A., \& Cote, J. (2011). Histone chaperones: Modulators of chromatin marks. Molecular Cell, 41(5), 502-514.

6Balaji, S., Iyer, L. M., \& Aravind, L. (2009). HPC2 and ubinuclein define a novel family of histone chaperones conserved throughout eukaryotes. Molecular bioSystems, 5(3), 269-275.

7Banumathy, G., Somaiah, N., Zhang, R., Tang, Y., Hoffmann, J., Andrake, M., et al. (2009). Human UBN1 is an ortholog of yeast Hpc2p and has an essential role in the HIRA/ASF1a chromatin-remodeling pathway in senescent cells. Molecular and Cellular Biology, 29(3), 758-770.

8Baxevanis, A. D., \& Landsman, D. (1998). Histone sequence database: New histone fold family members. Nucleic Acids Research, 26(1), 372-375.

9Beck, E., Ludwig, G., Auerswald, E. A., Reiss, B., \& Schaller, H. (1982). Nucleotide sequence and exact localization of the neomycin phosphotransferase gene from transposon Tn5. Gene, 19(3), 327-336.

10Birnboim, H. C., \& Doly, J. (1979). A rapid alkaline extraction procedure for screening recombinant plasmid DNA. Nucleic Acids Research, 7(6), 1513-1523.

11Bonnefoy, E., Orsi, G. A., Couble, P., \& Loppin, B. (2007). The essential role of drosophila HIRA for de novo assembly of paternal chromatin at fertilization. PLoS Genetics, 3(10), 1991-2006.

12Burgess, R. J., \& Zhang, Z. (2013). Histone chaperones in nucleosome assembly and human disease. Nature Structural \& Molecular Biology, 20(1), 14-22. 
13Campisi, J. (2005). Senescent cells, tumor suppression, and organismal aging: Good citizens, bad neighbors. Cell, 120(4), 513-522.

14Cassidy-Hanley, D., Bowen, J., Lee, J. H., Cole, E., VerPlank, L. A., Gaertig, J., et al. (1997). Germline and somatic transformation of mating tetrahymena thermophila by particle bombardment. Genetics, 146(1), 135-147.

15Chalker, D. L., \& Yao, M. C. (2011). DNA elimination in ciliates: Transposon domestication and genome surveillance. Annual Review of Genetics, 45, 227-246.

16Cole, E., \& Sugai, T. (2012). Developmental progression of tetrahymena through the cell cycle and conjugation. Methods in Cell Biology, 109, 177-236.

17Cui, B., Liu, Y., \& Gorovsky, M. A. (2006). Deposition and function of histone H3 variants in tetrahymena thermophila. Molecular and Cellular Biology, 26(20), 7719-7730.

18Daganzo, S. M., Erzberger, J. P., Lam, W. M., Skordalakes, E., Zhang, R., Franco, A. A., et al. (2003). Structure and function of the conserved core of histone deposition protein Asf1. Current Biology : CB, 13(24), 2148-2158.

19De Koning, L., Corpet, A., Haber, J. E., \& Almouzni, G. (2007). Histone chaperones: An escort network regulating histone traffic. Nature Structural \& Molecular Biology, 14(11), 997-1007.

20Eisen, J. A., Coyne, R. S., Wu, M., Wu, D., Thiagarajan, M., Wortman, J. R., et al. (2006). Macronuclear genome sequence of the ciliate tetrahymena thermophila, a model eukaryote. PLoS Biology, 4(9), e286.

21Farrell, M. J., Stadt, H., Wallis, K. T., Scambler, P., Hixon, R. L., Wolfe, R., et al. (1999). HIRA, a DiGeorge syndrome candidate gene, is required for cardiac outflow tract septation. Circulation Research, 84(2), 127-135.

22Fischle, W., Wang, Y., \& Allis, C. D. (2003). Histone and chromatin cross-talk. Current Opinion in Cell Biology, 15(2), 172-183.

23Gaertig, J., Gu, L., Hai, B., \& Gorovsky, M. A. (1994). High frequency vector-mediated transformation and gene replacement in tetrahymena. Nucleic Acids Research, 22(24), 53915398.

24Galvani, A., Courbeyrette, R., Agez, M., Ochsenbein, F., Mann, C., \& Thuret, J. Y. (2008). In vivo study of the nucleosome assembly functions of ASF1 histone chaperones in human cells. Molecular and Cellular Biology, 28(11), 3672-3685.

25Goldberg, A. D., Banaszynski, L. A., Noh, K. M., Lewis, P. W., Elsaesser, S. J., Stadler, S., et al. (2010). Distinct factors control histone variant H3.3 localization at specific genomic regions. Cell, 140(5), 678-691. 
26Green, E. M., Antczak, A. J., Bailey, A. O., Franco, A. A., Wu, K. J., Yates, J. R.,3rd, et al. (2005). Replication-independent histone deposition by the HIR complex and Asf1. Current Biology : CB, 15(22), 2044-2049.

27Herbig, U., Ferreira, M., Condel, L., Carey, D., \& Sedivy, J. M. (2006). Cellular senescence in aging primates. Science (New York, N.Y.), 311(5765), 1257.

28Howard-Till, R. A., \& Yao, M. C. (2006). Induction of gene silencing by hairpin RNA expression in tetrahymena thermophila reveals a second small RNA pathway. Molecular and Cellular Biology, 26(23), 8731-8742.

29Jeyapalan, J. C., Ferreira, M., Sedivy, J. M., \& Herbig, U. (2007). Accumulation of senescent cells in mitotic tissue of aging primates. Mechanisms of Ageing and Development, 128(1), $36-44$.

30Jin, J., Cai, Y., Li, B., Conaway, R. C., Workman, J. L., Conaway, J. W., et al. (2005). In and out: Histone variant exchange in chromatin. Trends in Biochemical Sciences, 30(12), 680687.

31Kang, B., Pu, M., Hu, G., Wen, W., Dong, Z., Zhao, K., et al. (2011). Phosphorylation of H4 ser 47 promotes HIRA-mediated nucleosome assembly. Genes \& Development, 25(13), 1359-1364.

32Kaufman, P. D., Cohen, J. L., \& Osley, M. A. (1998). Hir proteins are required for positiondependent gene silencing in saccharomyces cerevisiae in the absence of chromatin assembly factor I. Molecular and Cellular Biology, 18(8), 4793-4806.

33Kornberg, R. D. (1977). Structure of chromatin. Annual Review of Biochemistry, 46, 931-954.

34Lee, S. B., Ou, D. S., Lee, C. F., \& Juan, L. J. (2009). Gene-specific transcriptional activation mediated by the p150 subunit of the chromatin assembly factor 1. The Journal of Biological Chemistry, 284(21), 14040-14049.

35Li, B., Carey, M., \& Workman, J. (2007a). The role of chromatin during transcription. Cell, 128(4), 707-707-719.

36Li, B., Carey, M., \& Workman, J. L. (2007b). The role of chromatin during transcription. Cell, 128(4), 707-719.

37Li, Q., Zhou, H., Wurtele, H., Davies, B., Horazdovsky, B., Verreault, A., et al. (2008). Acetylation of histone $\mathrm{H} 3$ lysine 56 regulates replication-coupled nucleosome assembly. Cell, 134(2), 244-255.

38Liu, W. H., Roemer, S. C., Port, A. M., \& Churchill, M. E. (2012). CAF-1-induced oligomerization of histones $\mathrm{H} 3 / \mathrm{H} 4$ and mutually exclusive interactions with Asf1 guide 
H3/H4 transitions among histone chaperones and DNA. Nucleic Acids Research, 40(22), 11229-11239.

39Logan, C. Y., \& Nusse, R. (2004). The wnt signaling pathway in development and disease. Annual Review of Cell and Developmental Biology, 20, 781-810.

40Loppin, B., Bonnefoy, E., Anselme, C., Laurencon, A., Karr, T. L., \& Couble, P. (2005). The histone H3.3 chaperone HIRA is essential for chromatin assembly in the male pronucleus. Nature, 437(7063), 1386-1390.

41Malay, A. D., Umehara, T., Matsubara-Malay, K., Padmanabhan, B., \& Yokoyama, S. (2008). Crystal structures of fission yeast histone chaperone Asf1 complexed with the Hip1 Bdomain or the Cac2 C terminus. The Journal of Biological Chemistry, 283(20), 1402214031.

42Marino-Ramirez, L., Kann, M. G., Shoemaker, B. A., \& Landsman, D. (2005). Histone structure and nucleosome stability. Expert Review of Proteomics, 2(5), 719-729.

43Martindale, D. W., Allis, C. D., \& Bruns, P. J. (1982). Conjugation in tetrahymena thermophila. A temporal analysis of cytological stages. Experimental Cell Research, 140(1), 227-236.

44Matzke, M. A., \& Birchler, J. A. (2005). RNAi-mediated pathways in the nucleus. Nature Reviews.Genetics, 6(1), 24-35.

45Mello, J. A., Sillje, H. H., Roche, D. M., Kirschner, D. B., Nigg, E. A., \& Almouzni, G. (2002). Human Asf1 and CAF-1 interact and synergize in a repair-coupled nucleosome assembly pathway. EMBO Reports, 3(4), 329-334.

46Mochizuki, K. (2008). High efficiency transformation of tetrahymena using a codonoptimized neomycin resistance gene. Gene, 425(1-2), 79-83.

47Mochizuki, K., Fine, N. A., Fujisawa, T., \& Gorovsky, M. A. (2002). Analysis of a piwirelated gene implicates small RNAs in genome rearrangement in tetrahymena. Cell, 110(6), 689-699.

48Mochizuki, K., \& Gorovsky, M. A. (2004a). Conjugation-specific small RNAs in tetrahymena have predicted properties of scan (scn) RNAs involved in genome rearrangement. Genes \& Development, 18(17), 2068-2073.

49Mochizuki, K., \& Gorovsky, M. A. (2004b). Small RNAs in genome rearrangement in tetrahymena. Current Opinion in Genetics \& Development, 14(2), 181-187.

50Mochizuki, K., \& Gorovsky, M. A. (2005). A dicer-like protein in tetrahymena has distinct functions in genome rearrangement, chromosome segregation, and meiotic prophase. Genes \& Development, 19(1), 77-89. 
51Mousson, F., Lautrette, A., Thuret, J. Y., Agez, M., Courbeyrette, R., Amigues, B., et al. (2005). Structural basis for the interaction of Asf1 with histone H3 and its functional implications. Proceedings of the National Academy of Sciences of the United States of America, 102(17), 5975-5980.

52Narlikar, G. J., Fan, H. Y., \& Kingston, R. E. (2002). Cooperation between complexes that regulate chromatin structure and transcription. Cell, 108(4), 475-487.

53Orias, E. (2012). Tetrahymena thermophila genetics: Concepts and applications. Methods in Cell Biology, 109, 301-325.

54Orias, E., \& Flacks, M. (1975). Macronuclear genetics of tetrahymena. I. random distribution of macronuclear genecopies in T. pyriformis, syngen 1. Genetics, 79(2), 187-206.

55Phillips, R. B. (1968). Mating-type alleles in illinois strains of tetrahymena pyriformis, syngen 1. Genetical Research, 11(2), 211-214.

56Rai, T. S., Puri, A., McBryan, T., Hoffman, J., Tang, Y., Pchelintsev, N. A., et al. (2011). Human CABIN1 is a functional member of the human HIRA/UBN1/ASF1a histone H3.3 chaperone complex. Molecular and Cellular Biology, 31(19), 4107-4118.

57Ramirez, R. D., Morales, C. P., Herbert, B. S., Rohde, J. M., Passons, C., Shay, J. W., et al. (2001). Putative telomere-independent mechanisms of replicative aging reflect inadequate growth conditions. Genes \& Development, 15(4), 398-403.

58Ransom, M., Dennehey, B. K., \& Tyler, J. K. (2010). Chaperoning histones during DNA replication and repair. Cell, $140(2), 183-195$.

59Ray-Gallet, D., Woolfe, A., Vassias, I., Pellentz, C., Lacoste, N., Puri, A., et al. (2011). Dynamics of histone $\mathrm{H} 3$ deposition in vivo reveal a nucleosome gap-filling mechanism for H3.3 to maintain chromatin integrity. Molecular Cell, 44(6), 928-941.

60Roberts, C., Sutherland, H. F., Farmer, H., Kimber, W., Halford, S., Carey, A., et al. (2002). Targeted mutagenesis of the hira gene results in gastrulation defects and patterning abnormalities of mesoendodermal derivatives prior to early embryonic lethality. Molecular and Cellular Biology, 22(7), 2318-2328.

61Roth, S. Y., Denu, J. M., \& Allis, C. D. (2001). Histone acetyltransferases. Annual Review of Biochemistry, 70, 81-120.

62Sanematsu, F., Takami, Y., Barman, H. K., Fukagawa, T., Ono, T., Shibahara, K., et al. (2006). Asf1 is required for viability and chromatin assembly during DNA replication in vertebrate cells. The Journal of Biological Chemistry, 281(19), 13817-13827. 
63Sharp, J. A., Franco, A. A., Osley, M. A., \& Kaufman, P. D. (2002). Chromatin assembly factor I and hir proteins contribute to building functional kinetochores in S. cerevisiae. Genes \& Development, 16(1), 85-100.

64Spector, M. S., Raff, A., DeSilva, H., Lee, K., \& Osley, M. A. (1997). Hir1p and Hir2p function as transcriptional corepressors to regulate histone gene transcription in the saccharomyces cerevisiae cell cycle. Molecular and Cellular Biology, 17(2), 545-552.

65Strahl, B. D., \& Allis, C. D. (2000). The language of covalent histone modifications. Nature, 403(6765), 41-45.

66Su, D., Hu, Q., Li, Q., Thompson, J. R., Cui, G., Fazly, A., et al. (2012). Structural basis for recognition of H3K56-acetylated histone $\mathrm{H} 3-\mathrm{H} 4$ by the chaperone Rtt106. Nature, 483(7387), 104-107.

67Tagami, H., Ray-Gallet, D., Almouzni, G., \& Nakatani, Y. (2004). Histone H3.1 and H3.3 complexes mediate nucleosome assembly pathways dependent or independent of DNA synthesis. Cell, 116(1), 51-61.

68Turkewitz, A. P., Orias, E., \& Kapler, G. (2002). Functional genomics: The coming of age for tetrahymena thermophila. Trends in Genetics : TIG, 18(1), 35-40.

69Vishnoi, N., Flaherty, K., Hancock, L. C., Ferreira, M. E., Amin, A. D., \& Prochasson, P. (2011). Separation-of-function mutation in HPC2, a member of the HIR complex in S. cerevisiae, results in derepression of the histone genes but does not confer cryptic TATA phenotypes. Biochimica Et Biophysica Acta, 1809(10), 557-566.

70Winkler, D. D., Zhou, H., Dar, M. A., Zhang, Z., \& Luger, K. (2012). Yeast CAF-1 assembles histone (H3-H4)2 tetramers prior to DNA deposition. Nucleic Acids Research, 40(20), 10139-10149.

71Xu, M., Long, C., Chen, X., Huang, C., Chen, S., \& Zhu, B. (2010). Partitioning of histone $\mathrm{H} 3-\mathrm{H} 4$ tetramers during DNA replication-dependent chromatin assembly. Science (New York, N.Y.), 328(5974), 94-98.

72Yao, M. C. (1982). Elimination of specific DNA sequences from the somatic nucleus of the ciliate tetrahymena. The Journal of Cell Biology, 92(3), 783-789.

73 Yao, M. C., Yao, C. H., Halasz, L. M., Fuller, P., Rexer, C. H., Wang, S. H., et al. (2007). Identification of novel chromatin-associated proteins involved in programmed genome rearrangements in tetrahymena. Journal of Cell Science, 120(Pt 12), 1978-1989.

74Yao, M. C., Yao, C. H., \& Monks, B. (1990). The controlling sequence for site-specific chromosome breakage in tetrahymena. Cell, 63(4), 763-772. 
75Zeng, L., \& Zhou, M. M. (2002). Bromodomain: An acetyl-lysine binding domain. FEBS Letters, 513(1), 124-128.

76Zhang, R., Poustovoitov, M. V., Ye, X., Santos, H. A., Chen, W., Daganzo, S. M., et al. (2005). Formation of MacroH2A-containing senescence-associated heterochromatin foci and senescence driven by ASF1a and HIRA. Developmental Cell, 8(1), 19-30. 